\title{
A Population Study of Golden Eagles in the Altamont Pass Wind Resource Area
}

\section{Second-Year Progress Report}

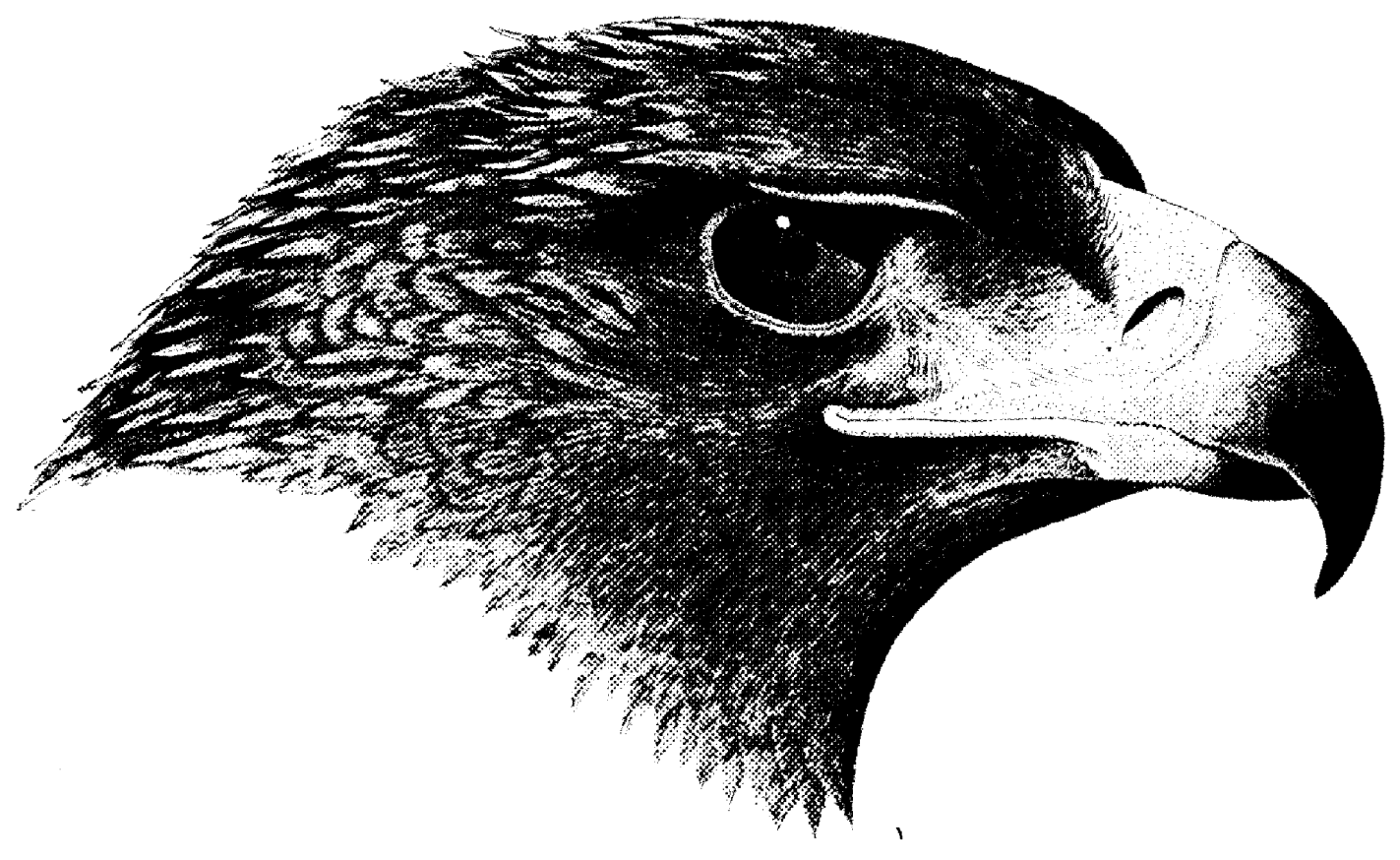

Prepared by

Predatory Bird Research Center

Long Marine Laboratory

University of California

Santa Cruz, California

Prepared for

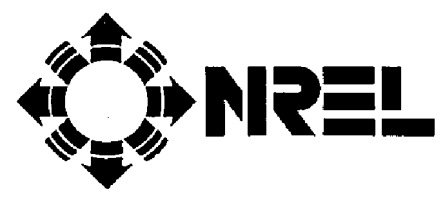

National Renewable Energy Laboratory

July 1997 


\section{A Population Study of Golden Eagles in the Altamont Pass Wind Resource Area}

\section{Second-Year Progress Report}

Prepared by

Predatory Bird Research Center

Long Marine Laboratory

University of California

Santa Cruz, California

NREL Technical Monitor: Karin Sinclair

Prepared for

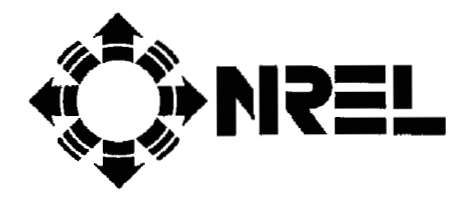

National Renewable Energy Laboratory 1617 Cole Boulevard Golden, Colorado 80401-3393

A national laboratory of the U.S. Department of Energy Managed by Midwest Research Institute for the U.S. Department of Energy under Contract No. DE-AC36-83CH10093

Prepared under Subcontract No. XAT-6-16459-01

July 1997 NREL/SR-440-23087 UC Category: 1210 


\section{NOTICE}

This report was prepared as an account of work sponsored by an agency of the United States government. Neither the United States government nor any agency thereof, nor any of their employees, makes any warranty, express or implied, or assumes any legal liability or responsibility for the accuracy, completeness, or usefulness of any information, apparatus, product, or process disclosed, or represents that its use would not infringe privately owned rights. Reference herein to any specific commercialproduct, process, or service by trade name, trademark, manufacturer, or otherwise does not necessarily constitute or imply its endorsement, recommendation, or favoring by the United States government or any agency thereof. The views and opinions of authord expressed herein do not necessarily state or reflect those of the United States government or any agency thereof.

Available to DOE and DOE contractors from:

Office of Scientific and Technical Information (OSTI)

P.O. Box 62

Oak Ridge, TN 37831

Prices available by calling (423) $576-8401$

Available to the public from:

National Technical Information Service (NTIS)

U.S. Department of Commerce

5285 Port Royal Road

Springfield, VA 22161

(703) 487-4650 


\section{FOREWORD}

The use of wind energy as an alternative electric generation source has resulted in concern over the possible impacts of wind farms on birds. The concern includes two primary areas: the effect of avian mortality on bird populations, and possible litigation over the killing of even one bird if it is protected by the Migratory Bird Treaty Act and/or the Endangered Species Act.

The habitat surrounding the Altamont Pass Wind Resource Area (WRA) supports a substantial resident population of golden eagles. Each year, the U.S. Fish and Wildlife Service receives reports from the wind industry of about 30 golden eagle casualties in the Altamont Pass WRA.

Recognizing the need to assess the impact of bird deaths in the Altamont Pass WRA on golden eagle population survival and reproduction, the National Renewable Energy Laboratory, funded by the U.S. Department of Energy, has supported the Santa Cruz Predatory Bird Research Group at the University of California, Santa Cruz, to conduct a golden eagle population study in the Altamont Pass WRA. The research is being conducted over a three-year period.

This research, started in 1994, included a preliminary field investigation of the ecology of the golden eagles (Aquila chrysaetos) in the vicinity of the Altamont Pass WRA. The first year report, A Pilot Golden Eagle Population Study in the Altamont Pass Wind Resource Area California, provides an extensive discussion of the natural history and ecology of the golden eagle in the Altamont Pass WRA.

The primary focus of the research is to quantify the effect of turbine-related mortality on the golden eagle population. To do this, the researchers must be able to quantify both survival and reproduction of the golden eagles. This second year progress report provides an excellent discussion of how the population is being sampled, the survival and distribution of the radio-tagged eagles through August 1996, and estimates of reproduction based on nesting surveys. The final report will provide more detailed discussions of the data and findings.

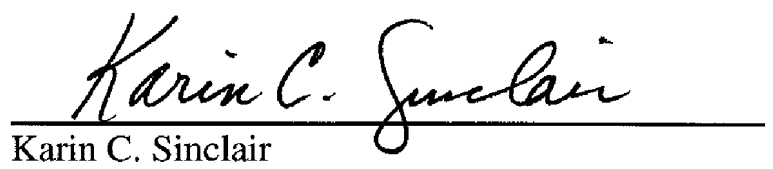

National Wind Technology Center

National Renewable Energy Laboratory

1617 Cole Boulevard

Golden, Colorado 80401

Internet Address: karin_sinclair@nrel.gov

Phone: (303) 384-6946

Fax: (303) 384-6901 


\section{Predatory Bird Research Group \\ University of California \\ Santa Cruz, California}

\section{PROJECT TEAM}

Principal Investigator

Grainger Hunt

\section{Biologists}

Pete Bloom

Teresa Brown

Jose Castañon

Lois Culp

Patti Lieberg-Clark

Daniel Driscoll

James Gilardi

John Gilardi

Craig Himmelwright

Ron Jackman

Brian Latta

Alex Lewis

Janet Linthicum

Victor Garcia Matarranz

Stan Moore

Ellie Newby

Hans Peeters

Robert Richmond

Randolph Skrovan

Robin Warne

Steve Watson

Project Managers

Brian Walton

Tery Drager 


\section{EXECUTIVE SUMMARY}

Since January 1994, the Predatory Bird Research Group, University of California, Santa Cruz, has been conducting a field investigation of the ecology of golden eagles (Aquila chrysaetos) in the vicinity of the Altamont Pass Wind Resource Area (WRA). The $190 \mathrm{~km}^{2}$ facility lies just east of San Francisco Bay in California and contains about 6,500 wind turbines. Grassland and oak savanna habitats surrounding the WRA support a substantial resident population of golden eagles. Each year, the U.S. Fish and Wildlife Service receives reports from the wind industry of about 30 golden eagle casualties occurring at the WRA, and it is probable that many more carcasses go unnoticed (see Orloff and Flannery 1992). Over 90 percent of the casualties are attributed to collisions with wind turbines. The main purpose of this study is to estimate the effect of turbine-related mortality on the golden eagle population of the area.

Assessing the impact of the WRA kills on the population requires quantification of both survival and reproduction. To estimate survival rates of both territorial and non-territorial golden eagles, we tagged 179 individuals with radio-telemetry transmitters expected to function for about four years and equipped with mortality sensors. Population segments represented in the tagged sample include 79 juveniles, 45 subadults, 17 floaters (non-territorial adults), and 38 breeders. Effective sample sizes in the older segments increase as younger eagles mature or become territorial.

Since the beginning of the study, we have conducted weekly roll-call surveys by airplane to locate the tagged eagles in relation to the WRA and to monitor their survival. The surveyed area extends from the Oakland Hills southeast through the Diablo Mountain Range to San Luis Reservoir about $75 \mathrm{~km}$ southeast of the WRA. The surveys show that breeding eagles rarely enter the WRA while the non-territorial eagles tend to move about freely throughout the study area and often visit the WRA.

Through 12 August 1996, we have detected 26 fatalities among the radio-tagged sample, 7 of which involved fledglings around the time of first flights from the nest. Of the 19 fatalities of free-ranging eagles, $9(47 \%)$ were struck by turbine blades, 4 were electrocuted (or struck electric wires), 1 was shot, 2 were victims of lead poisoning, 1 was probably poisoned, 1 was killed by another eagle, and 1 died of unknown causes.

In 1996 we observed 74 territorial pairs of eagles in the study area and were able to determine the reproductive outcome of 57 of these pairings from the incubation period onwards. The 57 pairs produced 37 young to fledging age, for an average of 0.65 young per territorial pair (S.E. $=0.10$ ). In our final report to NREL due in summer 1997, we will incorporate this estimate and those of survival to predict the effect of WRA mortality on population age structure. 


\section{TABLE OF CONTENTS}

1.0 INTRODUCTION $\ldots \ldots \ldots \ldots \ldots \ldots \ldots \ldots$

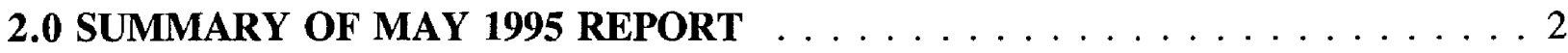

3.0 STRATEGY FOR ESTIMATING A POPULATION IMPACT $\ldots \ldots \ldots \ldots \ldots$

4.0 SAMPLING THE POPULATION $\ldots \ldots \ldots \ldots \ldots \ldots \ldots \ldots \ldots \ldots \ldots$

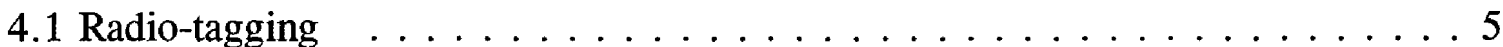

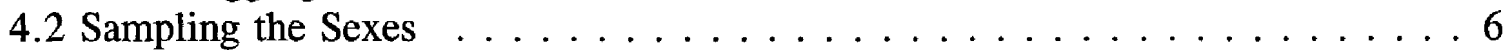

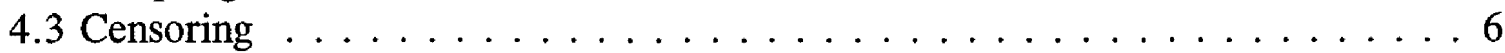

4.4 Transmitter Destruction Bias . . . . . . . . . . . . . . . . 7

4.5 Estimating Survival Rates $\ldots \ldots \ldots \ldots \ldots \ldots$

4.6 Estimating the Reproductive Rate $\ldots \ldots \ldots \ldots \ldots \ldots$

4.7 Calculating the Floater-to Breeder Ratio . . . . . . . . . . . . . 9

5.0 SURVIVAL AND DISTRIBUTION OF RADIO-TAGGED EAGLES . . . . . . 10

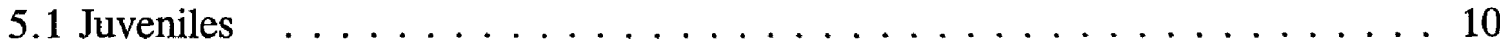

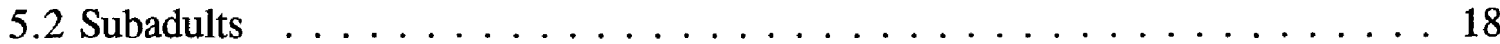

5.3 Floaters . . . . . . . . . . . . . . . . . . 26

5.4 Breeders . . . . . . . . . . . . . . . . . . 32

5.5 Adult Survival . . . . . . . . . . . . . . . . . . . 34

5.6 Risk and Mortality . . . . . . . . . . . . . . . . . 34

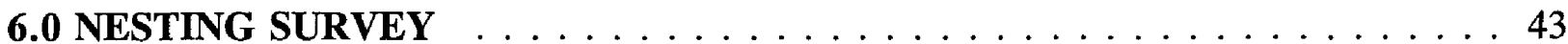

6.1 Reproduction in $1995 \ldots \ldots \ldots \ldots \ldots$. . . . . . . . . . . . . . . . .

6.2 Reproduction in $1996 \ldots \ldots$. . . . . . . . . . . . . . . . . 43

6.3 Discussion of Reproductive Estimate $\ldots \ldots \ldots \ldots \ldots$

7.0 PLANS FOR CONTINUED RESEARCH $\ldots \ldots \ldots \ldots \ldots$

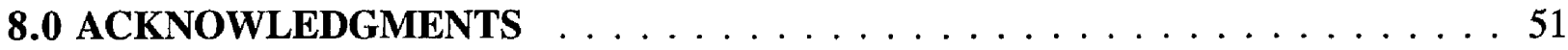

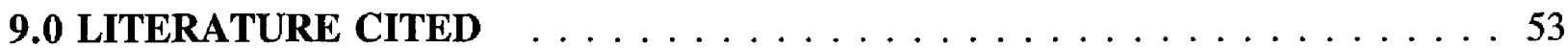




\section{LIST OF APPENDICES}

APPENDIX A: Why We Radio-tagged Both Sexes $\ldots \ldots \ldots \ldots \ldots$

APPENDIX B: Relocations of Ten Censored Golden Eagles

Whose Transmitters May Have Been Destroyed

by Turbine Blades . . . . . . . . . . . . . . . . . . . 59

APPENDIX C: Relocations of 19 Radio-tagged Golden Eagle

Casualties in the Diablo Range Study Area . . . . . . . . . . . 70

\section{LIST OF TABLES}

Table 5.1 Seventy-nine juveniles radio-tagged from January 1994

through June 1996 . . . . . . . . . . . . . . . . . . . . . . . . 11

Table 5.2 Eighty-six subadults radio-tagged from January 1994 through July $1996 \ldots \ldots \ldots$

Table 5.3 Seventy-two floaters and breeders radio-tagged from January 1994 to July $1996 \ldots \ldots \ldots$. . . . . . . . . . . . 27

Table 5.4. Relocations and fatalities of radio-tagged golden eagles in the WRA . . . . . . . . . . . . . . . 39

Table 6.1 Golden eagle productivity at breeding areas in the Diablo Range of California, $1995 \ldots \ldots \ldots$. . . . . . . 44

Table 6.2 Golden eagle productivity at breeding areas in the Diablo Range of California, $1996 \ldots \ldots \ldots \ldots$. . . . . . 47 


\section{LIST OF FIGURES}

Figure $2.1 \quad$ Vegetation types: Diablo Range Study Area $\ldots \ldots \ldots \ldots \ldots$

Figure 5.1 Relocations of 12 eagles tagged as fledglings at nests greater than $20 \mathrm{~km}$ rom the WRA $\ldots \ldots \ldots \ldots \ldots \ldots$

Figure 5.2 Relocations of 79 radio-tagged juveniles $\ldots \ldots \ldots \ldots$

Figure 5.3 Relocations of 86 radio-tagged subadults $\ldots \ldots \ldots \ldots 22$

Figure 5.4 Relocations of 32 radio-tagged floaters $\ldots \ldots \ldots \ldots$. . . . . . . 30

Figure 5.5 Relocations of 40 radio-tagged territory holders $\ldots \ldots \ldots 33$

Figure 5.6 Relocations of all radio-tagged juveniles in the vicinity of the WRA $\ldots \ldots \ldots \ldots \ldots \ldots \ldots \ldots$

Figure 5.7 Relocations of all radio-tagged subadults in the vicinity of the WRA $\ldots \ldots \ldots \ldots \ldots \ldots \ldots \ldots$

Figure 5.8 Relocations of all radio-tagged floaters in the vicinity of the WRA $\ldots \ldots \ldots \ldots \ldots \ldots \ldots \ldots$

Figure 5.9 Relocations of all radio-tagged territory-holders

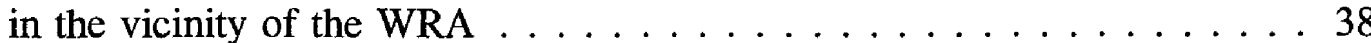

Figure 5.10 Risk index values based on the proportion of relocations in or near the WRA $\ldots \ldots \ldots \ldots \ldots \ldots$

Figure 5.11 Fatalities of 26 radio-tagged golden eagles in the Diablo Range . . . . . . . . . . . . . . . . . . . . . . . . . 40

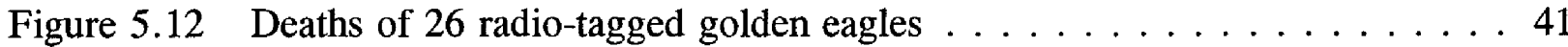

Figure 5.13 Golden eagle casualties found in the WRA $\ldots \ldots \ldots \ldots . \ldots \ldots 4$ 


\subsection{INTRODUCTION}

This report details the results of continuing studies of golden eagles (Aquila chrysaetos) by the Predatory Bird Research Group (PBRG), University of California, Santa Cruz, to quantify the effect of mortality associated with wind energy production at the Altamont Pass Wind Resource Area (WRA). This facility, occupying about $190 \mathrm{~km}^{2}$ of rolling grassland near San Francisco Bay in California, contains about 6,500 wind turbines. On the basis of foot surveys, Orloff and Flannery (1992) estimated that about 40 eagles are killed each year in the WRA, mainly as a result of turbine blade strikes. Incidental discoveries by industry employees of 28 carcasses in 1993 and 34 in 1994 within the WRA support that estimate and suggest the possibility that even higher numbers are killed. Because golden eagles are slow to reach maturity and reproduce less rapidly than most raptors, the U.S. Fish and Wildlife Service and others have expressed concern for the welfare of the population. Golden eagles are classified as a Species of Special Concern in California and are protected under the federal Bald Eagle Protection Act.

The investigation that PBRG initiated in January 1994 was supported for the first several months by Kenetech Windpower, Inc. and then by the National Renewable Energy Laboratory (NREL) under Subcontract No. XCG-4-14200. The first year's study (Jan-Dec 1994) had the purpose of laying the groundwork for a research program that would identify, (1) the effect of turbinerelated mortality on the golden eagle population, (2) factors attracting eagles to the WRA, and (3) conditions that increase the risk of turbine strikes. PBRG believed that the latter two points of inquiry might suggest turbine-related or habitat modifications that would result in a lower incidence of eagle mortality. PBRG described the results of the first year's investigation in a report titled, "A Pilot Golden Eagle Population Study in the Altamont Pass Wind Resource Area, California" (Hunt et al. 1995), as summarized in Section 2.0, below.

The current report, in partial fulfillment of NREL subcontracts XAT-5-15174-01 and XAT-616459-01, updates and supplements the first year's report (Hunt et al. 1995) with data obtained from November 1994 to August 1996. Because of budgetary constraints, the study now focuses more or less exclusively on the quantification of population effect (\#1, above) rather than the discovery of ways to reduce the kill (\#2 and \#3). Pursuant to the former, we have almost tripled our 1994 sample of radio-tagged eagles as a means toward more accurately estimating survival rates for the various age classes. By the conclusion of our study in late 1997 or 1998, these data, together with those on reproductive performance, will show a far clearer picture of population response to WRA-related mortality than is available at the time of this writing.

In examining the current document, the reader may benefit by having on hand a copy of our first report (Hunt et al. 1995). The latter reviews those aspects of the natural history and ecology of the golden eagle bearing upon our investigation, describes the study area in some detail, explains our methods, contains a glossary, and discusses our strategy for estimating the population consequence of WRA-related mortality. 


\subsection{SUMMARY OF MAY 1995 REPORT}

The perspective when our study began in January 1994 was that golden eagles were being killed in the WRA and were known to breed at scattered sites in the local area. Clearly, our first objective was to define the population potentially at risk from WRA influence. Obviously, a population of eagles native to the area around Altamont Pass would be in greater jeopardy than one existing far away whose constituents only visit the WRA seasonally or as nomads. Our approach to discovering the geographic sources of eagles entering the WRA was to use radiotelemetry. Transmitters of sufficient power would be detectable at large distances in airplane surveys $^{1}$ and would be equally locatable in all habitats (Hunt 1987).

We radio-tagged 31 eagles in the WRA vicinity in winter 1994 and estimated by means of twiceweekly airplane surveys the proportion of tagged birds remaining in the area. The results showed that at least three-quarters of the eagles frequenting the WRA vicinity were year-round residents of the northern Diablo Range, an area of about $3,500 \mathrm{~km}^{2}$ extending from the Oakland Hills southeast to San Luis Reservoir near Los Banos (Fig. 2.1). In addition to acquiring information on tenure and habitat selection of eagles within this area by comparing relocations with digitized (GIS) vegetational and topographic maps, we began obtaining data on rates and sources of mortality. Each transmitter, expected to function four or five years, was equipped with a mortality sensor. During 1994, we detected four fatalities among the winter-tagged sample, two of which were struck by turbine blades, one died of lead poisoning, and one was killed by another eagle.

To estimate the reproductive component of the demographic equation, we conducted a golden eagle nest survey during January-June 1994 in the area within about $30 \mathrm{~km}$ of the WRA. Our results showed a nesting density far greater than anticipated. In all, we observed pairs at 54 locations. Some were on inaccessible private property and could not be closely observed, but we were able to monitor the activities of 37 pairs. Thirty-two of these laid eggs, three pairs failed in the egg stage, and the remaining 29 pairs fledged 47 young. In an $820 \mathrm{~km}^{2}$ section of oak savanna where we were given access to conduct a detailed survey, we calculated a density of one pair per $22 \mathrm{~km}^{2}$, a value among the highest recorded for the species.

To examine the dispersal of juveniles and their rates of survival, we radio-tagged 25 eagles as fledglings. During 1994, we recorded no fatalities among the 23 individuals whose transmitters remained functional. Of these, two or possibly three left the study area (an additional transmitter may have failed), and the remaining 20 birds were alive in or near the study region in December 1994, most remaining within $30 \mathrm{~km}$ of the WRA.

We identified 339 prey items from collections made at golden eagle nests in the study area. The only prey species common to every pair was the California ground squirrel (Spermophilus beecheyii). It represented 69 percent of prey numbers and 64 percent of prey biomass identified

\footnotetext{
${ }^{1}$ We have several times detected transmitters on soaring raptors at distances exceeding $150 \mathrm{~km}$.
} 


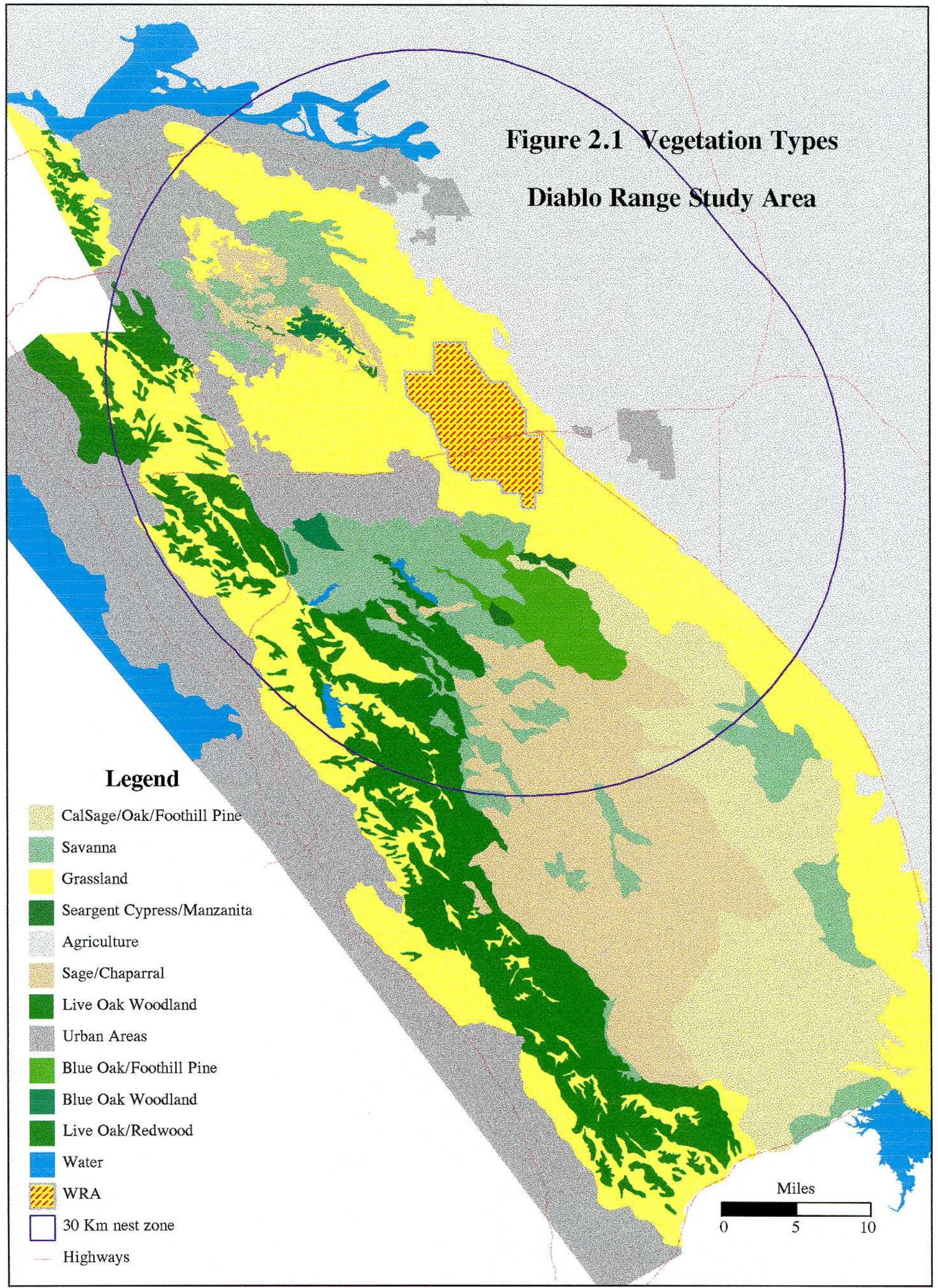


from remains. The second most important species was the black-tailed jackrabbit (Lepus californicus) at eight percent biomass; the third was the black-tailed deer (Odocoileus hemionus) at six percent. In all, mammals accounted for 92 percent of prey biomass, followed by seven percent birds, and one percent reptiles. These proportions reflect very closely the food habits of breeding eagles studied in other parts of North America.

To investigate the occurrence and behavior of golden eagles within the WRA we conducted weekly ground-based surveys from late May through November during which we recorded all sightings and activities of eagles. Routine examination of 4,543 turbine towers (of 21 types) and the surrounding area yielded 249 sightings of golden eagles, of which 155 were flying and 94 were perched; 23 of these were on turbine towers, all of the lattice-type. The ground-based data suggested that an average of 14-17 eagles occupied the WRA during the months of survey, while the aerial telemetry surveys pointed to considerable variation in individual tenure. Both tagged and untagged eagles were most commonly recorded in the northwestern and southern extremes of the WRA. A comparable ground survey conducted on an adjacent area of grassland (Site 300 of Lawrence Livermore Labs) without turbines suggested a higher average density of eagles.

\subsection{STRATEGY FOR ESTIMATING A POPULATION IMPACT}

The goal of our research is to estimate the extent to which the losses incurred in the WRA alter the demographic potential of the golden eagle population inhabiting the northern portion of the Diablo Range. The assessment must ignore the possibility that immigrants from other populations may buffer the breeding segment from a possible deficit in recruitment resulting from increased mortality. Instead, we wish to measure the level at which the population operates as a potential source of recruits to surrounding or distant populations in less favorable habitats, or as a drain of recruits from outside populations through excessive mortality. To accomplish our goal, we must, (1) estimate the annual survival rates of each population segment for which a difference in survival is reasonably expected, and (2) quantify the reproductive rate. We must try to anticipate in our assessment any large scale yearly variation in death rates or reproductive rates that may result, say, from normal fluctuations in food supply or weather.

Our results are showing that the Livermore Valley and surrounding environs are of exceptional quality as nesting and foraging habitat for golden eagles. Therefore, it is fair to assume that, in the absence of high levels of human-related mortality, the area can be expected to contribute to population stability within the larger region. The potential of the population as a "source" (Pulliam 1988) and, indeed, the measure of its own stability, lies in its ability to produce adult eagles. That potential is reflected in the ratio of breeders to non-breeding adults (floaters, as defined by Brown 1969) when the population is at equilibrium with the existing regime of natality and mortality. That bird populations may exist at equilibrium numbers as a consequence of restricted fecundity per unit area of landscape has been discussed by Ratcliffe (1962), Murray (1979, 1982), Hunt (1988), and others. A golden eagle population such as the one resident in the Diablo Range is especially inclined to stable equilibrium because of the tendency for the number of territorial pairs to remain constant from year to year (Newton 1991, 1992; Gargett 
1975,1977; Tjernberg 1985; see Hunt et al. 1995, Section 3.2). Because of this, we believe the best approach is to compare predicted changes in equilibrium floater-to-breeder ratios as functions of demographic parameters with and without the effect of the WRA-related fatalities.

\subsection{SAMPLING THE POPULATION}

Our sampling program falls into three general categories of effort: (1) radio-tagging, (2) radiotracking, and (3) nesting surveys. Most of the techniques associated with each of these are described in our 1995 report. Below is additional information necessary to update the reader regarding our current methods and levels of sampling, how we have solved certain problems and deficiencies, and some biases we have yet to overcome.

\subsection{Radio-tagging}

Much of our effort during the course of the current contract (since 1 April 1995) is being directed toward augmenting our samples of radio-tagged eagles within the various categories pertaining to our analysis of WRA-related effects on the population. These categories, properly called population segments, include, (1) juveniles, (2) subadults, (3) floaters, and (4) breeders (territory-holders).

The reader will note that, for the purpose of radio-relocation and survival monitoring, the number of tagged eagles represented in each segment listed in Section 5 exceeds the overall number of eagles tagged since the beginning of the study. The reason is that when juveniles reach one year of age, they become subadults and begin to contribute data for that segment. The same is true for "near-adults" (Basic III plumage) that become floaters (or occasionally breeders) by acquiring adult plumage in their fifth calendar year of life. We have somewhat arbitrarily chosen 15 June as the date of transition from one age class to the next, a convention that provides a full year of tracking data for the juvenile segment which fledges from late May to early July. The exception to this scheme is that fledglings enter the juvenile segment when they are radio-tagged in May or June at 8-10 weeks of age, even if tagging occurs before 15 June.

Our methods of determining the ages of the three classes of subadults are based on those developed by Pete Bloom (Western Foundation of Vertebrate Zoology) and Bill Clark (Cape May Bird Observatory) who described a complex pattern of overlapping feather molt in a workshop presentation at the October 1995 meeting of The Raptor Research Foundation in Duluth, Minnesota. Using their system, we are able to determine the natal year for subadults and clearly distinguish between juvenile, subadult-1 (Basic I), subadult-2 (Basic II), near-adult (Basic III), and adult (Definitive) plumages. Accordingly, we have revised our identification code for each tagged eagle. For example, SM05 ("subadult male \#5") has become 42M11, the first character referring to the year of tagging (1994), the second to the year of birth (1992), the third to sex (male). The last two numbers, in this case, indicate that the bird was the eleventh male in the radio-tagged series. This system reduces the confusion that arises when individuals enter and exit the various population segments each year. 
The considerable literature on the effects of transmitters on birds (e.g., Gessaman and Nagy 1988, Burger et al. 1991) show that transmitters may reduce flight speeds, survival, and reproduction. These consequences appear largely species-specific and dependent on package size and attachment configuration. During the past decade we have placed our 65-gram detachable units on hundreds of bald and golden eagles and have detected no direct impacts on survival, nor has there been any indication that tags interfered with territory acquisition or breeding (see Hunt et al. 1992). However, because a comparison of survival and reproductive effects between samples of tagged and untagged eagles is unavailable, we shall remain uncertain as to a possible difference. We note, however, that our transmitters weigh only about 1.3 percent of the weight of the average female and 1.7 percent of the male. Comparative studies reported in the literature deal mainly with transmitters in the $2.5-5.0$ percent of body weight range.

\subsection{Sampling the Sexes}

Since January 1994, we have radio-tagged 179 golden eagles, including 76 females and 103 males. Of these, there were 79 juveniles, 45 subadults, 17 floaters, and 38 breeders. As explained above, the effective sample in the advanced age categories has greatly enlarged because surviving juveniles from two cohorts became subadults one year after fledging, nearadults survived to become adults, and two itinerant eagles became territorial.

Rather than focus on one sex for survival estimation, we chose to radio-tag both sexes. We did so in consideration of funds available and the resulting uncertainty of capturing enough individuals of a preselected sex to achieve a level of statistical confidence appropriate to modeling. Furthermore, we lacked insight into which sex was limiting. If we inadvertently chose the one in surplus, our modeling results would be far less predictive of population impacts than a pooled sample of both sexes.

We are currently obtaining survival estimates by pooling the sexes within each population segment. However, as the number of tracking surveys increases, the confidence limits surrounding the estimates may tighten to a point where the sexes can be properly considered separately. This eventuality appears more likely for males because of their greater representation in sample. This is fortunate because males are believed, in most cases, to be the limiting sex in raptors (Dr. Ian Newton, in litt.).

Because of the importance of these considerations to the predictive power of any population model dealing with the impact of WRA fatalities, we have endeavored in Appendix A to explain the concepts associated with the traditional use of females in population modeling and the implications of pooling the sexes for survival estimation. In summary of our conclusions, we believe that the reasons normally advanced for modeling only females do not apply to raptors, and that pooling raptor sexes for survival estimation is likely of less consequence than is the case with many other kinds of birds.

\subsection{Censoring}

If conditions were ideal for survival rate estimation, sample size would not be reduced by emigration, all the transmitters would continue to function, we would locate all tagged fatalities soon after death, and we would detect all extant transmitters on every roll-call survey. Instead, 
some of the eagles move in and out of the area or depart altogether, some eagles temporarily escape detection even though they are present (this is uncommon on a per-eagle basis), and some of the transmitters fail. Possible causes of transmitter failure include battery discharge, circuit breakage, component malfunction, antenna dislocation, separation of attachment ribbon bindings, and transmitter destruction. All but the last of these (see Section 4.4, below) may be fairly regarded as occurring independently of the eagle's fate.

This assumption of independence allows for a system of censoring, where eagles whose transmitters have failed or those that have departed - the two possibilities are indistinguishable - are deleted from survival calculations (see Hunt et al. 1995, Section 4.4). The assigned date of deletion is midway between the date of last detection and that of the first indication of signal disappearance. If, in the case of an eagle leaving the study area or being missed in the survey, the signal is later redetected, the eagle is reinstated within the current survival interval. However, survival status during the period of signal absence is not restored, even though the eagle was obviously alive during that period. The reason is that, if the eagle was indeed outside the study area during the period of signal absence, considering it alive through that period would contribute to an upward bias in the survival estimate for the overall sample. This is because, while survival might eventually be verified by the return of the bird, its death outside the study area would likely never be known (Bunck et al. 1995).

\subsection{Transmitter Destruction Bias}

In our earlier report, we discussed the possibility that transmitters might occasionally be destroyed by the mortality agent, a factor that violates a core assumption essential to accurate survival estimation from radio-telemetry data. The assumption is that censoring is independent of fate (Bunck 1987). While several modes of transmitter destruction may conceivably be caused by a lethal agent, including poaching and car kills (Heisey and Fuller 1985), none seems to us more likely than a turbine blade strike.

Not surprisingly, three of the nine turbine kills of radio-tagged eagles recorded during our study were discovered, not by means of telemetry, but by wind industry employees who happened upon them in the course of maintenance work. In two cases, it was clear that transmitter function had been destroyed by the turbine blade, and in the third, we were unable to find the transmitter despite a lengthy visual search and use of a metal detector. These events suggest the very real possibility that more tagged birds have been killed in the wind plant than is apparent in our data, a prospect that would result in an underestimate of population impact.

4.4.1 Examining the Kills. One way of estimating the number of destroyed transmitters would be to use existing casualty data to calculate the probability of destruction per turbine strike. Over the past several years Kenetech has been collecting information on golden eagles and other raptors killed and injured at the WRA. The data consist of photographs and descriptions of wounds and dismemberment. Karen Lougheed of Kenetech examined the reports of 184 golden eagle casualties in the WRA collected from 1989 to the present, 119 of which contained sufficient data for analysis. Of these, 80 blade strikes involved heads and appendages only, 
while 39 included the body trunk. Lougheed judged that in 37 of the latter cases the blade would likely have destroyed a transmitter, an overall incidence of 31 percent.

4.4.2 Modeling the Physical Aspects. Another technique of computing a correction factor for turbine-destroyed transmitters may be to model the physical probability that a blade would strike the transmitter or its antenna, given the aspects of configuration and motion appropriate to an eagle, its transmitter, and the turbine itself. We asked Dr. Vance Tucker, Professor of Zoology at Duke University, to consider calculating such a probability based on his recent research on bird collisions with wind turbines (Tucker 1996).

In our opinion, a strike virtually anywhere along the length of the antenna or the transmitter would either destroy its function entirely or reduce its signal-generating capability. Our transmitters are ca. $40 \mathrm{~cm}$ in length overall, the body of the instrument contributing about 6.6 $\mathrm{cm}$ and it's antenna ca. $33.5 \mathrm{~cm}$. Dr. Tucker intends to apply our measurements of transmitter length and the general dimensions of a flying eagle (ca. $55 \times 200 \mathrm{~cm}$ ) in estimating transmitter destruction rate per eagle casualty.

4.4.3 Looking at Circumstantial Evidence. For our purposes, there is yet another technique for estimating the number of transmitters destroyed by the turbines. This is to examine the movements of each tagged eagle prior to signal disappearance. For example, the relocation data might show that one censored eagle was never detected near the WRA, while another was there frequently in the weeks prior to signal loss. The former could be censored with little danger of error, but the latter would suggest the possibility of a turbine strike.

There were, in fact, ten eagles whose signals disappeared without evidence of departure, transmitter failure, or transmitter detachment during the 31 months this study has been underway (analysis to 12 August 1996). We can eliminate two of these from consideration on the basis of their being detected rarely (Case S5) or never (Case S1) near the WRA boundary. Thus, eight eagles may be regarded as candidates for transmitter destruction by turbine blades. Appendix B shows their itineraries, and in sections 5.1.1 and 5.2.1, below, we examine the records regarding each of these censored birds (cases J13, J14, S2, S3, S4, S22, F7, and F8).

\subsection{Estimating Survival Rates}

In our last report, we estimated survival in each population segment by the Trent-Rongstad method (Trent and Rongstad 1974, Krebs 1989), a simple equation that considers the overall number of relocation periods for the entire radio-tagged sample and the number of deaths occurring over the entire period. Assumptions of this technique for survival estimation are that, (1) each period of detection is an independent event during which the eagle either lives or dies, (2) the probability of dying is constant over the entire period, and (3) the date of death is known.

We have since abandoned the Trent-Rongstad method in favor of the Kaplan-Meier estimate as developed for staggered entry of radio-tagged individuals by Pollock et al. (1989). This method focuses on fatality dates, thereby escaping our inevitable violation of the second assumption listed above (see Bunck 1987). The Kaplan-Meier procedure calculates the Trent-Rongstad rate 
in each of a series of successive periods (e.g., weeks), and then multiplies it by the survival value obtained for the previous period. The resulting survival estimate for the entire series is therefore cumulative, declining over the year.

We censored birds according to procedures described in Section 4.3 above. We chose two-week periods as the basic survival interval because, in retrospect, the data are more consistent than those for one-week periods. The reason is that adverse weather frequently prevented us from performing the weekly aerial surveys, especially during the cooler months.

Rather than consider each survival year separately, we pooled corresponding (Julian) two-week periods in a combined estimate for the years, making the assumption of no survival rate differences within the Julian periods between years. Our data suggest a strong seasonal component to mortality, e.g., the majority of juvenile deaths occur soon after fledging. Moreover, wind turbine activity at Altamont Pass is distinctly seasonal and, not surprisingly, eight of the nine turbine blade strikes of radio-tagged eagles occurred during the windy season. Other seasonal factors likely to influence survival include annual cycles of nesting activity, prey availability, weather phenomena, and cycles of human recreational activity.

Another assumption we are tentatively making concerns sampling independence of birds radiotagged as siblings or as members of the same pair. In the current report, we are ignoring the possibility that commonality of causal factors may affect the fates of individuals who share territorial origin or ownership. However, for members of breeding pairs, the danger of violating the rule of sampling independence may indeed be significant. In the future, we may purge from the data set those records for one randomly selected member of each of four pairs for which this consideration is applicable. On the other hand, for sibling juveniles, our policy of acceptance may not be of much consequence. While local circumstances influencing post-fledging mortality may affect siblings equally, the death of one individual may increase the chance of survival in the other, particularly in cases involving food or sibling aggression. Moreover, siblings do not tend to remain together after fledging, and the vast majority of relocations are away from the nest.

\subsection{Estimating the Reproductive Rate}

The natality parameter we are using in calculating equilibrium population size and the floater-tobreeder ratio is the number of fledged young per territorial pair, the latter being only those pairs observed during or before incubation. This method will overcome the bias that may have affected our 1994 estimate, namely that of successful pairs being easier to locate and identify late in the breeding season than pairs that have failed (see Steenhof and Kochert 1982, Steenhof 1987).

\subsection{Calculating the Floater-to-breeder Ratio}

The rationale for calculating the floater-to-breeder ratio by using a simple life table is described in Section 3.2 and Appendix I of Hunt et al. 1995 and in Hunt (1988). For the present, we are assuming that the number of breeding pairs, mean productivity, and survival are constant over years and that the maximum ecological age of a golden eagle is 20 years. Equations for 
calculating the number of adults $(\mathrm{Z})$ at equilibrium and the floater-to-breeder ratio $(\mathrm{R})$ are as follows:

$$
\begin{aligned}
& \mathrm{Z}=\left(\operatorname{CJS}^{\mathrm{V}}\left(1-\mathrm{A}^{\mathrm{w}}\right)\right) / 1-\mathrm{A} \\
& \mathrm{R}=(\mathrm{Z} / \mathrm{B})-1
\end{aligned}
$$

where:

$\mathrm{C}=$ cohort size

$\mathrm{J}=$ juvenile survival rate

$\mathrm{S}=$ subadult survival rate

$\mathrm{A}=$ adult survival rate

$\mathrm{B}=$ number of breeders

$\mathrm{V}=$ number of years of subadulthood

$\mathrm{W}=$ number of years of adulthood

We obtain the variance surrounding the equilibrium population estimate by generating 1000 random values within the error probability distribution (normally distributed) for each vital parameter estimate. From these, we calculate a corresponding list of 1000 equilibrium estimates and obtain the coefficient of variation for the series.

\subsection{SURVIVAL AND DISTRIBUTION OF RADIO-TAGGED EAGLES}

Throughout this study we have conducted weekly roll-call airplane surveys (weather and mechanical circumstances permitting) for all radio-tagged eagles $(n=179)$ throughout the entire study area according to procedures described in our first report (Section 5.1.3). Each transmitter is equipped with a "mortality switch" controlling the pulse rate, a feature that allows the ready detection of fatalities. Our efficiency and safety during the surveys increased with the addition of a second person in the aircraft whose duties were to record the GPS locations and other data, and to watch for aircraft. Weather influenced our ability to perform the surveys with regularity, particularly in winter and spring.

\subsection{Juveniles}

In all, we have radio-tagged 79 golden eagles as juveniles, 7 of them as free-ranging birds and 72 as fledglings (Table 5.1). These include 28 tagged in 1994, 25 of which were tagged as fledglings and 3 as free-ranging birds. During April-June 1995, we tagged 26 individuals of which 22 were fledglings and 4 were free-ranging when captured. We tagged 25 additional fledglings in June 1996.

The dilemma we had described in Section 5.1.2 of last year's report in judging the fit of the transmitter attachment ribbons on birds not fully grown was resolved on the basis of our 
Table 5.1. Seventy-nine juveniles radio-tagged from January 1994 through June 1996.

\begin{tabular}{|c|c|c|c|c|c|}
\hline Tag Date & Bird ID & $\begin{array}{l}\text { Hatching } \\
\text { Year }\end{array}$ & Sex & $\begin{array}{l}\text { Status at } \\
\text { Tagging }\end{array}$ & $\begin{array}{l}\text { Nest } \\
\text { (Tagging Location) }\end{array}$ \\
\hline $1-27-94$ & $43 \mathrm{M} 09 *$ & 1993 & M & Free-ranging & (Morgan Territory) \\
\hline $2-02-94$ & $43 \mathrm{~F} 05$ & 1993 & $\mathrm{~F}$ & Free-ranging & (Site 300) \\
\hline $2-07-94$ & $43 \mathrm{~F} 09 *$ & 1993 & $\mathrm{~F}$ & Free-ranging & (Site 300) \\
\hline $5-21-94$ & $44 \mathrm{~F} 15$ & 1994 & $\mathrm{~F}$ & Fledgling & Adelaide Nest \\
\hline $5-21-94$ & $44 \mathrm{M} 18^{*}$ & 1994 & M & Fledgling & Adelaide Nest \\
\hline $5-23-94$ & $44 \mathrm{M} 19 *$ & 1994 & $\mathbf{M}$ & Fledgling & Wally Nest \\
\hline $5-27-94$ & $44 \mathrm{M} 20$ & 1994 & M & Fledgling & Welch Creek Nest \\
\hline $5-27-94$ & $44 \mathrm{M} 21 *$ & 1994 & M & Fledgling & Vasco Road Nest \\
\hline $5-31-94$ & $44 \mathrm{M} 22 *$ & 1994 & $\mathbf{M}$ & Fledgling & Los Vaqueros Nest \\
\hline $6-01-94$ & $44 \mathrm{~F} 16 *$ & 1994 & $\mathrm{~F}$ & Fledgling & Shell Ridge Nest \\
\hline $6-01-94$ & $44 \mathrm{M} 23 *$ & 1994 & $\mathbf{M}$ & Fledgling & Del Valle S. Nest \\
\hline $6-02-94$ & $44 \mathrm{~F} 17 *$ & 1994 & $\mathrm{~F}$ & Fledgling & Mines Road Nest \\
\hline $6-02-94$ & $44 \mathrm{~F} 18 *$ & 1994 & $\mathbf{F}$ & Fledgling & Lindl Nest \\
\hline $6-02-94$ & $44 \mathrm{M} 24 *$ & 1994 & $\mathbf{M}$ & Fledgling & Mines Road Nest \\
\hline $6-02-94$ & $44 \mathrm{M} 25^{*}$ & 1994 & M & Fledgling & Lindl Nest \\
\hline $6-03-94$ & $44 \mathrm{M} 26^{*}$ & 1994 & M & Fledgling & Camino Diablo Nest \\
\hline $6-03-94$ & $44 \mathrm{M} 27^{*}$ & 1994 & $\mathbf{M}$ & Fledgling & Camino Diablo Nest \\
\hline $6-04-94$ & $44 \mathrm{M} 28^{*}$ & 1994 & $\mathbf{M}$ & Fledgling & Mount Allison Nest \\
\hline $6-05-94$ & $44 \mathrm{~F} 19 *$ & 1994 & $\mathrm{~F}$ & Fledgling & Pipe Cross Nest \\
\hline $6-05-94$ & $44 F 20$ & 1994 & $\mathrm{~F}$ & Fledgling & Pipe Cross Nest \\
\hline $6-06-94$ & $44 \mathrm{M} 29$ & 1994 & $\mathbf{M}$ & Fledgling & Foley Nest \\
\hline $6-06-94$ & $44 \mathrm{M} 30$ & 1994 & M & Fledgling & Sibley Nest \\
\hline $6-07-94$ & 44M31 & 1994 & M & Fledgling & Niles Canyon Nest \\
\hline $6-07-94$ & $44 \mathrm{M} 32 *$ & 1994 & $\mathbf{M}$ & Fledgling & High Corral Nest \\
\hline $6-07-94$ & $44 \mathrm{M} 33 *$ & 1994 & M & Fledgling & High Corral Nest \\
\hline $6-08-94$ & $44 \mathrm{~F} 21 *$ & 1994 & $\mathrm{~F}$ & Fledgling & Calaveras Creek Nest \\
\hline $6-15-94$ & $44 \mathrm{~F} 22 *$ & 1994 & $\mathrm{~F}$ & Fledgling & Indian Creek Nest \\
\hline $7-01-94$ & $44 \mathrm{~F} 23^{*}$ & 1994 & $\mathrm{~F}$ & Fledgling & Eagle's Run Nest \\
\hline $4-12-95$ & $54 \mathrm{M} 35 *$ & 1994 & M & Free-ranging & (Site 300) \\
\hline $4-14-95$ & $54 \mathrm{~F} 26^{*}$ & 1994 & $\mathrm{~F}$ & Free-ranging & (WRA-Brushy Peak) \\
\hline $5-21-95$ & $54 \mathrm{~F} 31 *$ & 1994 & $\mathrm{~F}$ & Free-ranging & (Site 300$)$ \\
\hline $5-21-95$ & $54 \mathrm{M} 42 *$ & 1994 & $\mathbf{M}$ & Free-ranging & (Site 300) \\
\hline $5-23-95$ & $55 \mathrm{~F} 32$ & 1995 & $\mathrm{~F}$ & Fledgling & Round Valley Nest \\
\hline $5-23-95$ & $55 \mathrm{~F} 33 *$ & 1995 & $\mathrm{~F}$ & Fledgling & Round Valley Nest \\
\hline
\end{tabular}


Table 5.1. (continued).

\begin{tabular}{|c|c|c|c|c|c|}
\hline Tag Date & Bird ID & $\begin{array}{l}\text { Hatching } \\
\text { Year }\end{array}$ & Sex & $\begin{array}{l}\text { Status at } \\
\text { Tagging }\end{array}$ & $\begin{array}{l}\text { Nest } \\
\text { (Tagging Location) }\end{array}$ \\
\hline $5-24-95$ & $55 \mathrm{M} 47$ & 1995 & $\mathbf{M}$ & Fledgling & Adelaide Nest \\
\hline $5-24-95$ & $55 \mathrm{M} 48^{*}$ & 1995 & $M$ & Fledgling & Hollow Nest \\
\hline $5-24-95$ & $55 \mathrm{M} 49 *$ & 1995 & M & Fledgling & Hollow Nest \\
\hline $6-02-95$ & $55 \mathrm{M} 51 *$ & 1995 & M & Fledgling & Hairpin Nest \\
\hline $6-02-95$ & $55 \mathrm{M} 52^{*}$ & 1995 & M & Fledgling & Patterson Nest \\
\hline $6-04-95$ & $55 F 34$ & 1995 & $\mathrm{~F}$ & Fledgling & Pipe Cross Nest \\
\hline $6-07-95$ & $55 \mathrm{~F} 35^{*}$ & 1995 & $\mathrm{~F}$ & Fledgling & Welch Creek Nest \\
\hline $6-07-95$ & $55 \mathrm{~F} 36$ & 1995 & $\mathrm{~F}$ & Fledgling & Vasco Road Nest \\
\hline $6-07-95$ & $55 \mathrm{M} 53 *$ & 1995 & $\mathbf{M}$ & Fledgling & Vasco Road Nest \\
\hline $6-08-95$ & $55 \mathrm{~F} 37$ & 1995 & $\mathrm{~F}$ & Fledgling & Lindl Nest \\
\hline $6-08-95$ & $55 \mathrm{M} 54 *$ & 1995 & M & Fledgling & Lindl Nest \\
\hline $6-08-95$ & $55 \mathrm{M} 55^{*}$ & 1995 & M & Fledgling & Lindl Nest \\
\hline $6-09-95$ & $55 \mathrm{M} 56^{*}$ & 1995 & $\mathbf{M}$ & Fledgling & Morgan Territory Nest \\
\hline $6-10-95$ & $55 F 38$ & 1995 & $\mathrm{~F}$ & Fledgling & Calaveras Creek Nest \\
\hline $6-11-95$ & $55 \mathrm{M} 57^{*}$ & 1995 & $\mathbf{M}$ & Fledgling & Del Valle S. Nest \\
\hline $6-14-95$ & $55 \mathrm{~F} 40^{*}$ & 1995 & $\mathrm{~F}$ & Fledgling & Eagle's Run Nest \\
\hline $6-14-95$ & $55 \mathrm{M} 58^{*}$ & 1995 & $\mathbf{M}$ & Fledgling & Eagle's Run Nest \\
\hline $6-15-95$ & $55 \mathrm{~F} 41 *$ & 1995 & $\mathrm{~F}$ & Fledgling & Ordway Nest \\
\hline $6-15-95$ & $55 \mathrm{M} 59 *$ & 1995 & $\mathbf{M}$ & Fledgling & Wally Nest \\
\hline $6-15-95$ & $55 \mathrm{M} 60 *$ & 1995 & M & Fledgling & Ordway Nest \\
\hline $6-01-96$ & $66 \mathrm{~F} 66 * *$ & 1996 & $\mathrm{~F}$ & Fledgling & Mendenhall Nest \\
\hline $6-01-96$ & $66 \mathrm{M} 85 * *$ & 1996 & $\mathbf{M}$ & Fledgling & Mendenhall Nest \\
\hline $6-01-96$ & $66 \mathrm{~F} 67 * *$ & 1996 & $F$ & Fledgling & Adelaide Nest \\
\hline $6-02-96$ & $66 \mathrm{~F} 68^{* *}$ & 1996 & $\mathrm{~F}$ & Fledgling & Oak Flat Golf Nest \\
\hline $6-02-96$ & $66 \mathrm{M} 86^{* *}$ & 1996 & M & Fledgling & Oak Flat Golf Nest \\
\hline $6-02-96$ & $66 \mathrm{M} 87 * *$ & 1996 & $\mathbf{M}$ & Fledgling & Hairpin Nest \\
\hline $6-02-96$ & $66 \mathrm{M} 88 * *$ & 1996 & $\mathrm{M}$ & Fledgling & Hairpin Nest \\
\hline $6-03-96$ & $66 \mathrm{~F} 69 * *$ & 1996 & $\mathrm{~F}$ & Fledgling & Wally Nest \\
\hline $6-03-96$ & $66 \mathrm{M} 89 * *$ & 1996 & $\mathrm{M}$ & Fledgling & Wally Nest \\
\hline $6-04-96$ & $66 \mathrm{~F} 71 * *$ & 1996 & $\mathrm{~F}$ & Fledgling & Round Valley Nest \\
\hline $6-04-96$ & $66 \mathrm{M} 90 * *$ & 1996 & $\mathrm{M}$ & Fledgling & Indian Creek Nest \\
\hline $6-04-96$ & $66 \mathrm{M} 91 * *$ & 1996 & $\mathbf{M}$ & Fledgling & Indian Creek Nest \\
\hline $6-04-96$ & $66 \mathrm{M} 92 * *$ & 1996 & M & Fledgling & Round Valley Nest \\
\hline $6-05-96$ & $66 \mathrm{~F} 72 * *$ & 1996 & $\mathrm{~F}$ & Fledgling & Rocky Ridge Nest \\
\hline
\end{tabular}

(continued on next page) 
Table 5.1. (continued).

\begin{tabular}{llccll}
\hline \hline Tag Date & Bird ID & $\begin{array}{c}\text { Hatching } \\
\text { Year }\end{array}$ & Sex & $\begin{array}{l}\text { Status at } \\
\text { Tagging }\end{array}$ & $\begin{array}{l}\text { Nest } \\
\text { (Tagging Location) }\end{array}$ \\
\hline $6-05-96$ & $66 \mathrm{M} 93^{* *}$ & 1996 & $\mathrm{M}$ & Fledgling & William's Gulch Nest \\
$6-06-96$ & $66 \mathrm{M} 94^{* *}$ & 1996 & $\mathrm{M}$ & Fledgling & Lindl Nest \\
$6-06-96$ & $66 \mathrm{M} 95^{* *}$ & 1996 & $\mathrm{M}$ & Fledgling & Lindl Nest \\
$6-06-96$ & $66 \mathrm{M} 96^{* *}$ & 1996 & $\mathrm{M}$ & Fledgling & Crane Ridge Nest \\
$6-07-96$ & $66 \mathrm{M} 97^{* *}$ & 1996 & $\mathrm{M}$ & Fledgling & Vasco Road Nest \\
$6-07-96$ & $66 \mathrm{M} 98^{* *}$ & 1996 & $\mathrm{M}$ & Fledgling & Vasco Road Nest \\
$6-08-96$ & $66 \mathrm{~F} 74^{* *}$ & 1996 & $\mathrm{~F}$ & Fledgling & Calaveras Creek Nest \\
$6-08-96$ & $66 \mathrm{M} 99^{* *}$ & 1996 & $\mathrm{M}$ & Fledgling & Mid. Indian Cr. Nest \\
$6-09-96$ & $66 \mathrm{~F} 75^{* *}$ & 1996 & $\mathrm{~F}$ & Fledgling & Patterson Nest \\
$6-10-96$ & $66 \mathrm{F76} * *$ & 1996 & $\mathrm{~F}$ & Fledgling & Ordway Nest \\
$6-12-96$ & $66 \mathrm{M} 100^{* *}$ & 1996 & $\mathrm{M}$ & Fledgling & Upper Indian Cr. Nest \\
& & & & & \\
\hline
\end{tabular}

* Bird present in more than one population segment during study.

** Juveniles tagged in 1996 were not used in survival estimates. 
experience and re-examination of several tagged birds months after independence. The latter showed transmitter fit to be slightly loose but nevertheless perfectly functional.

From the aerial roll-call surveys, we noted much variation in the length of time that radio-tagged juveniles remained within or near their natal territories. Some stayed until September or October, and, at the extreme, a few individuals remained until January, nearing the time when the adults began courting and incubating. In general, eagles from nests just northwest of the WRA tended to remain in that vicinity, while those from territories across the Livermore Valley to the south tended to move in the direction of the WRA. Figure 5.1 shows the distribution of relocations of 12 eagles tagged as fledglings in nests located at distances of over $20 \mathrm{~km}$ from the WRA. The overall distribution of juvenile relocations in the study area is shown in Figure 5.2.

5.1.1. Juvenile Censoring and Fatalities. Of the 79 tagged juveniles, 10 were censored (4o $\delta^{\star}$ and $6 \% q)$ and 8 died $(6 \delta \delta$ and $2 q q)$ within the study area during the period from tagging to 15 June of the following calendar year, the date of transition from juvenile to subadult. One of the censored birds (Case J8) died outside the study area. Among the 18 birds, the conditions of censoring or death were as follows:

Case J1. Juvenile Female 43F05, captured near the WRA (Site 300) on 2 February 1994, was last detected on 29 March 1994, $8.4 \mathrm{~km} \mathrm{SE}$ of the WRA. Its nearest relocation to the WRA was $3.0 \mathrm{~km}$. We heard its signal twice as a subadult (18 September 1994 and 17 March 1995) emanating from outside the study area. Censored, departed.

Case J2. Juvenile Female 55F34, tagged 4 June 1995 as a fledgling at the Pipe Cross Nest near San Antonio Reservoir ca. $16 \mathrm{~km}$ west of the WRA, was last detected on 25 October 1995. It was never detected outside its nest area. We suspect transmitter failure, but there was no evidence for it. Censored because of lost signal, unknown cause.

Case J3. Juvenile Male 55M53, tagged at the Vasco Road Nest on 7 June 1995, was last detected on 20 October 1995 before departing the study area. However, it returned by late May 1996. Censored, departed but later returned to the study area.

Case J4. Juvenile Female 44F20, tagged as a fledgling at the Pipe Cross Nest on 5 June 1994, was last located on 12 October 1994 near San Luis Reservoir in the southern end of the study area, and heard its signal again in that area on 16 October 1994 . We may have also heard it on 27 October 1994. We found its transmitter detached near Taft, California, over $300 \mathrm{~km}$ south of the study area, on 24 July 1996. Censored, departed.

Case J5. Juvenile Male 44M20 was tagged as a fledgling at the Welch Creek Nest near Calaveras Reservoir on 27 May 1994. It was last detected still near its nest on 23 July 1994. The signal was very weak and suggestive of transmitter antenna failure. Censored with circumstantial evidence of transmitter failure. 


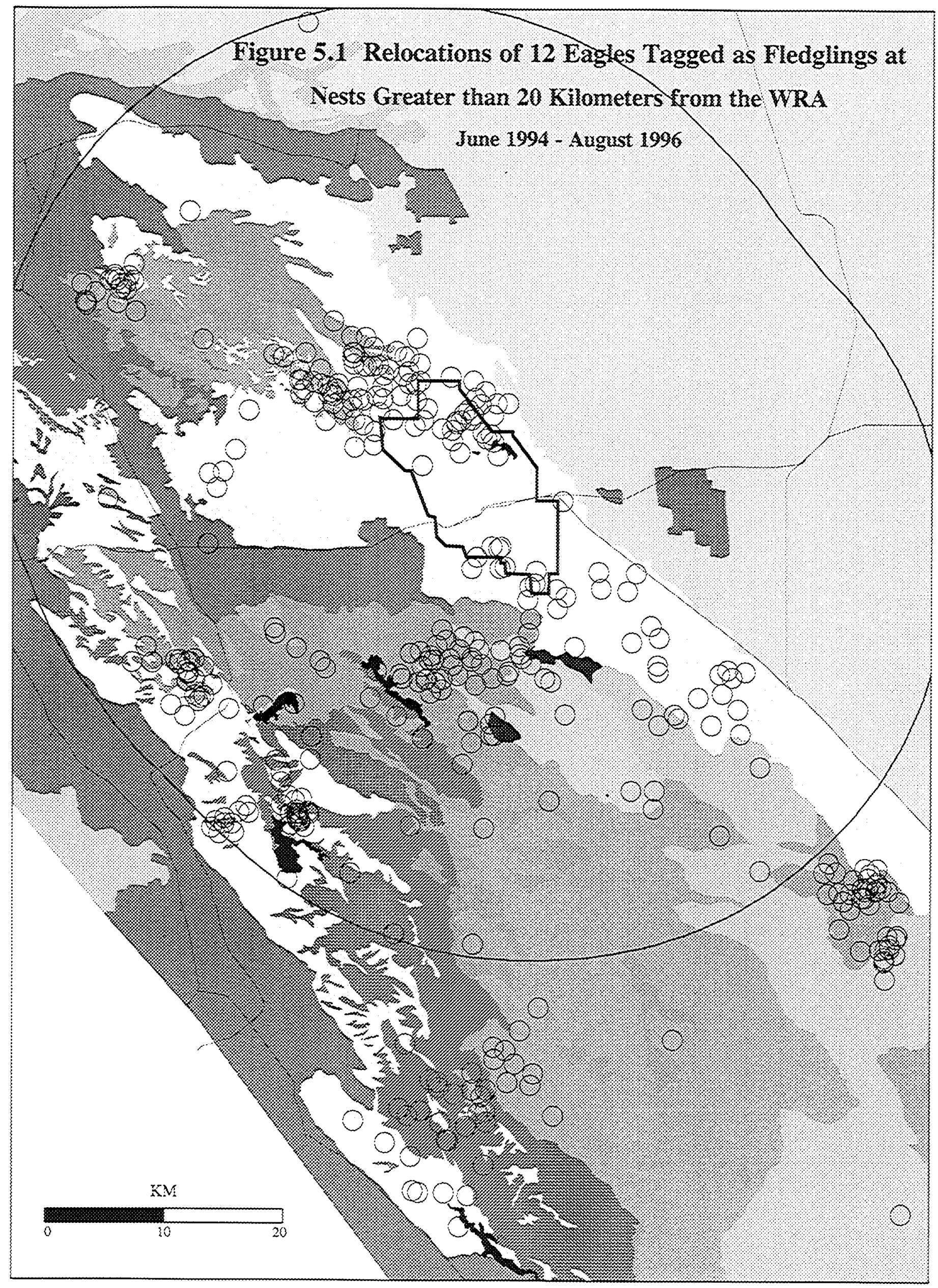




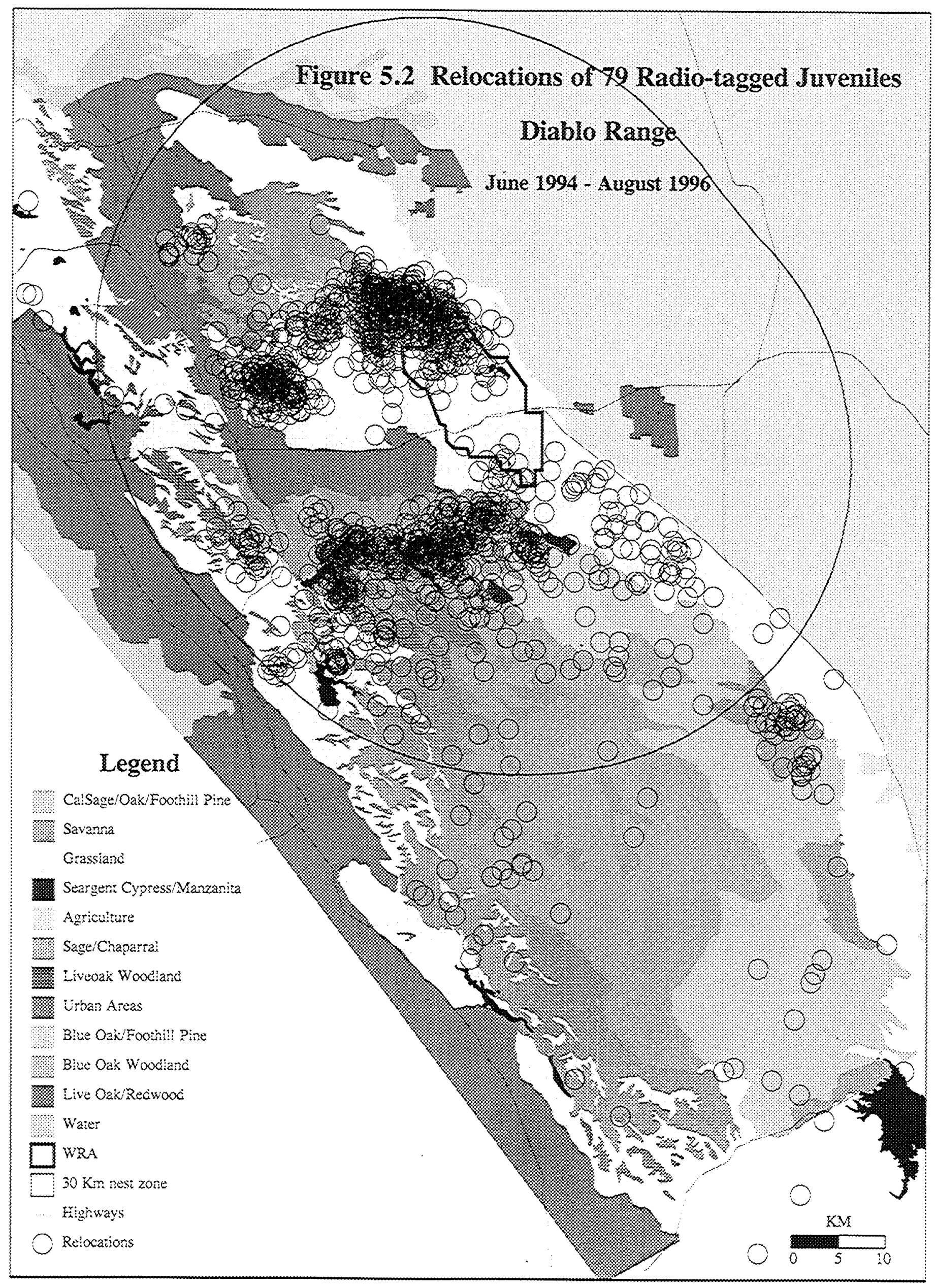


Case J6. Juvenile Male 44M30, tagged as a fledgling at the Sibley Nest on 6 June 1994, was last detected, still in its natal territory, on 14 August 1994. We suspect transmitter failure, but there was no evidence for it. Censored because of lost signal, unknown cause.

Case J7. Juvenile Female 44F15, tagged as a fledgling at the Adelaide Nest on 21 May 1994, dropped its transmitter near the nest on 13 July 1994. Censored because of failure of threads binding transmitter attachment ribbons.

Case J8. Juvenile Male 44M29 was tagged as a fledgling at the Foley Nest on 6 June 1994. It departed the study area to the south in the week following 11 November 1994. It was hit by a car in early March 1995 in the Cuyama Valley ca. $340 \mathrm{~km}$ south of the WRA. Censored rather than considered a fatality because the death occurred far outside the study area and was reported incidentally.

Case J9. Juvenile Male 44M31, tagged as a fledgling at the Niles Canyon Nest on 7 June 1994, and was electrocuted on ca. 21 May 1995 on Crane Ridge near Livermore (see Appendix C). Fatality.

Case J10. Juvenile Female 55F36, tagged as a fledgling at the Vasco Road Nest on 7 June 1995, apparently starved in a thistle thicket ca. 1 July 1995 in a neighboring pair's territory (Ordway) where it had flown out of reach of its parents. Fatality.

Case J11. Juvenile Female 55F38, tagged as a fledgling at the Calaveras Creek Nest on 10 June 1995 , fledged beneath the forest canopy and probably starved ca. 8 July 1995 as a result of being hidden from its parents. Fatality.

Case J12. Juvenile Male 55M47, tagged as a fledgling at the Adelaide Nest on 24 May 1995, was killed in a collision with a fence near its nest ca. 4 June 1995. Fatality.

Case J13. Juvenile Female 55F32, tagged as a fledgling at the Round Valley Nest on 23 May 1995, was last detected in the WRA on 14 May 1996. Ten of 37 total relocations in the study area were within the boundaries of the WRA. It is plausible that the transmitter on this bird was destroyed by a turbine blade (see Section 4.4 and Appendix B). Censored because of lost signal, unknown cause.

Case J14. Juvenile Female 55F37, tagged as a fledgling at the Lindl Nest on 8 June 1995, was last detected approximately $0.7 \mathrm{~km}$ northwest of the WRA on 14 May 1996. Of 31 total relocations recorded of this individual, 3 were within the WRA, and 2 were within $2 \mathrm{~km}$ of its boundary (Appendix B). Censored because of lost signal, unknown cause.

Case J15. Juvenile Male 66M88, tagged as a fledgling at the Hairpin Nest on 2 June 1996 , died of unknown causes near its nest on ca. 10 June 1996. Fatality. 
Case J16. Juvenile Male 66M97, tagged as a fledgling at the Vasco Road Nest on 7 June 1996, died of unknown causes near its nest on ca. 16 June 1996. Fatality.

Case J17. Juvenile Male 66M93, tagged as a fledgling at the William's Gulch Nest on 5 June 1996, died approximately $0.8 \mathrm{~km}$ from its nest on 21 June 1996 . Head injuries suggested that this bird may have been seized by another eagle. Fatality.

Case J18. Juvenile Male 66M96, tagged as a fledgling at the Crane Ridge Nest on 6 June 1996, died of unknown causes near its nest on ca. 23 June 1996. Fatality.

5.1.2 Juvenile Survival Rate. Because of the strong seasonal component in juvenile mortality apparent in our data (most deaths occur in post-fledging mishaps), we are presently considering only samples from the 1994 and 1995 cohorts. Survival data from the 1996 cohort will be included after 15 June 1997 when we have tracked the survivors for a full year. We chose to censor Case $\mathrm{J} 8$ which died $340 \mathrm{~km}$ from the WRA and was discovered incidentally (see Section 4.3 for censoring rationale).

Considering all remaining fatalities in the 1994 and 1995 juvenile samples, we currently estimate the yearly survival rate of juveniles in the study area at $0.9216(95 \%$ C.I. $=0.8514-0.9917)$. For females alone, the estimate is $0.8824(0.7463-1.000)$, and for males, $0.9466(0.8720$ 1.000).

We continue to contemplate the best way of weighting these estimates to accommodate the incidence of transmitter destruction by the turbine blades (see Section 4.2). Cases J3, J13 and $\mathrm{J} 14$ are candidates for inclusion in the kill list; however, in one of them (J3), we found the eagle no closer than $3.3 \mathrm{~km}$ from the WRA boundary. In the other cases, the eagles frequented the WRA vicinity. For now, we decline to weight the survival estimates until we have a clearer view of the problem.

\subsection{Subadults}

We added 28 subadults to our sample (Table 5.2) during the current study period (to 12 August 1996), capturing them mainly in or near the WRA. These, with the 17 subadults tagged in 1994, were further augmented by 41 tagged as juveniles in 1994 and 1995 that remained in the area to become subadults in June of the year after hatching. This brings to 86 the total number of subadults contributing survival data to this analysis.

Figure 5.3 shows the distribution of all radio-relocations in the study area for 86 subadults throughout the 31-month study period. Although we have not yet looked carefully at their distribution in relation to habitat, the area of highest relocation density appears to surround Altamont Pass, with lower densities at its center, i.e., along Highway 580 in the central WRA. Some of this pattern may relate to capture location, but, as discussed in Section 9.3 of our first report, much of it does not. The area holding the largest concentration of relocations is that along the northern boundary of the WRA in the area of the future Los Vaqueros Reservoir, now under construction. 
Table 5.2. Eighty-six subadults radio-tagged from January 1994 through July 1996.

\begin{tabular}{|c|c|c|c|c|}
\hline $\begin{array}{l}\text { Segment } \\
\text { Entry Date }\end{array}$ & Bird ID & $\begin{array}{c}\text { Hatching } \\
\text { Year }\end{array}$ & Sex & $\begin{array}{l}\text { Tagging } \\
\text { Location }\end{array}$ \\
\hline $1-06-94$ & 41F01 & 1991 & $\mathrm{~F}$ & Site 300 \\
\hline $1-11-94$ & $42 \mathrm{MO} 2$ & 1992 & $\mathbf{M}$ & Site 300 \\
\hline $1-12-94$ & $42 \mathrm{M} 03$ & 1992 & $\mathbf{M}$ & Site 300 \\
\hline $1-14-94$ & $42 \mathrm{~F} 03$ & 1992 & $\mathrm{~F}$ & Site 300 \\
\hline $1-19-94$ & 42M07 & 1992 & M & Site 300 \\
\hline $1-26-94$ & 40M08* & 1990 & $\mathbf{M}$ & Site 300 \\
\hline $2-02-94$ & $41 \mathrm{~F} 06 *$ & 1991 & $\mathrm{~F}$ & Morgan Territory \\
\hline $2-04-94$ & 41F08 & 1991 & $\mathrm{~F}$ & Site 300 \\
\hline $2-04-94$ & $42 \mathrm{M} 11$ & 1992 & $\mathbf{M}$ & Site 300 \\
\hline $2-07-94$ & $40 \mathrm{~F} 10^{*}$ & 1990 & $\mathrm{~F}$ & Site 300 \\
\hline $2-11-94$ & $42 \mathrm{M} 12$ & 1992 & M & Site 300 \\
\hline $2-12-94$ & $41 \mathrm{~F} 11 *$ & 1991 & $\mathrm{~F}$ & WRA-Brushy Peak \\
\hline $2-23-94$ & $40 \mathrm{M} 14 *$ & 1990 & $\mathbf{M}$ & Site 300 \\
\hline $2-23-94$ & $41 \mathrm{M} 15^{*}$ & 1991 & M & Site 300 \\
\hline $2-25-94$ & $42 \mathrm{M} 16$ & 1992 & $\mathbf{M}$ & WRA-Brushy Peak \\
\hline $2-28-94$ & $42 \mathrm{M} 17$ & 1992 & $\mathbf{M}$ & Morgan Territory \\
\hline $6-15-94$ & $43 \mathrm{~F} 09 *$ & 1993 & $\mathrm{~F}$ & Site 300 \\
\hline $6-15-94$ & 43M09* & 1993 & M & Morgan Territory \\
\hline $7-29-94$ & $41 \mathrm{~F} 24$ & 1991 & $\mathrm{~F}$ & WRA-SE Border \\
\hline $4-05-95$ & $52 \mathrm{M} 34$ & 1992 & M & WRA-Gate 3 \\
\hline $4-06-95$ & $52 \mathrm{~F} 25$ & 1992 & $\mathrm{~F}$ & WRA-Gate 3 \\
\hline $4-13-95$ & $53 \mathrm{M} 36$ & 1993 & M & WRA-Brushy Peak \\
\hline $4-13-95$ & $53 \mathrm{M} 37$ & 1993 & $\mathbf{M}$ & WRA-Brushy Peak \\
\hline $4-14-95$ & $52 \mathrm{M} 38^{*}$ & 1992 & $\mathbf{M}$ & WRA-Brushy Peak \\
\hline $4-18-95$ & $53 \mathrm{M} 39$ & 1993 & M & WRA-Brushy Peak \\
\hline $4-20-95$ & $52 \mathrm{~F} 27$ & 1992 & $\mathrm{~F}$ & Site 300 \\
\hline $5-16-95$ & $52 \mathrm{~F} 29 *$ & 1992 & $\mathrm{~F}$ & Site 300 \\
\hline $5-16-95$ & $53 \mathrm{M} 40$ & 1993 & M & Site 300 \\
\hline $5-20-95$ & $53 \mathrm{~F} 30$ & 1993 & $\mathrm{~F}$ & Site 300 \\
\hline $5-21-95$ & $51 \mathrm{M} 44 *$ & 1991 & $\mathbf{M}$ & Site 300 \\
\hline $5-21-95$ & $53 \mathrm{M} 43$ & 1993 & M & Site 300 \\
\hline $5-21-95$ & $53 \mathrm{M} 46$ & 1993 & $\mathbf{M}$ & Site 300 \\
\hline $5-27-95$ & $52 \mathrm{M} 50$ & 1992 & M & Site 300 \\
\hline $6-15-95$ & $44 \mathrm{~F} 16 *$ & 1994 & $\mathrm{~F}$ & Shell Ridge Nest \\
\hline
\end{tabular}


Table 5.2. (continued)

\begin{tabular}{|c|c|c|c|c|}
\hline $\begin{array}{l}\text { Segment } \\
\text { Entry Date }\end{array}$ & Bird ID & $\begin{array}{c}\text { Hatching } \\
\text { Year }\end{array}$ & Sex & $\begin{array}{l}\text { Tagging } \\
\text { Location }\end{array}$ \\
\hline $6-15-95$ & $44 \mathrm{~F} 17 *$ & 1994 & $\mathrm{~F}$ & Mines Road Nest \\
\hline $6-15-95$ & $44 \mathrm{~F} 18^{*}$ & 1994 & $\mathrm{~F}$ & Lindl Nest \\
\hline $6-15-95$ & $44 \mathrm{~F} 19^{*}$ & 1994 & $\mathrm{~F}$ & Pipe Cross Nest \\
\hline $6-15-95$ & $44 \mathrm{~F} 21 *$ & 1994 & $\mathrm{~F}$ & Calaveras Creek Nest \\
\hline $6-15-95$ & $44 \mathrm{~F} 22 *$ & 1994 & $\mathrm{~F}$ & Indian Creek Nest \\
\hline $6-15-95$ & $44 \mathrm{~F} 23 *$ & 1994 & $\mathrm{~F}$ & Eagle's Run Nest \\
\hline $6-15-95$ & $44 \mathrm{M} 18^{*}$ & 1994 & $\mathrm{M}$ & Adelaide Nest \\
\hline $6-15-95$ & $44 \mathrm{M} 19 *$ & 1994 & $\mathbf{M}$ & Wally Nest \\
\hline $6-15-95$ & $44 \mathrm{M} 21^{*}$ & 1994 & $\mathbf{M}$ & Vasco Road Nest \\
\hline $6-15-95$ & $44 \mathrm{M} 22 *$ & 1994 & M & Los Vaqueros Nest \\
\hline $6-15-95$ & $44 \mathrm{M} 23^{*}$ & 1994 & $\mathbf{M}$ & Del Valle S. Nest \\
\hline $6-15-95$ & $44 \mathrm{M} 24^{*}$ & 1994 & $\mathbf{M}$ & Mines Road Nest \\
\hline $6-15-95$ & $44 \mathrm{M} 25^{*}$ & 1994 & $\mathbf{M}$ & Lindl Nest \\
\hline $6-15-95$ & $44 \mathrm{M} 26^{*}$ & 1994 & $\mathrm{M}$ & Camino Diablo Nest \\
\hline $6-15-95$ & $44 \mathrm{M} 27^{*}$ & 1994 & $\mathbf{M}$ & Camino Diablo Nest \\
\hline $6-15-95$ & $44 \mathrm{M} 28^{*}$ & 1994 & $\mathrm{M}$ & Mount Allison Nest \\
\hline $6-15-95$ & $44 \mathrm{M} 32 *$ & 1994 & M & High Corral Nest \\
\hline $6-15-95$ & $44 \mathrm{M} 33 *$ & 1994 & $\mathbf{M}$ & High Corral Nest \\
\hline $6-15-95$ & $54 \mathrm{~F} 26 *$ & 1994 & $\mathrm{~F}$ & WRA-Brushy Peak \\
\hline $6-15-95$ & $54 \mathrm{~F} 31 *$ & 1994 & $\mathrm{~F}$ & Site 300 \\
\hline $6-15-95$ & $54 \mathrm{M} 35^{*}$ & 1994 & $\mathrm{M}$ & Site 300 \\
\hline $6-15-95$ & $54 \mathrm{M} 42 *$ & 1994 & $\mathrm{M}$ & Site 300 \\
\hline $12-07-95$ & $52 \mathrm{~F} 45^{*}$ & 1992 & $\mathrm{~F}$ & Lover's Leap \\
\hline $12-16-95$ & $52 \mathrm{~F} 47 *$ & 1992 & $\mathrm{~F}$ & Los Vaqueros \\
\hline $12-16-95$ & $52 \mathrm{M} 67^{*}$ & 1992 & $\mathbf{M}$ & Mallory \\
\hline $1-25-96$ & $62 \mathrm{M} 73^{*}$ & 1992 & M & Mallory \\
\hline $2-01-96$ & $62 \mathrm{~F} 48^{*}$ & 1992 & $\mathrm{~F}$ & Mallory \\
\hline $2-24-96$ & $62 \mathrm{M} 76^{*}$ & 1992 & $\mathbf{M}$ & Site 300 \\
\hline $2-24-96$ & $62 \mathrm{M} 77 *$ & 1992 & $\mathbf{M}$ & Site 300 \\
\hline $2-24-96$ & $64 \mathrm{M} 75$ & 1994 & $\mathrm{M}$ & Site 300 \\
\hline $2-27-96$ & $64 \mathrm{~F} 50$ & 1994 & $\mathrm{~F}$ & Site 300 \\
\hline $2-28-96$ & $62 \mathrm{M} 79 *$ & 1992 & $\mathbf{M}$ & Site 300 \\
\hline $3-02-96$ & $63 F 52$ & 1993 & $\mathrm{~F}$ & WRA-Brushy Peak \\
\hline $5-14-96$ & $63 \mathrm{~F} 57$ & 1993 & $\mathrm{~F}$ & N3 Bathtub \\
\hline
\end{tabular}


Table 5.2. (continued)

\begin{tabular}{lllll}
\hline \hline $\begin{array}{l}\text { Segment } \\
\text { Entry Date }\end{array}$ & Bird ID & $\begin{array}{c}\text { Hatching } \\
\text { Year }\end{array}$ & Sex & $\begin{array}{l}\text { Tagging } \\
\text { Location }\end{array}$ \\
\hline $6-15-96$ & $55 \mathrm{F33} *$ & 1995 & $\mathrm{~F}$ & Round Valley Nest \\
$6-15-96$ & $55 \mathrm{M} 48^{*}$ & 1995 & $\mathrm{M}$ & Hollow Nest \\
$6-15-96$ & $55 \mathrm{M} 49^{*}$ & 1995 & $\mathrm{M}$ & Hollow Nest \\
$6-15-96$ & $55 \mathrm{M} 51^{*}$ & 1995 & $\mathrm{M}$ & Hairpin Nest \\
$6-15-96$ & $55 \mathrm{M} 52^{*}$ & 1995 & $\mathrm{M}$ & Patterson Nest \\
$6-15-96$ & $55 \mathrm{~F} 35^{*}$ & 1995 & $\mathrm{~F}$ & Welch Creek Nest \\
$6-15-96$ & $55 \mathrm{M} 53^{*}$ & 1995 & $\mathrm{M}$ & Vasco Road Nest \\
$6-15-96$ & $55 \mathrm{M} 54^{*}$ & 1995 & $\mathrm{M}$ & Lindl Nest \\
$6-15-96$ & $55 \mathrm{M} 55^{*}$ & 1995 & $\mathrm{M}$ & Lindl Nest \\
$6-15-96$ & $55 \mathrm{M} 56^{*}$ & 1995 & $\mathrm{M}$ & Morgan Territory Nest \\
$6-15-96$ & $55 \mathrm{M} 57^{*}$ & 1995 & $\mathrm{M}$ & Del Valle S. Nest \\
$6-15-96$ & $55 \mathrm{~F} 40^{*}$ & 1995 & $\mathrm{~F}$ & Eagle's Run Nest \\
$6-15-96$ & $55 \mathrm{M} 58^{*}$ & 1995 & $\mathrm{M}$ & Eagle's Run Nest \\
$6-15-96$ & $55 \mathrm{~F} 41^{*}$ & 1995 & $\mathrm{~F}$ & Ordway Nest \\
$6-15-96$ & $55 \mathrm{M} 59^{*}$ & 1995 & $\mathrm{M}$ & Wally Nest \\
$6-15-96$ & $55 \mathrm{M} 60^{*}$ & 1995 & $\mathrm{M}$ & Ordway Nest \\
$6-20-96$ & $63 \mathrm{~F} 77$ & 1993 & $\mathrm{~F}$ & North Crane Ridge \\
$7-12-96$ & $64 \mathrm{M} 102$ & 1994 & $\mathrm{M}$ & Del Valle Ridge \\
\hline \hline
\end{tabular}

* Bird present in more than one population segment during study. 


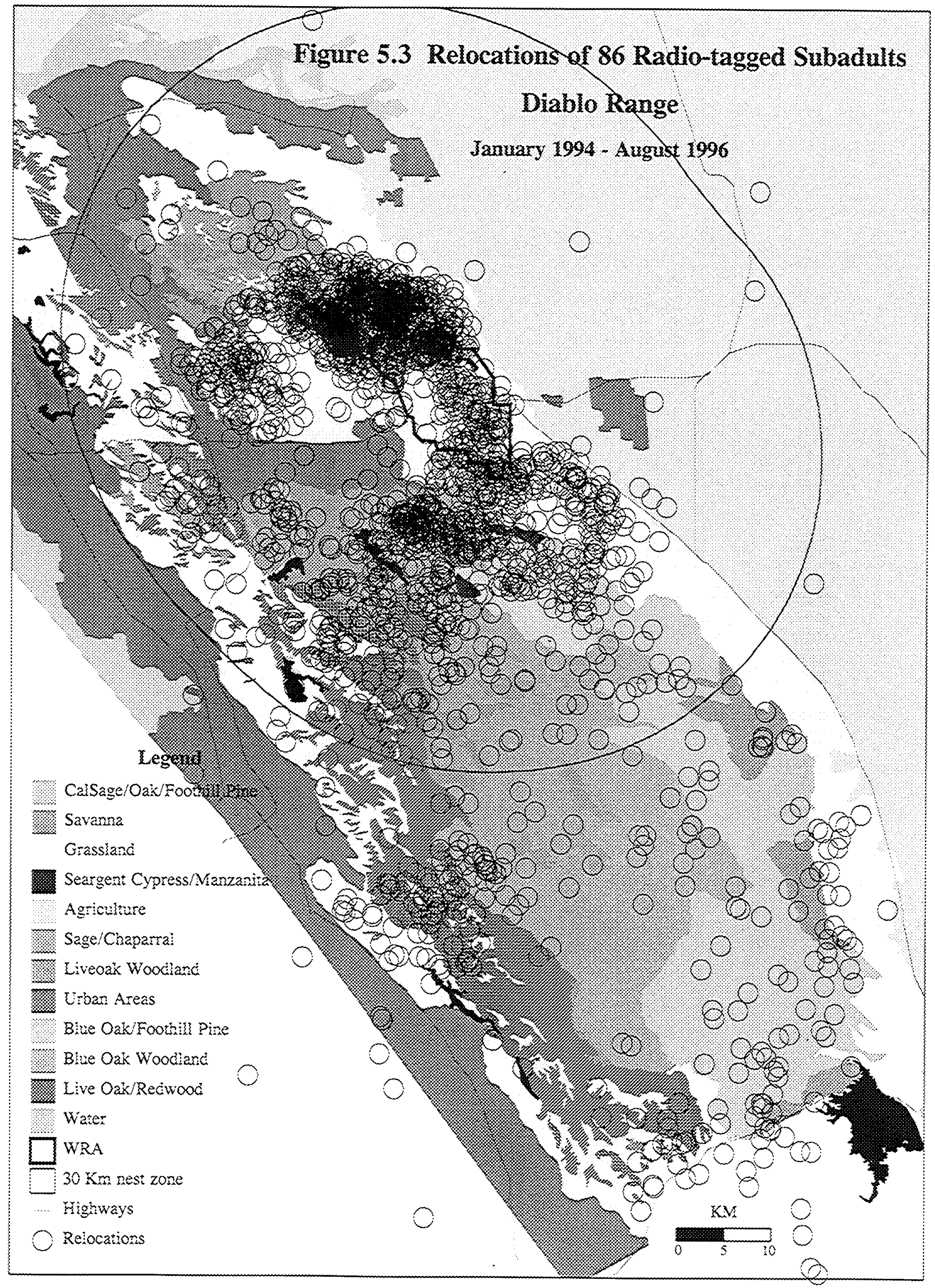


5.2.1. Subadult Censoring and Fatalities. Of the 86 subadults in the analyzed sample, 15 died $(10 \delta \delta$ and $5 \% q)$ and 12 were censored $\left(7 \delta \delta^{\star}\right.$ and $\left.5 \% q\right)$. The conditions of censoring or death were as follows:

Case S1. Subadult Female 41F01, tagged at Site 300 on 6 January 1994 and last detected 12 July 1994, was never relocated closer than $7 \mathrm{~km}$ from the WRA. Censored because of signal loss, cause unknown.

Case S2. Subadult Male 42M11, tagged at Site 300 on 4 February 1994 and last relocated on 7 June 1994 at $1.1 \mathrm{~km}$ south of the WRA. It was never recorded within the WRA boundaries. Censored because of signal loss, cause unknown (see Appendix B).

Case S3. Subadult Male 44M22 was tagged as a fledgling on 31 May 1994 at the Los Vaqueros Nest. It was last detected on 28 September 1995, $10.1 \mathrm{~km}$ from the WRA. There was very bad radio interference (a loud squeal) on this frequency, and the bird may have remained for some time undetected. However, 22 out of 46 relocations of this bird were within the WRA boundary. It is therefore plausible that the transmitter was destroyed by a turbine blade (see Section 4.4 and Appendix B). Censored because of signal loss, cause unknown.

Case S4. Subadult Female 52F25, captured within the WRA on 6 April 1995, was subsequently relocated only once (24 April 1995 in the WRA) and never heard from again. It is plausible that the transmitter was destroyed by a turbine blade, but considering that the eagle was relocated only once, there is the distinct possibility that it was transient. Censored because of signal loss, cause unknown (see Appendix B).

Case S5. Subadult Male 53M46 was captured at Site 300 on 21 May 1995 and last relocated on 15 September 1995, $17 \mathrm{~km}$ west of the WRA. We twice detected it near the WRA, once within $1.4 \mathrm{~km}$, but never within its boundaries. Censored because of signal loss, cause unknown.

Case S6. Subadult Male 42M12 was tagged at Site 300 on 11 February 1994. It dropped its transmitter ca. 14 February 1996. Censored because of failure of threads binding transmitter attachment ribbons.

Case S7. Subadult Male 42M16 was captured within the WRA on 25 February 1994. Dropped its transmitter ca. 1 June 1995. Censored because of failure of threads binding transmitter attachment ribbons.

Case S8. Subadult Female 41F24, tagged in the WRA on 29 July 1994, departed to more than $150 \mathrm{~km}$ southeast within a week of tagging. Censored, departed. 
Case S9. Subadult Male 54M42 was tagged as a free-ranging juvenile at Site 300 on 21 May 1995 and immediately departed the study area. It is currently living in the vicinity of King City, $185 \mathrm{~km}$ to the south. Censored, departed.

Case S10. Subadult Female 42F03, tagged at Site 300 on 14 January 1994, died of lead poisoning ca. 6 March 1994 near Mt. Stakes in the central portion of the Diablo Mountains (see Appendix C). Fatality.

Case S11. Subadult Female 44F17 was tagged as a fledgling at the Mines Road Nest on 2 June 1994 (see Appendix C). It died of lead poisoning on 21 November 1995 on Crane Ridge near its natal territory. Fatality.

Case S12. Subadult Female 41F08, captured at Site 300 on 4 Feb 1994, was killed by a Kenetech 56-100 turbine on a 60-foot tower on ca. 8 September 1994 (see Appendix C). In 30 total relocations, we never found it in the WRA but recorded seven relocations within $2 \mathrm{~km}$ of its boundary. Fatality.

Case S13. Subadult Male 42M07, tagged at Site 300 on 19 January 1994, died on ca. 27 February 1995 near Mt. Oso in the Diablo Mountains. The condition of the carcass was very similar to that of $42 \mathrm{~F} 03$, known to have died of lead poisoning (see Appendix $\mathrm{C}$ ). Necropsy pending. Fatality.

Case S14. Subadult Male 42M03, tagged at Site 300 on 12 January 1994, was killed by a turbine blade on a Kenetech 56-100 turbine on a 60-foot tower on ca. 9 May 1994. Nine out of 21 total relocations were recorded within the WRA and 2 within $2 \mathrm{~km}$ of its boundary (see Appendix C). Fatality.

Case S15. Subadult Male 42M17, captured in Morgan Territory near Mt. Diablo on 28 February 1994, was killed by the blade of a Kenetech 56-100 turbine on a $60-\mathrm{ft}$ tower. The bird, missing from the aerial roll-call survey since 30 May 1995, was found by a Kenetech employee on 11 August 1995 (see Appendix C). The transmitter was not recovered, and was very likely destroyed by the blade. Fatality.

Case S16. Subadult Male 44M25 was tagged as a fledgling at the Lindl Nest near Del Valle Reservoir on 2 June 1994. It was killed as a subadult by the blade of a Danregn Vind/Kraft Bonus turbine on a tubular tower during 12-21 December 1995. It was found by a Foras employee, the transmitter destroyed by the blade strike. Of 60 relocations of this bird since tagging, 8 were within the WRA and 8 were within $2 \mathrm{~km}$ of its boundary (see Appendix C). Fatality.

Case S17. Subadult Male 42M02 was tagged at Site 300 on 11 January 1994 and killed by a Kenetech 56-100 turbine on a 60-ft tower on ca. 8 April 1996 . Of 94 total relocations, 11 were recorded within the WRA, and 13 within $2 \mathrm{~km}$ (see Appendix C). Fatality. 
Case S18. Subadult Female 52F27, captured at Site 300 on 20 April 1995, was killed by a Kenetech turbine blade strike. The nearest turbine to the carcass was a 56-100 turbine on a 140-ft tower in a "windwall." Other nearby tower types included the Kenetech 56100 turbine on 60-foot towers (see Appendix C in Hunt et al. 1995). The eagle was discovered long dead and decomposed by a Kenetech employee on 3 October 1995, the transmitter destroyed. We had last detected its signal in the WRA on 10 May, the last of only 2 relocations since tagging. We estimate its death occurring before $17 \mathrm{May}$, the next survey date (see Appendix C). Fatality.

Case S19. Subadult Male 52M34, tagged in the WRA on 5 April 1995, was killed by a Kenetech 56-100 turbine on a 60-ft tower on ca. 1 November 1995. Out of a total of 23 relocations, 11 were in the WRA and 3 were within $2 \mathrm{~km}$ of its boundary (see Appendix C). Fatality.

Case S20. Subadult Male 52M50, tagged at Site 300 on 27 May 1995, was electrocuted by a powerline near Livermore Airport on ca. 20 September 1995 . The powerline was configured with two of its three wires close enough together to easily allow phase-tophase contact by a bird the size of an eagle (see Appendix C). Fatality.

Case S21. Subadult Male 54M35, tagged as a free-ranging juvenile at Site 300 on 12 April 1995 was found electrocuted under a power/transformer pole in mid-September 1995 near Ingomar, California at the southeast edge of the study area (see Appendix C). Fatality.

Case S22. Subadult Male 44M18 was tagged as a fledgling on 21 May 1994 at the Adelaide Nest. It was last detected on 15 March 1996 near Los Vaqueros just northwest of the WRA. Transmitter destruction by a blade strike is plausible in view of the fact that 27 of 31 total relocations as a subadult were in or near the WRA. Censored because of signal loss, cause unknown (see Appendix B).

Case S23. Subadult Female 53F30, tagged at Site 300 on 20 May 1995, was absent from the study area from late September 1995 until February 1995. Censored, departed but later returned to the study area.

Case S24. Subadult Female 54F31, tagged as a free-ranging juvenile at Site 300 on 21 May 1995, departed the study area and was last relocated south of San Luis Reservoir on 8 August 1996. Censored, departed.

Case S25. Subadult Male 53M39, tagged on 18 April 1995 in the WRA near Brushy Peak, was killed by a Kenetech 56-100 turbine on a 60-ft tower on ca. 27 May 1996 (see Appendix C). Of 48 total relocations, 22 were recorded within the WRA, and 15 within $2 \mathrm{~km}$ of its boundary. Fatality. 
Case S26. Subadult Male 44M28, tagged as a fledgling at the Mount Allison Nest on 4 June 1994, was killed by the blade of a Kenetech 56-100 turbine on a 60-ft tower on ca. 24 June 1996. Physical evidence on the blade indicated that the bird hit it at approximately $0.5 \mathrm{~m}$ from the tip. A second untagged eagle was found dead under an adjacent turbine which also appeared to have hit the blade $0.5 \mathrm{~m}$ from the tip (see Appendix C). Of 45 total relocations as a subadult, 9 were recorded within the WRA, and 7 within $2 \mathrm{~km}$ of its boundary. Fatality.

Case S27. Subadult Female 55F41, tagged as a fledgling at the Ordway Nest on 15 June 1995, died from electrocution near the Tracy Dump on ca. 13 July 1996. The radio on this bird had transmitted normal signals from the same location during several consecutive surveys, suggesting the bird was dead (see Appendix C). Fatality.

5.2.2 Subadult Survival Rate. Considering the 15 subadult fatalities occurring in the study area by 12 August 1996, our current unweighted estimate of annual subadult survival (sexes pooled) is 0.7606 (C.I. $=0.6758-0.8454)$. For females alone, the estimate is $0.7645(0.6245-$ $0.9044)$ and for males, it is $0.7537(0.6467-0.8606)$. Excluding the nine turbine-related fatalities which occurred during the study period, the survival rate estimate from the pooled sample of the sexes increases to 0.8880 (0.8203 - 0.9557). Additional cases where circumstantial evidence suggests a plausibility of transmitter destruction include $S 2, S 3, S 4$, and S22.

\subsection{Floaters}

Our sample of 32 floaters includes 7 tagged in 1994, 5 in 1995, 4 in 1996, 15 tagged as subadults in 1994, and one territorial adult which became a floater in 1996 (Table 5.3). The overall distribution of relocations for radio-tagged floaters in the study area (Fig. 5.4) appears very similar to that of subadults (Fig. 5.3).

5.3.1 Floater Censoring and Fatalities. To date (12 August 1996), there have been 5 floaters censored ( $4 \phi q$ and $1 \delta$ ), one recorded as a winter visitor and periodically censored $(\delta)$, and two deaths (both $\delta \delta$ ). The conditions of censoring or death for each of these eagles are listed below:

Case F1. Floater Female 4AF13, tagged at Site 300 on 1 March 1994, dropped its transmitter in the WRA in early February 1995. Censored because of failure of threads binding transmitter attachment ribbons.

Case F2. Floater Female 40F10 was captured as a subadult at Site 300 on 7 February 1994. It soon moved southward and was never detected closer than $9 \mathrm{~km}$ from the WRA. Its range centered in the southeast portion of the study area, and it was last detected on 27 July near San Luis Reservoir, about $75 \mathrm{~km}$ SSE of the WRA. Censored, departed. 
Table 5.3. Seventy-two floaters and breeders radio-tagged from January 1994 to July 1996.

\begin{tabular}{|c|c|c|c|c|}
\hline $\begin{array}{l}\text { Segment } \\
\text { Entry Date }\end{array}$ & Bird ID & Sex & Status & $\begin{array}{l}\text { Nest or Territory } \\
\text { (Tagging Location) }\end{array}$ \\
\hline $1-17-94$ & 4AM04 & $\mathbf{M}$ & Floater & (Site 300) \\
\hline $1-19-94$ & 4AM05 & M & Floater & (Site 300) \\
\hline $1-19-94$ & 4AM06 & $\mathbf{M}$ & Floater & (Site 300) \\
\hline $1-31-94$ & 4AM10 & $\mathbf{M}$ & Floater & (Hodges Ranch) \\
\hline $2-14-94$ & 4AM13 & M & Floater & (WRA-Brushy Peak) \\
\hline $2-28-94$ & $4 \mathrm{AF} 12$ & $\mathrm{~F}$ & Floater & (Morgan Territory) \\
\hline $3-01-94$ & $4 \mathrm{AF} 13$ & $\mathrm{~F}$ & Floater & (Site 300) \\
\hline $6-15-94$ & $40 \mathrm{~F} 10^{*}$ & $\mathrm{~F}$ & Floater & (Site 300) \\
\hline $6-15-94$ & 40M08* & $\mathbf{M}$ & Floater & (Site 300) \\
\hline $6-15-94$ & $40 \mathrm{M} 14^{*}$ & M & Floater & (Site 300) \\
\hline $5-20-95$ & 5AM41 & M & Floater & (Site 300) \\
\hline $6-15-95$ & $41 \mathrm{~F} 11^{*}$ & $\mathrm{~F}$ & Floater & (WRA-Brushy Peak) \\
\hline $6-15-95$ & $41 \mathrm{M} 15^{*}$ & $\mathbf{M}$ & Floater & (Site 300$)$ \\
\hline $6-15-95$ & $51 \mathrm{M} 44 *$ & M & Floater & (Site 300) \\
\hline $12-13-95$ & $51 \mathrm{~F} 46$ & $\mathrm{~F}$ & Floater & (Patterson) \\
\hline $12-13-95$ & 5AM64 & $\mathbf{M}$ & Floater & (Del Valle) \\
\hline $12-13-95$ & 5AM65 & $\mathbf{M}$ & Floater & (Del Valle) \\
\hline $12-16-95$ & $51 \mathrm{M} 68$ & $\mathbf{M}$ & Floater & (Mallory) \\
\hline $2-09-96$ & 6AF49 & $\mathrm{F}$ & Floater & (Patterson) \\
\hline $2-24-96$ & 6AM78 & M & Floater & (Site 300) \\
\hline $2-28-96$ & $6 \mathrm{AF} 51$ & $\mathrm{~F}$ & Floater & (Site 300) \\
\hline $6-15-96$ & $52 \mathrm{~F} 29^{*}$ & $\mathrm{~F}$ & Floater & (Site 300) \\
\hline $6-15-96$ & $52 \mathrm{~F} 47 *$ & $\mathrm{~F}$ & Floater & (Los Vaqueros) \\
\hline $6-15-96$ & $52 \mathrm{M} 38 *$ & M & Floater & (WRA-Brushy Peak) \\
\hline $6-15-96$ & $52 \mathrm{M} 67 *$ & M & Floater & (Mallory) \\
\hline $6-15-96$ & $62 \mathrm{~F} 48^{*}$ & $\mathrm{~F}$ & Floater & (Mallory) \\
\hline $6-15-96$ & $62 \mathrm{M} 73 *$ & M & Floater & (Mallory) \\
\hline $6-15-96$ & $62 \mathrm{M} 76^{*}$ & $\mathrm{M}$ & Floater & (Site 300) \\
\hline $6-15-96$ & $62 \mathrm{M} 77^{*}$ & $\mathbf{M}$ & Floater & (Site 300) \\
\hline $6-15-96$ & $62 \mathrm{M} 79 *$ & $\mathbf{M}$ & Floater & (Site 300) \\
\hline $6-15-96$ & $62 \mathrm{M} 101$ & $\mathbf{M}$ & Floater & (Mines Road) \\
\hline $12-15-95$ & 5AM66 & $\mathbf{M}$ & Floater & (Mallory) \\
\hline $6-15-96$ & $52 \mathrm{~F} 45^{*}$ & $\mathrm{~F}$ & Territorial & Lover's Leap \\
\hline
\end{tabular}


Table 5.3. (continued).

\begin{tabular}{|c|c|c|c|c|}
\hline $\begin{array}{l}\text { Segment } \\
\text { Entry Date }\end{array}$ & Bird ID & Sex & Status & $\begin{array}{l}\text { Nest or Territory } \\
\text { (Tagging Location) }\end{array}$ \\
\hline $1-05-94$ & 4AM01 & M & Breeder & Seeno Nest \\
\hline $1-08-94$ & 4AF02 & $\mathrm{F}$ & Breeder & Seeno Nest \\
\hline $1-25-94$ & 4AF04 & $\mathrm{F}$ & Breeder & High Corral Nest \\
\hline $2-02-94$ & 4AF07 & $\mathrm{F}$ & Breeder & Morgan Territory Nest \\
\hline $3-02-94$ & $40 \mathrm{~F} 14$ & $\mathrm{~F}$ & Breeder & Seeno Nest \\
\hline $5-09-95$ & 5AF28 & $\mathrm{F}$ & Breeder & Los Vaqueros Nest \\
\hline $5-21-95$ & 5AM45 & $\mathbf{M}$ & Breeder & Diablo Cliffs Nest \\
\hline $6-12-95$ & $5 \mathrm{AM} 80$ & $\mathbf{M}$ & Breeder & Wally Nest \\
\hline $6-15-95$ & $41 \mathrm{~F} 06^{*}$ & $\mathrm{~F}$ & Breeder & Pleasanton Ridge Nest \\
\hline $6-30-95$ & 5AM61 & $\mathbf{M}$ & Breeder & Welch Creek Nest \\
\hline $7-02-95$ & $5 \mathrm{AF} 42$ & $\mathrm{~F}$ & Breeder & Del Valle S. Nest \\
\hline $11-22-95$ & $5 \mathrm{AF} 43$ & $\mathrm{~F}$ & Breeder & Ordway Nest \\
\hline $11-29-95$ & 5AM62 & $\mathrm{M}$ & Breeder & Vasco Road Nest \\
\hline $12-01-95$ & 5AF44 & $\mathrm{F}$ & Breeder & Round Valley Nest \\
\hline $12-07-95$ & 5AM63 & $\mathbf{M}$ & Breeder & Mid. Indian Cr. Nest \\
\hline $1-05-96$ & 6AM69 & $\mathbf{M}$ & Breeder & Upper Indian Cr. Nest \\
\hline $1-09-96$ & 6AM70 & $\mathrm{M}$ & Breeder & Lydia Lane Nest \\
\hline $1-12-96$ & $6 \mathrm{AM} 71$ & M & Breeder & Del Valle S. Nest \\
\hline $1-17-96$ & 6AM72 & $\mathbf{M}$ & Breeder & Seeno Nest \\
\hline $1-26-96$ & 6AM74 & $\mathbf{M}$ & Breeder & Corral Hollow Nest \\
\hline $4-24-96$ & 6AF53 & $\mathrm{F}$ & Breeder & Rocky Ridge Nest \\
\hline $4-26-96$ & $6 \mathrm{AF} 54$ & $\mathrm{~F}$ & Breeder & SRI Nest \\
\hline $5-06-96$ & 6AM81 & M & Breeder & Eagle's Run Nest \\
\hline $5-08-96$ & 6AF55 & $\mathrm{F}$ & Breeder & William's Gulch Nest \\
\hline $5-09-96$ & $6 \mathrm{AF} 56$ & $\mathrm{~F}$ & Breeder & Patterson-Foley Nest \\
\hline $5-10-96$ & 6AM82 & $\mathbf{M}$ & Breeder & Mines Road Nest \\
\hline $5-19-96$ & 6AF58 & $\mathrm{F}$ & Breeder & Hairpin Nest \\
\hline $5-20-96$ & 6 AF59 & $\mathrm{F}$ & Breeder & Mill Creek Nest \\
\hline $5-21-96$ & $6 \mathrm{AF} 60$ & $\mathrm{~F}$ & Breeder & Oak Flat Golf Nest \\
\hline $5-21-96$ & $6 \mathrm{AM} 83$ & $\mathbf{M}$ & Breeder & Oak Flat Golf Nest \\
\hline $5-24-96$ & 6AF61 & $F$ & Breeder & Lower JD Grant Nest \\
\hline $5-27-96$ & 6AM84 & $\mathbf{M}$ & Breeder & N3 Bathtub Nest \\
\hline $5-28-96$ & 6AF62 & $\mathrm{F}$ & Breeder & Upper JD Grant Nest \\
\hline
\end{tabular}


Table 5.3. (continued).

\begin{tabular}{lllll}
\hline $\begin{array}{l}\text { Segment } \\
\text { Entry Date }\end{array}$ & Bird ID & Sex & Status & $\begin{array}{l}\text { Nest or Territory } \\
\text { (Tagging Location) }\end{array}$ \\
\hline $5-30-96$ & 6AF63 & F & Breeder & Indian Creek Nest \\
$5-31-96$ & 6AF64 & F & Breeder & Adelaide Nest \\
$6-01-96$ & 6AF65 & F & Breeder & Mendenhall Nest \\
$6-04-96$ & 6AF70 & F & Breeder & Quimbey Nest \\
$6-07-96$ & 6AF73 & F & Breeder & Mid. Indian Cr. Nest \\
$7-10-96$ & 6AF78 & F & Breeder & Hi-C Nest \\
\hline \hline
\end{tabular}

* Bird present in more than one population segment during study. 


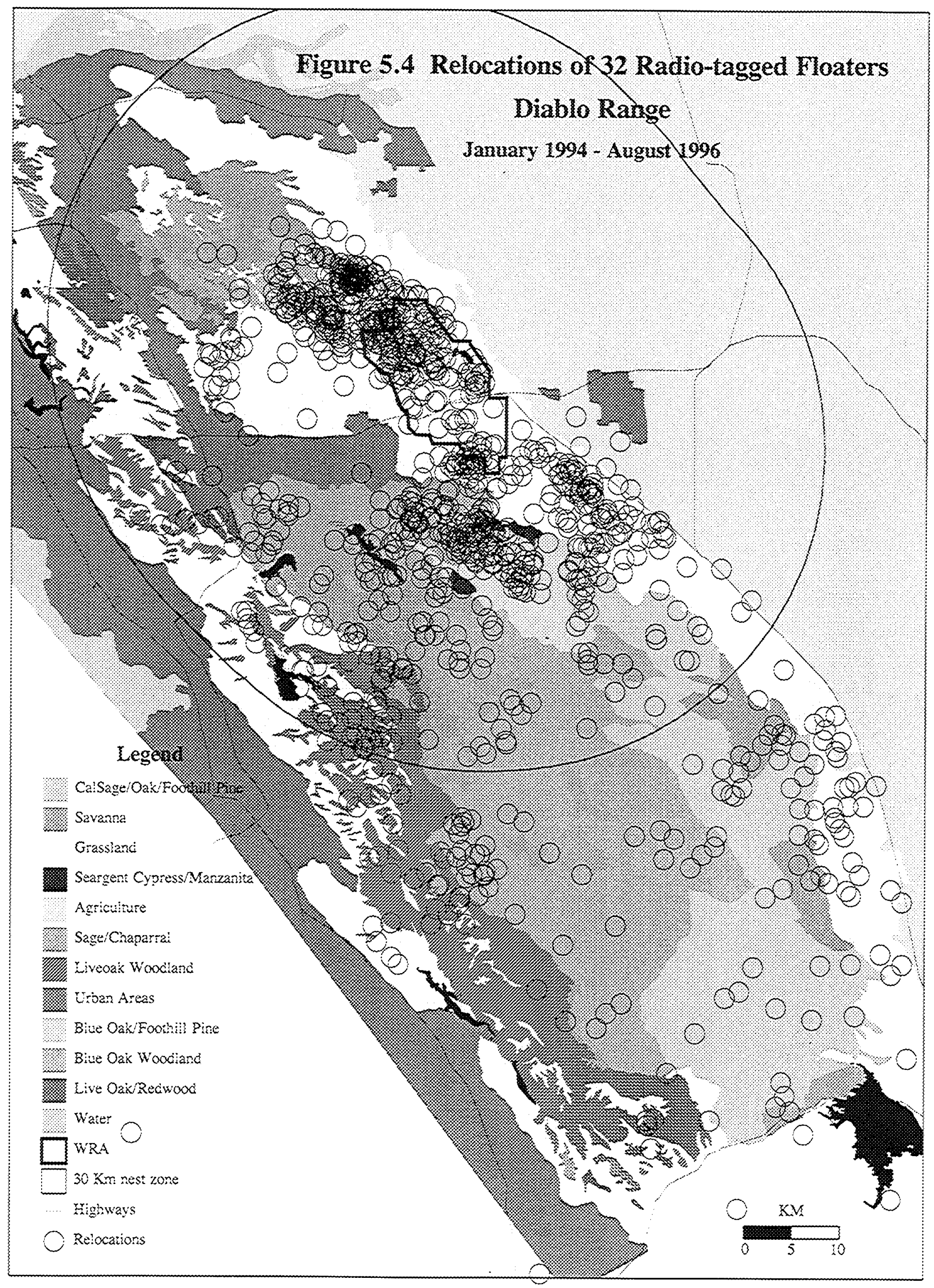


Case F3. Floater Female 4AF12, tagged at Morgan Territory on 28 February 1994, frequented the study area for only one month before departing south where it remained until reappearing near the WRA on 24 May 1994. It stayed there until late October and then departed to the area around King City, $185 \mathrm{~km}$ to the south. We detected it off and on in that direction until 17 March 1995. Censored, departed.

Case F4. Floater Male 4AM13 was tagged in the WRA on 14 February 1994. This bird has spent each of the past three winters in the area along the northwestern boundary of the WRA, arriving in October or November and departing in late February. He apparently comes from the direction of the Sierra Nevada. Censored periodically with evidence of departure.

Case F5. Floater Male 4AM10, tagged at Hodges Ranch near San Antonio Reservoir on 31 January 1994, was shot in the WRA on ca. 10 February 1996. The eagle lay ca. 60 $\mathrm{m}$ from a high-voltage overhead collection line and had been previously considered an electrocution based on apparent burns on one foot. This eagle resided almost exclusively within the WRA during the year prior to its death. Of 90 relocations, 37 were within the WRA and 21 were within $2 \mathrm{~km}$ (see Appendix C). Fatality.

Case F6. Floater Male 40M14 was tagged as a subadult at Site 300 on 23 February 1994. It died of unknown causes in the WRA during the first week of March 1996. There was no evidence of trauma or electrocution. The carcass had been partially consumed by one or more raptors, possibly another eagle (see Appendix C). A necropsy is pending. Fatality.

Case F7. Floater Male 5AM66, tagged on 15 December 1995, may have held a territory within the WRA near Byron until 23 April 1996, after which its signal was no longer detected. It is plausible that the transmitter was destroyed by a blade strike because all relocations were within or near the WRA (see Appendix B). Censored, because of signal loss, cause unknown.

Case F8. Floater Female 6AF51, tagged at Site 300 on 28 February 1996, was last detected on 6 July 1996 in the WRA. It is plausible that the transmitter was destroyed by a turbine blade in view of the fact that 13 of 15 total relocations were in or near the WRA (see Appendix B). Censored, because of signal loss, cause unknown.

5.3.2 Floater Survival Rate. Considering the two fatalities occurring before 12 August 1996, we estimate the annual floater survival rate (pooled sample of sexes) at 0.9231 (C.I. $=0.8282$ 1.000). For females alone, the estimate is 1.000 (no fatalities); for males, it is $0.9087(0.7940$ - 1.000). As to question of eventual weighting, the itineraries of two censored floaters (cases F7 and F8) suggest that their transmitters may have been destroyed by turbine blades, i.e., both frequented the WRA prior to signal loss. 


\subsection{Breeders}

Until recently, we found it difficult to capture breeders for radio-tagging. Our sample now includes 38 individuals, 5 tagged in 1994 and 33 more tagged since then (Table 5.3). Two additional eagles, tagged as subadults, exhibited territorial behavior in adulthood; one of these became a breeder. Thus, our sample of territory-holders totals 40 individuals tagged since the beginning of the study.

Figure 5.5 shows the movements of the radio-tagged territory-holders. Clearly, their activities center on their nesting areas and, in general, these birds are unlikely to enter the WRA if their territories are sufficiently distant, say, greater than $5-10 \mathrm{~km}$. There has been no indication of seasonality in breeder movements other than during the late stages of the brood cycle when both parents tend to move longer distances to forage.

5.4.1. Breeder Censoring and Fatalities. The total number of territorial birds tagged since the beginning of the study stands at 40 . Thus far, 1 breeder $(\%)$ has died and 4 (3 $q \%$ and 1 o) were censored:

Case B1. Breeder Female 40F14, who became a member of the Seeno pair in early February 1994, was tagged at Morgan Territory on 2 March 1994. We last detected her radio on 24 August 1995 but have twice visually confirmed her continued presence on territory. Censored, transmitter failure.

Case B2. Breeder Female 4AF04, tagged at Site 300 on 25 January 1994, soon proved to be a member of the High Corral pair. Her transmitter began malfunctioning (very slow pulse rate) on 8 August, occasionally returning to normal, and failing altogether by 12 March 1995. Censored, transmitter failure.

Case B3. Breeder Male 4AM01, tagged at Morgan Territory on 5 January 1994, was a member of the Seeno pair. His radio began rapid pulsing by 22 February 1996 and failed by 25 March 1996. Censored, transmitter failure.

Case B4. Breeder Female 4AF02 was tagged at Morgan Territory on 8 January 1994. She was killed by another eagle on ca. 30 January 1994. 4AF02, blind in one eye and in somewhat ragged plumage when captured, had been a member of the Seeno pair, her mate being 4AM01, also radio-tagged. She was soon, if not immediately replaced by another radio-tagged female (see Appendix C). Fatality.

Case B5. Breeder Female 4AF07, a member of the Morgan Territory pair, was tagged at Morgan Territory on 2 February 1994. She dropped her transmitter after 1 March 1996. Censored, because of failure of threads binding transmitter attachment ribbons.

5.4.2 Breeder Survival Rate. There has been only one fatality within the study period among our sample of breeders, and the survival estimate is 0.9615 (C.I. $=0.9016-1.000$ ). For females, the estimate is $0.9167(0.8035-1.000)$; for males, it is 1.000 (no fatalities). The death 


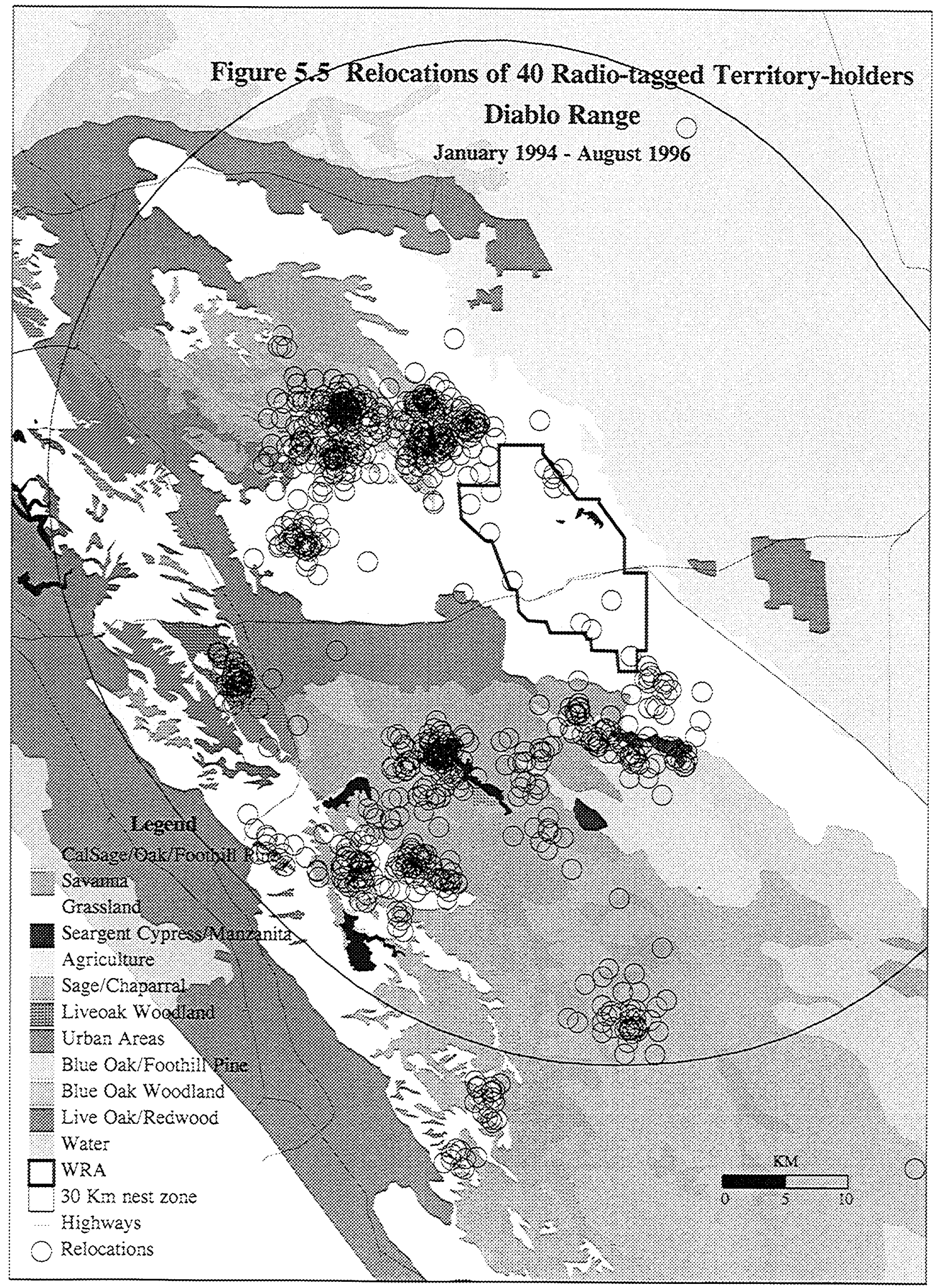


occurred outside the WRA. No weighting is being considered because breeders rarely visit the WRA and all censored breeders had failed transmitters or failed attachment ribbons. We have only recently achieved our full sample of breeders, - and thus anticipate much firmer survival estimates by summer 1997 when our final report is to be completed.

\subsection{Adult Survival}

For modeling purposes in Section 7 , it is currently more convenient to view annual adult survival than to consider survival estimates for breeders and floaters separately. In the data obtained to 12 August, the survival estimates for these two segments are fairly similar (see section 5.3.2 and 5.4.2). By lumping them, we obtain a yearly estimate of 0.9415 with a somewhat more respectable confidence interval of $0.8866-0.9964$. For females only, the estimate is $0.9333(0.8424-1.000)$, and for males, it is $0.9426(0.8717-1.000)$.

As a matter of interest, in a population at equilibrium with a substantial floating contingent, the loss of a floater may be more or less equivalent to the loss of a breeder. While it is true that the death of a breeder may result in a temporary reduction in productivity at a particular site, that cost in reproductive performance may be relatively small compared to the loss of the adult itself (see Section 7.2). There is general agreement that, in healthy populations of golden eagles, floaters rapidly replace missing breeders (see Section 3.1 in Hunt et al. 1995).

\subsection{Risk and Mortality}

Figures 5.6 - 5.9 suggest that a difference in exposure to WRA-mortality exists among our radio-tagged samples representing each population segment. To some extent, the differences may be related to sample size and proximity of tagging location to the WRA, but there are expected differences in behavior as well. Breeders, for example, rarely visit the WRA, not only because of territory distance from it, but also because of their very limited home ranges. Juveniles remain at natal territories for extended periods after fledging (Section 5.1), but after leaving them, their tendency to enter the WRA appears comparable to that of subadults and floaters as a proportion of total relocations (Table 5.4).

Unless eagles in the various segments behave differently, we might expect them to be killed in the WRA in proportion to their occurrence there. Table 5.4 shows about twice the number of subadult relocations in the WRA as those of juveniles and floaters, while all nine WRA-related fatalities involved subadults. As sample sizes of WRA-related kills increase, we will compare the proportions of each segment occurring in the wind plant as a way of revealing possible age differences in susceptibility to turbine interaction. One way of doing so would be to examine risk on an individual basis. Pursuant to this, we calculated a risk index value as the number of times an eagle is found within $2 \mathrm{~km}$ of the WRA as a proportion of its total relocations in the study area, excluding those individuals with less than 10 total relocations. Although the kill samples are still too small for comparison, Figure 5.10 suggests that subadults are more vulnerable to turbine strikes than juveniles or floaters, i.e., despite high index values of juveniles and floaters, we found turbine-kills only among the subadult sample. A possible reason is that juveniles may be more prone than subadults to soar in search of carrion and less likely than 


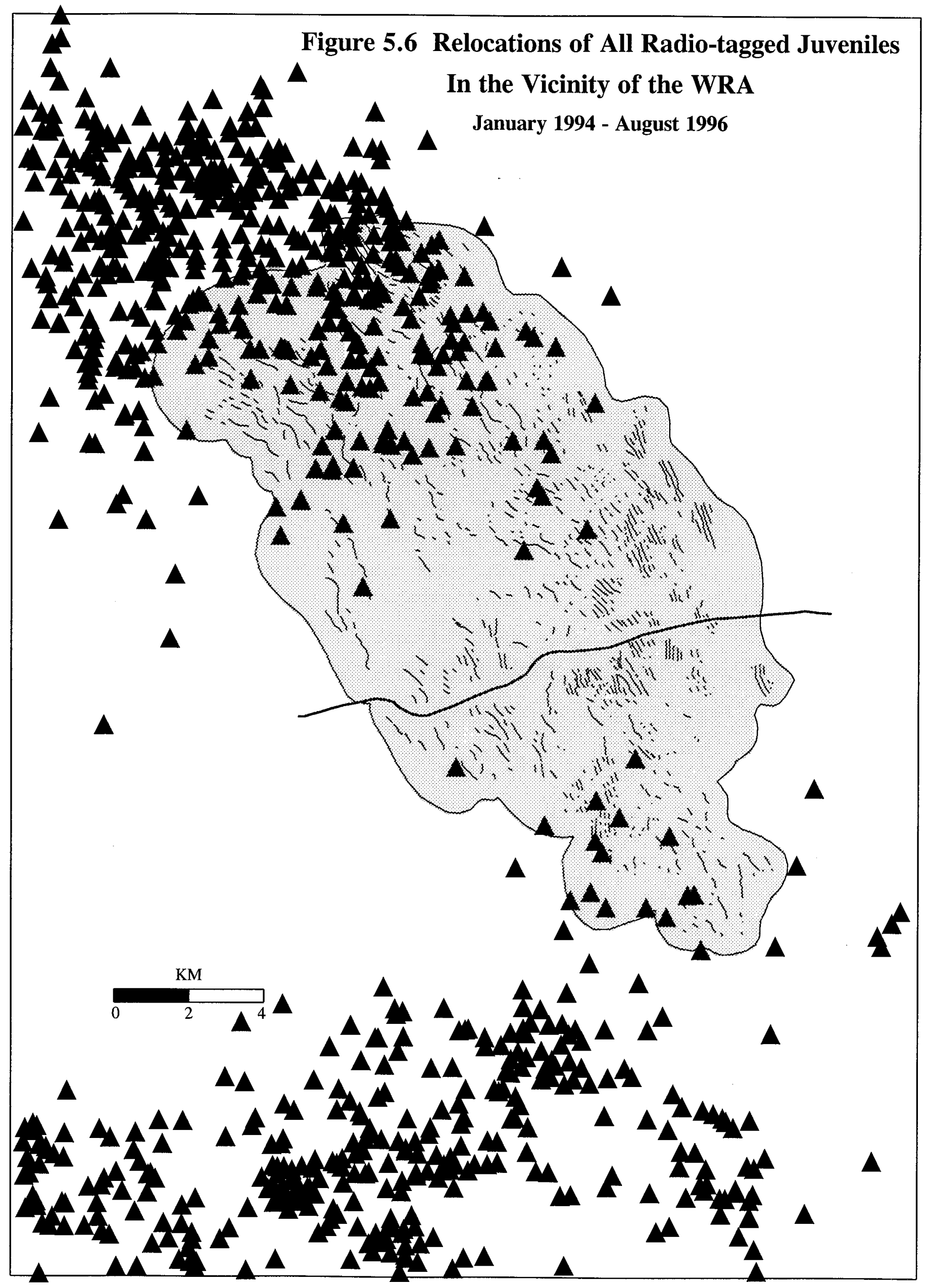




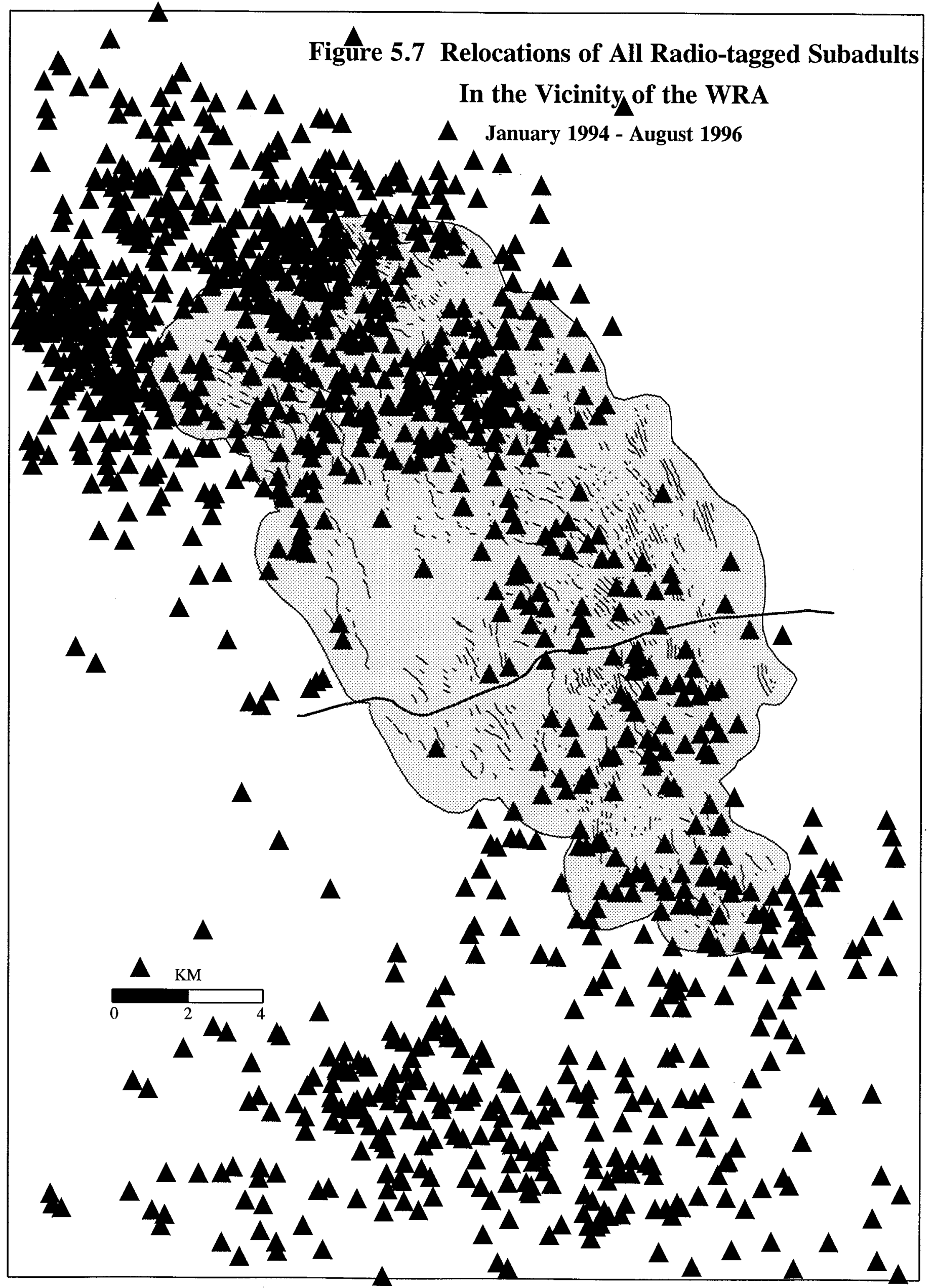




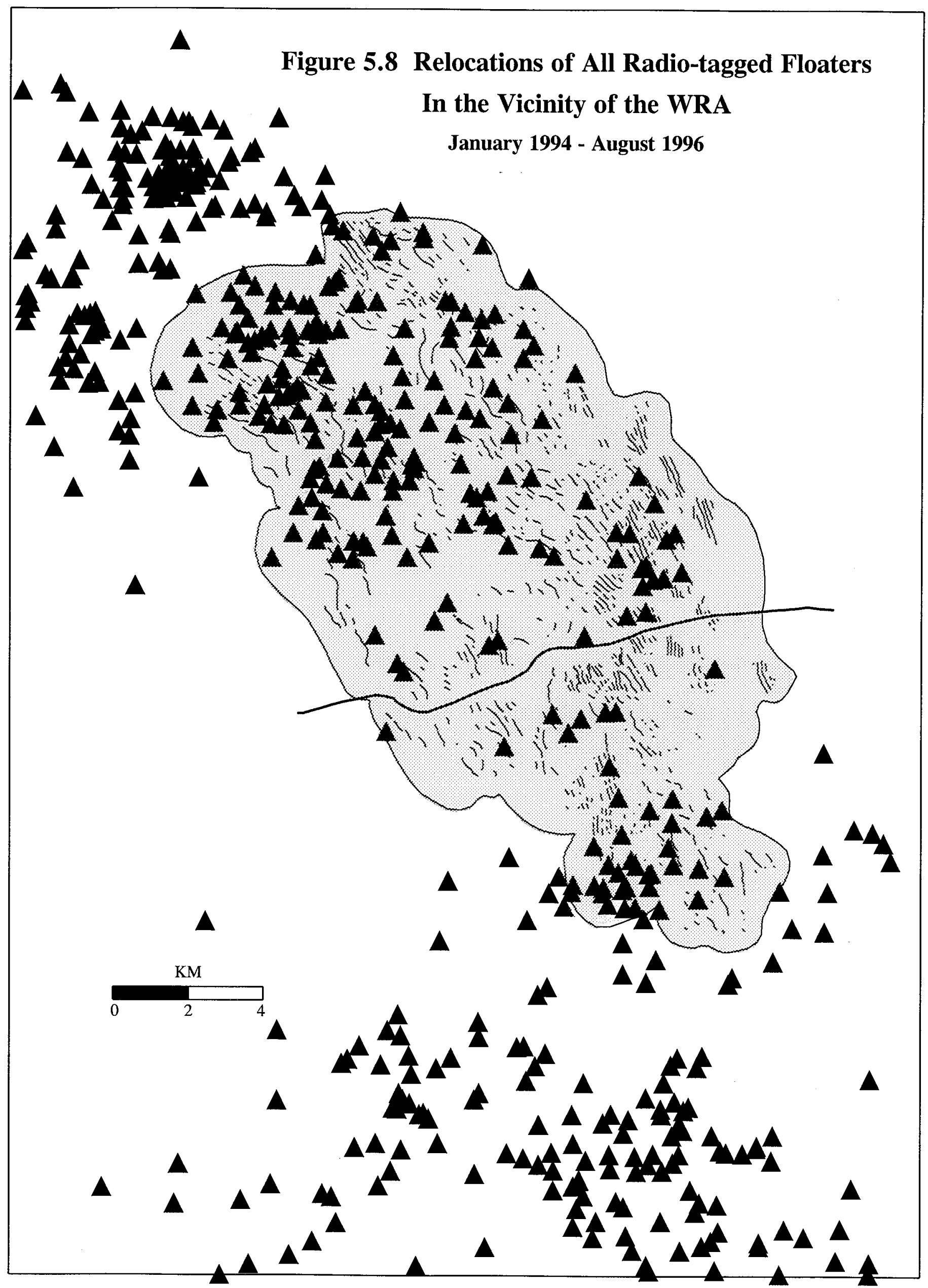




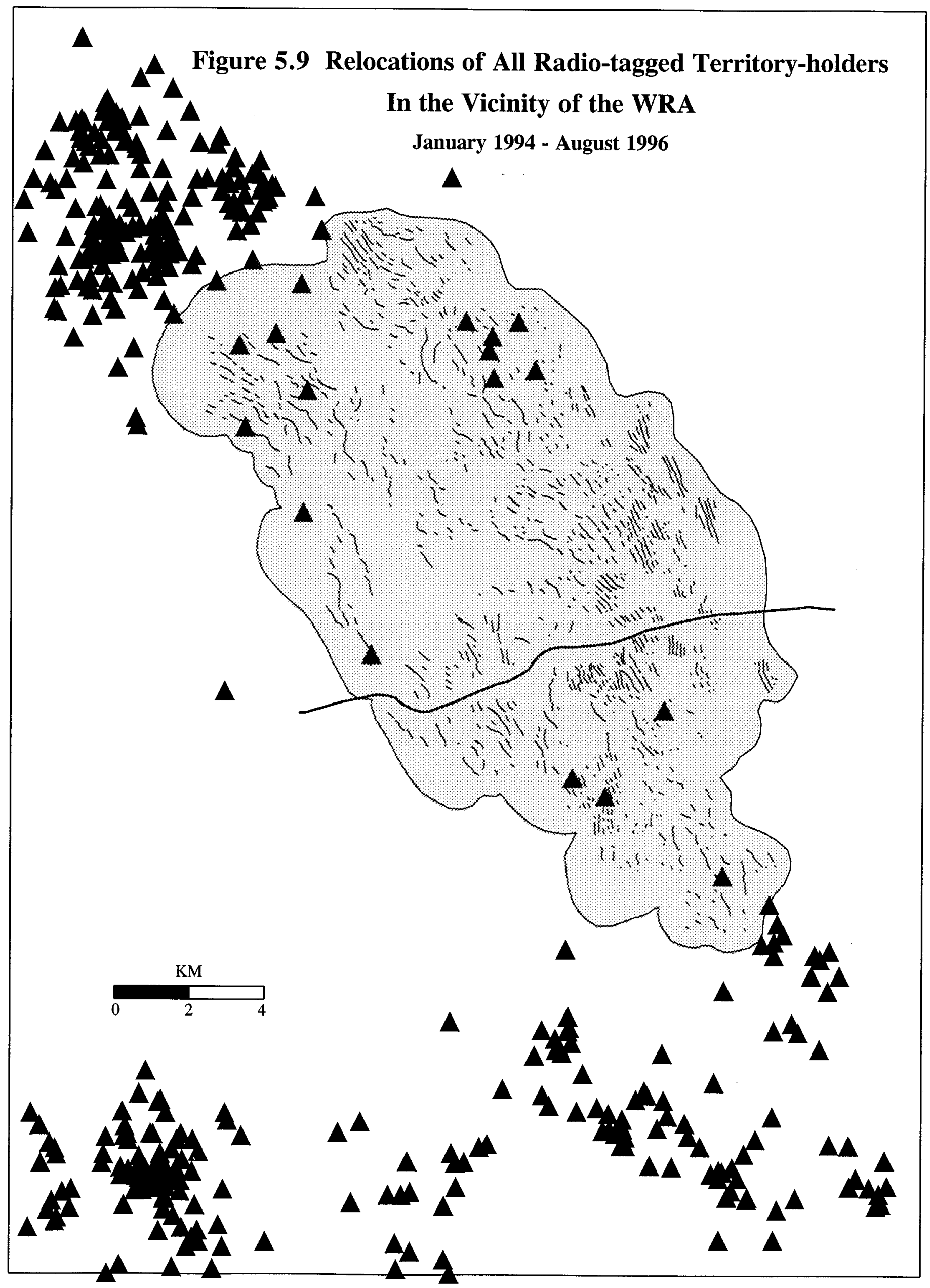


subadults to hunt ground squirrels, a behavior requiring mid- and low-level flight over considerable distances.

Table 5.4. Relocations and fatalities of radio-tagged golden eagles in the WRA. Total relocations indicate standard surveys only. The reason why the total number of birds $(n=208)$ exceeds the number of tagged birds in the analysis $(n=154)$ is because some juveniles became subadults and some subadults became floaters.

\begin{tabular}{|c|c|c|c|c|c|}
\hline Segment & Birds & $\begin{array}{l}\text { Birds } \\
\text { in WRA }\end{array}$ & $\begin{array}{c}\text { Total } \\
\text { Relocations }\end{array}$ & $\begin{array}{l}\text { Relocations } \\
\text { in WRA }\end{array}$ & $\begin{array}{l}\text { WRA-related } \\
\text { Kills }\end{array}$ \\
\hline Juvenile $^{1}$ & 50 & $31(62 \%)$ & 1095 & $173(11 \%)$ & 0 \\
\hline Subadult & 86 & $62(72 \%)$ & 2350 & $509(22 \%)$ & 9 \\
\hline Floater & 32 & $19(59 \%)$ & 1061 & $221(21 \%)$ & 0 \\
\hline Breeder & 40 & $6(15 \%)$ & 993 & $14(1 \%)$ & 0 \\
\hline Total & 208 & 118 & 5499 & 917 & 9 \\
\hline
\end{tabular}

${ }^{1}$ Data reported here represent relocations of juveniles outside their nest areas.

Figure 5.11 shows the frequency of deaths per cause in the study area, of which turbine blade strikes comprised 35 percent in the tagged sample. If one discounts the mishaps associated with the fledging process, turbine strikes accounted for 47 percent of deaths among the free-ranging eagles. Figure 5.12 displays the geographic distribution of fatalities of radio-tagged eagles in the study area.

To estimate age structure of a larger sample of golden eagles killed at the WRA, primarily as reported by wind industry employees who happened upon them, Pete Bloom and Bill Clark examined plumage characteristics of a sample of 74 individuals. These fatalities, including 23 females, 29 males, and 22 eagles of undetermined sex, were collected by U.S. Fish and Wildlife Service (USFWS) Special Agent Cynthia Haynes and Kenetech employees Denise Weingart, Ron Barsic, and Karen Lougheed during 1993-1995. Five of the eagles were in their first calendar year of life, 45 were subadults, 23 were adults, and 1 was of unknown age.

The array of golden eagle casualties shown in Figure 5.13 largely follows the distribution of Kenetech holdings at the WRA. Agent Haynes, who receives casualty reports from all the wind companies, informs us that, of the 88 golden eagle casualties (85 turbine strikes, 2 electrocutions, and 1 wire strike) reported to her by all companies during 1993-1995, 79 were by Kenetech and 9 by all other companies combined. Of the latter casualties, 8 were blade strikes and 1 was an electrocution. It is unknown whether this uneven distribution of reported kills is related to variation in, (a) industry procedures with respect to carcass discovery and reporting, (b) the distribution of certain turbine configurations that may have greater tendencies to kill eagles, (c) the turbine deployment schedules of the various companies, or (d) the distribution of environmental conditions (e.g., wind speeds, prey) conducive to eagle-turbine 
Figure 5.10 Risk index* values based on the proportion of relocations in or near the WRA. Each bar represents a radio-tagged individual. $X$ 's indicate turbine kills, all of which were subadults.

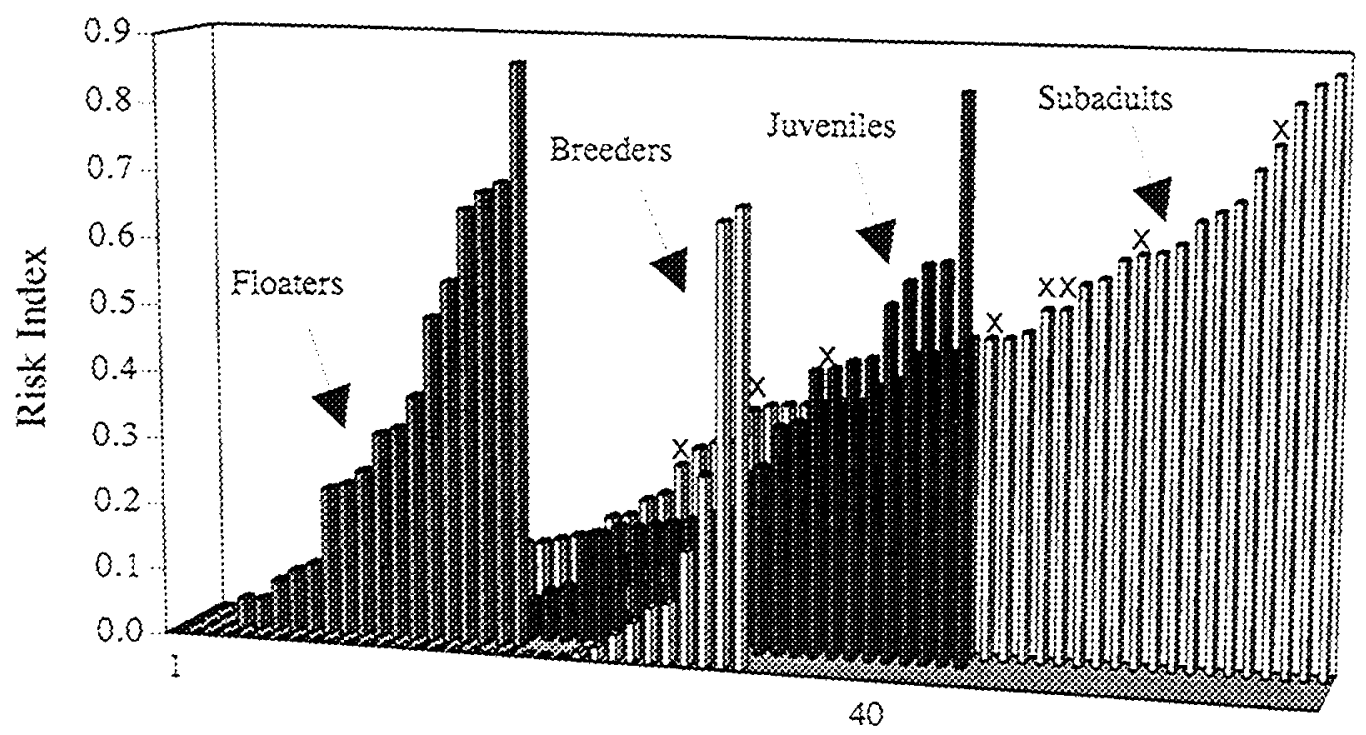

Number of Radio-tagged Individuals with $\geq 10$ Relocations

$*$ Risk fadex $=\frac{\text { telocations within } 2 \mathrm{~km} \text { of WRA }}{\text { all relocations }}$

Figure 5.11 Fatalities of 26 Radio-tagged Golden Eagles in the Diablo Range.

Xiled by Eagie - :

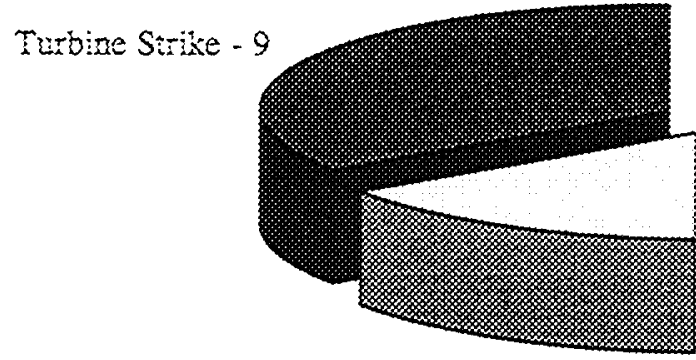

Electrocution Wire Strike - 4

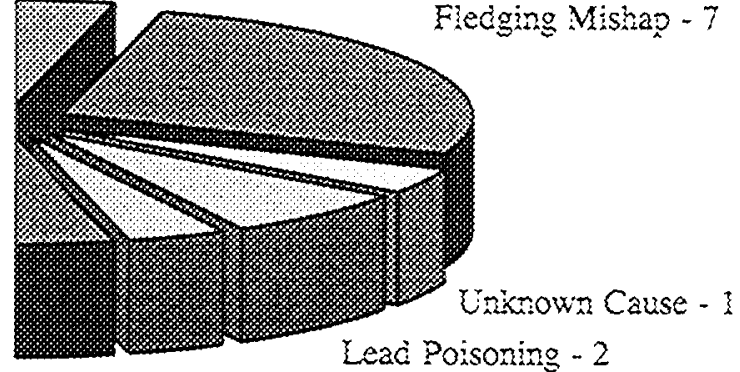

Shot - 1 Probabie Poisoning - I 


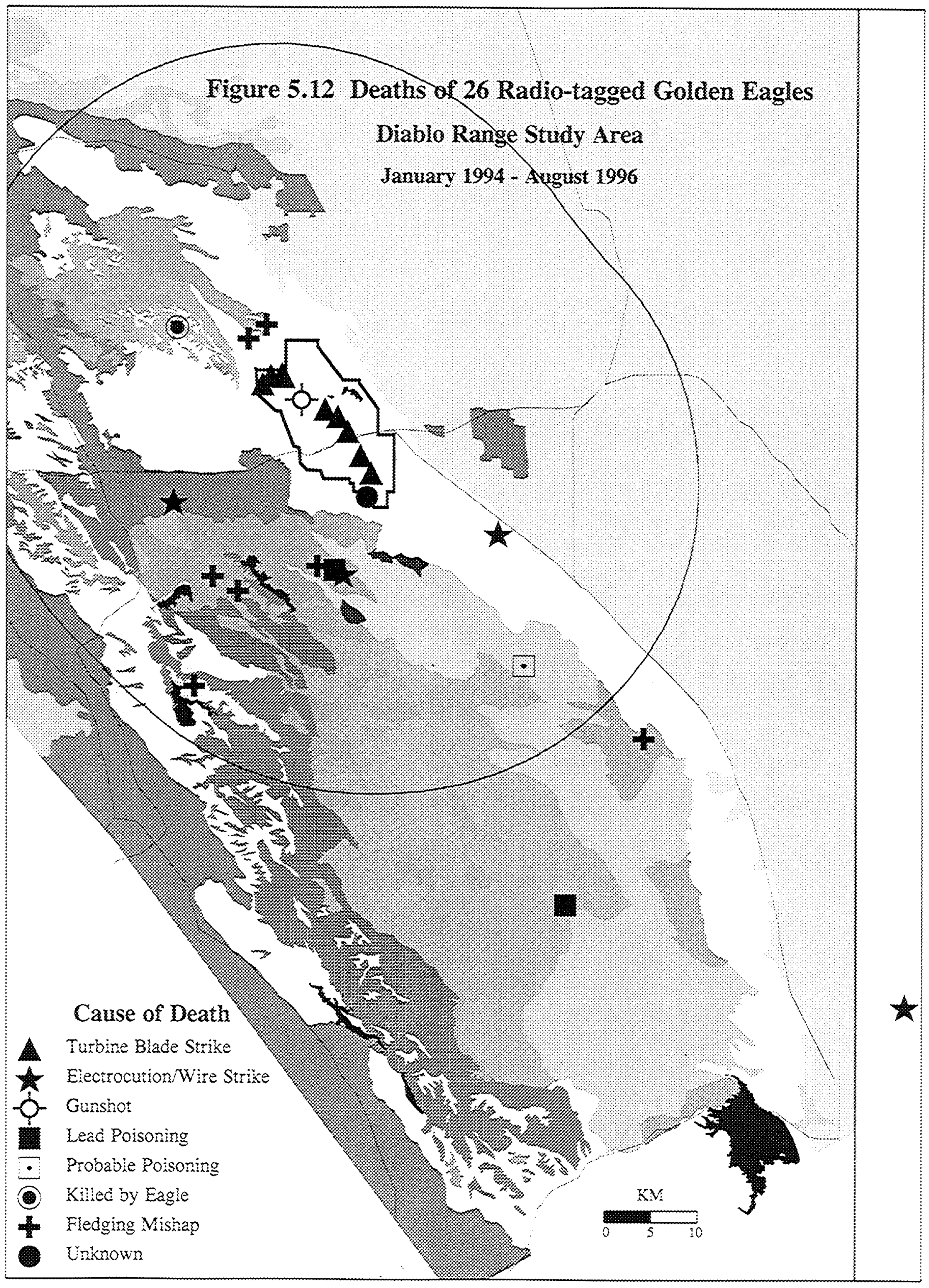




\section{Figure 5.13 Golden Eagle Casualties}

Found in the WRA $(n=85)$

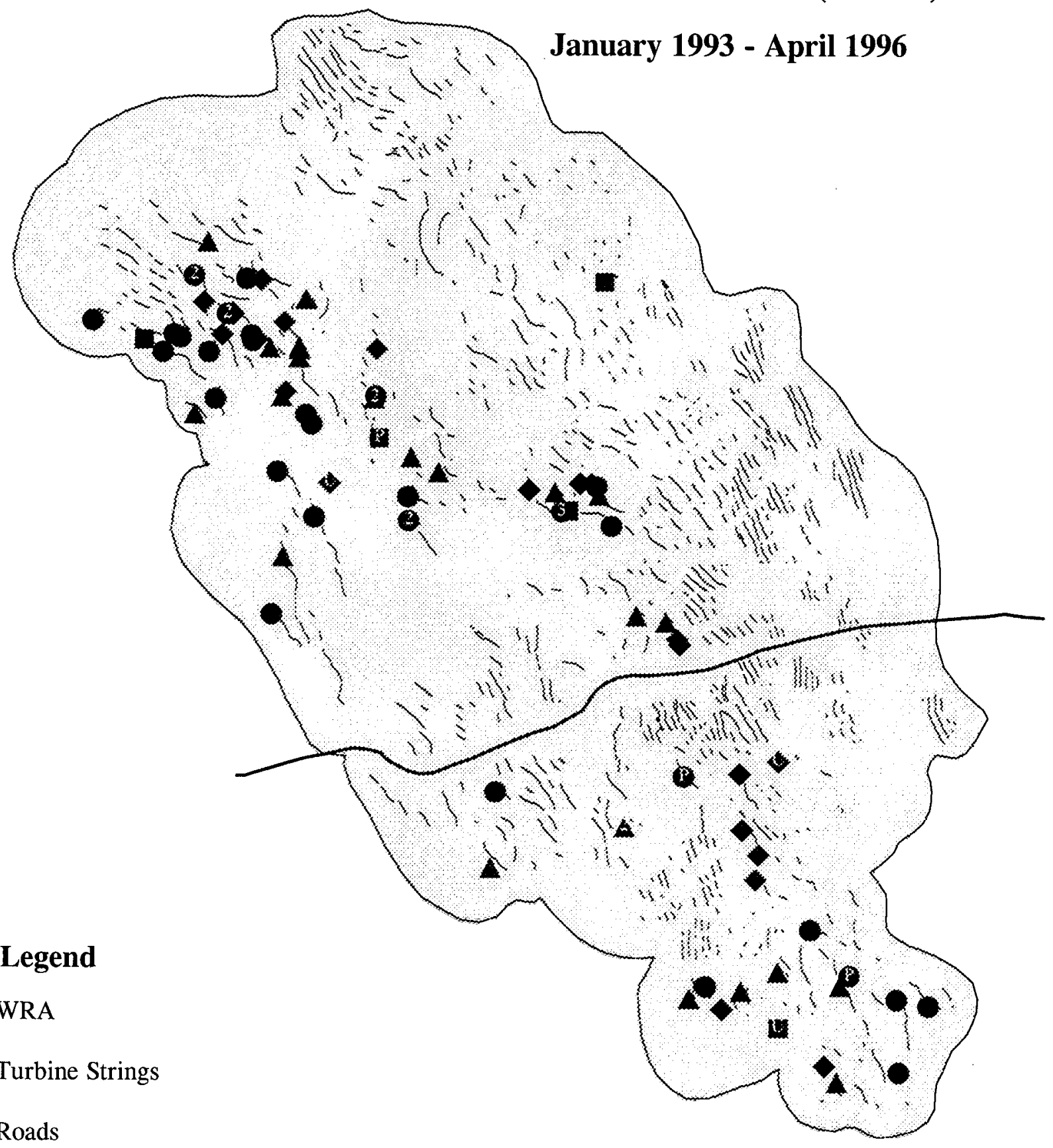

Points

A 1993 Unlabeled symbols $=$ Single turbine-related incident

- 1994 Numbered symbols = Number of turbine-related incidents at location

- $1995 \mathrm{P}=$ Electrical pole/wire-related incident

- $1996 \mathrm{U}=$ Unknown cause

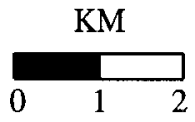


interaction. The near absence of kill records in the northeastern portion of the WRA is inconsistent with the high density of telemetry relocations there (Figs. 5.6 - 5.9) and suggests that the overall distribution of casualties relates to something other than eagle abundance.

\subsection{NESTING SURVEY}

Golden eagle pairs in the Diablo Range participate in courtship and nest-building in December and January, lay eggs in February and March (incubation lasts 6.5 weeks), and fledge their 10 to 11-week-old young from mid-May to late June (see Section 3.1.4 in the last report). Our goal is to estimate the number of fledged young per territorial pair for use as a parameter with survival estimates in assessing population trends in age structure.

\subsection{Reproduction in 1995}

Because of the late start in 1995 (our contract started in April), we were unable to conduct a nesting survey that would contribute to our overall estimate of productivity and its annual variation. The problem lay in establishing the actual number of territorial pairs containing the subset of those successful. Without such information, we would be apt to overestimate reproductive success, an error we probably made in 1994, the year we began our work. Extending the survey for new nests late into the chick cycle in 1994 presented the bias that, as the season progressed, successful pairs were more likely to be found than unsuccessful ones (see Steenhof and Kochert 1982). The unsuccessful pairs were less active, less interactive, and therefore less conspicuous, especially during the period when successful pairs were feeding large young. It may also be the case that the population was more productive in 1994 than was apparent in 1995 and 1996. We are examining this possibility.

Table 6.1 lists information on nest status we obtained during 1995 when we observed eagles at 53 territories. We have no information on the reproductive performance of 34 of these, but at least 19 pairs hatched eggs, and 17 of those fledged 25 young, for an average of 1.5 fledged young per successful pair. Of 30 young known to have hatched, 2 were apparently killed in one nest by an eagle, possibly a floater, and 3 young from 2 nests died of unknown causes about midway through the chick cycle. Because we have incomplete information on the number of unproductive pairs in 1995, we are hesitant to estimate the number of fledged young per territorial pair.

\subsection{Reproduction in 1996}

For the first time in this study, conditions were favorable for a relatively unbiased reproductive estimate. These included, (1) that we were able to begin the survey in December, the period of courtship and territorial display when pairs were most conspicuous, (2) that we knew the general location of a substantial number of territories from previous surveys, and (3) that we had prior experience obtaining access from landowners. In the past, the latter was often the most difficult and time-consuming problem to overcome, and remains so, even now.

In all, we observed 74 territorial pairs in the study area in 1996 and were able to determine the reproductive outcome of 58 of these pairings (Table 6.2). Fifty of these were known to us prior 
Table 6.1. Golden eagle productivity at breeding areas in the Diablo Range of California, $1995 .^{1}$

\begin{tabular}{|c|c|c|c|c|}
\hline Breeding Area & Status & Eggs? & Hatching $^{2}$ & $\begin{array}{l}\text { Young } \\
\text { Fledged }\end{array}$ \\
\hline Adelaide & Successful & Yes & 23 March & 1 \\
\hline Anderson Reservoir & Occupied & Unknown & Unknown & $?$ \\
\hline Apperson Ridge & Unknown & - & - & $?$ \\
\hline Beartrap Ridge & Unknown & - & - & $?$ \\
\hline Black Diamond & Unknown & - & - & $?$ \\
\hline Calaveras Creek & Successful & Yes & 13 April & 1 \\
\hline Calera Creek & Occupied & Unknown & Unknown & $?$ \\
\hline Camino Diablo & Occupied & Unknown & Unknown & $?$ \\
\hline Corral Hollow & Occupied & Unknown & Unknown & $?$ \\
\hline Crane Ridge & Occupied & Unknown & Unknown & $?$ \\
\hline Deer Valley Road & Occupied & Unknown & Unknown & $?$ \\
\hline Del Puerto Creek & Occupied & Unknown & Unknown & $?$ \\
\hline Del Valle South & Successful & Yes & 9 April & 1 \\
\hline Eagle's Run & Successful & Yes & 12 April & 2 \\
\hline Foley & Unknown & - & - & $?$ \\
\hline Hairpin & Successful & Yes & 5 April & 1 \\
\hline Hi-C (Daub's Cabin) & Unknown & - & - & $?$ \\
\hline High Corral (14 Mile) & Occupied & Unknown & Unknown & $?$ \\
\hline Hollow & Successful & Yes & 29 March & 2 \\
\hline I-5 Tower & Successful & Yes & $22 \mathrm{March}$ & 1 \\
\hline Indian Creek & Unknown & - & - & $?$ \\
\hline Koopman Road & Occupied & Unknown & Unknown & $?$ \\
\hline La Costa Creek & Occupied & Unknown & Unknown & $?$ \\
\hline Lindl & Successful & Yes & 11 April & 3 \\
\hline Los Vaqueros & Failed & Unknown & No & 0 \\
\hline Lover's Leap & Unknown & - & - & $?$ \\
\hline Lower JDG & Occupied & Unknown & Unknown & $?$ \\
\hline Lydia Lane & Occupied & Unknown & Unknown & $?$ \\
\hline Marino & Occupied & Unknown & Unknown & $?$ \\
\hline Mendenhall & Occupied & Unknown & Unknown & $?$ \\
\hline Mexican House & Unknown & - & - & $?$ \\
\hline Mill Creek Road & Occupied & Unknown & Unknown & $?$ \\
\hline Mines Road & Occupied & Unknown & Unknown & $?$ \\
\hline
\end{tabular}


Table 6.1. (continued).

\begin{tabular}{|c|c|c|c|c|}
\hline Breeding Area & Status & Eggs? & Hatching & $\begin{array}{c}\text { Young } \\
\text { Fledged }\end{array}$ \\
\hline Minniear & Occupied & Unknown & Unknown & $?$ \\
\hline Morgan Territory & Successful & Yes & 4 April & 1 \\
\hline Morrison Canyon & Unknown & - & - & $?$ \\
\hline Mount Allison & Failed & Yes & 20 April & 0 \\
\hline N3 Bathtub & Occupied & Unknown & Unknown & $?$ \\
\hline N3 Coulter & Unknown & - & - & $?$ \\
\hline $\mathrm{N} 3 \mathrm{HQ}$ & Occupied & Unknown & Unknown & $?$ \\
\hline Niles Canyon & Occupied & Unknown & Unknown & $?$ \\
\hline Oak Flat Golf Course & Occupied & Unknown & Unknown & $?$ \\
\hline Ordway Ranch & Successful & Yes & 24 April & 2 \\
\hline Patterson & Successful & Yes & 7 April & 1 \\
\hline Patterson Pass & Occupied & Unknown & Unknown & $?$ \\
\hline Pegleg Ridge & Unknown & - & - & $?$ \\
\hline Pine Canyon & Successful & Yes & 6 April & 2 \\
\hline Pipe Cross & Successful & Yes & 6 April & 1 \\
\hline Pleasanton Ridge & Occupied & Unknown & Unknown & $?$ \\
\hline Rocky Ridge & Occupied & Unknown & Unknown & $?$ \\
\hline Rose Peak & Unknown & - & - & $?$ \\
\hline Round Valley & Successful & Yes & 21 March & 2 \\
\hline Salt Grass Canyon & Occupied & Unknown & Unknown & $?$ \\
\hline Seeno & Occupied & Unknown & Unknown & $?$ \\
\hline Shell Ridge & Occupied & Unknown & Unknown & $?$ \\
\hline Sibley & Failed & Unknown & Unknown & 0 \\
\hline South Livermore & Occupied & Unknown & Unknown & $?$ \\
\hline SRI & Failed & Yes & 14 April & 0 \\
\hline Sulphur Spring & Unknown & - & - & $?$ \\
\hline Tassajara & Unknown & - & - & $?$ \\
\hline Tunnel Creek & Occupied & Unknown & Unknown & $?$ \\
\hline Upper Indian Creek & Unknown & - & - & $?$ \\
\hline Upper JDG & Occupied & Unknown & Unknown & $?$ \\
\hline Vasco Road & Successful & Yes & 16 April & 2 \\
\hline Wally & Successful & Yes & 24 April & 1 \\
\hline Walpert Ridge & Occupied & Unknown & Unknown & $?$ \\
\hline
\end{tabular}


Table 6.1. (continued).

\begin{tabular}{|c|c|c|c|c|}
\hline Breeding Area & Status & Eggs? & Hatching & $\begin{array}{l}\text { Young } \\
\text { Fledged }\end{array}$ \\
\hline Welch Creek & Successful & Yes & 12 April & 1 \\
\hline William's Gulch & Occupied & Unknown & Unknown & $?$ \\
\hline \multirow[t]{2}{*}{ Totals: } & \multirow{2}{*}{\multicolumn{2}{|c|}{$\begin{array}{l}\text { Known Breeding Areas } \\
\text { Breeding Areas Known to be Occupied }\end{array}$}} & 68 & 25 \\
\hline & & & 53 & \\
\hline
\end{tabular}

1 Reproductive terminology follows Postupalsky (1974).

2 Hatching dates usually extrapolated from age of fledglings. 
Table 6.2. Golden eagle productivity at breeding areas in the Diablo Range of California, $1996 .^{1}$

\begin{tabular}{|c|c|c|c|c|}
\hline Breeding Area & Status & Eggs? & Hatching $^{2}$ & $\begin{array}{l}\text { Young } \\
\text { Fledged }\end{array}$ \\
\hline Adelaide & Successful & Yes & 2 April & 1 \\
\hline Anderson & Occupied & Unknown & Unknown & $?$ \\
\hline Apperson & Occupied & Yes & $30 \mathrm{March}$ & $?$ \\
\hline Arroyo Mocho & Occupied & Unknown & Unknown & $?$ \\
\hline Beartrap Ridge & Unknown & - & - & $?$ \\
\hline Beehive & Occupied & Unknown & Unknown & $?$ \\
\hline Black Diamond & Unknown & - & - & $?$ \\
\hline Calaveras Creek & Successful & Yes & 15 April & 1 \\
\hline Calera Creek & Failed & Yes & 15 April & 0 \\
\hline Camino Diablo & Failed & Yes & 15 April & 0 \\
\hline Corral Hollow & Occupied & Unknown & Unknown & 0 \\
\hline Crane Ridge & Successful & Yes & 15 April & 1 \\
\hline Deer Valley Road & Occupied & Unknown & Unknown & $?$ \\
\hline Del Puerto Creek & Occupied & Unknown & Unknown & 0 \\
\hline Del Valle Picnic & Occupied & Unknown & Unknown & 0 \\
\hline Del Valle South & Occupied & Unknown & Unknown & 0 \\
\hline Devil's Hole & Occupied & Unknown & Unknown & $?$ \\
\hline Diablo Cliffs & Occupied & Unknown & Unknown & $?$ \\
\hline Eagle's Run & Occupied & Unknown & Unknown & 0 \\
\hline Foley & Failed & Yes & Unknown & 0 \\
\hline Hairpin & Successful & Yes & 10 April & 2 \\
\hline Hi-C (Daub’s Cabin) & Occupied & Unknown & Unknown & 0 \\
\hline High Corral (14 Mile) & Failed & Yes & Unknown & 0 \\
\hline Hollow & Failed & Yes & No & 0 \\
\hline I-5 Tower & Successful & Yes & 19 March & 2 \\
\hline Indian Creek & Successful & Yes & 9 April & 2 \\
\hline Kellogg Creek & Occupied & Unknown & Unknown & $?$ \\
\hline Koopman Road & Failed & Yes & Yes & 0 \\
\hline La Costa Creek & Occupied & Unknown & Unknown & 0 \\
\hline Leyden Creek & Occupied & Unknown & Unknown & $?$ \\
\hline Lindl & Successful & Yes & 11 April & 2 \\
\hline Los Vaqueros & Occupied & Unknown & No & 0 \\
\hline Lover's Leap & Unknown & - & - & $?$ \\
\hline Lower JDG & Successful & Yes & 11 April & 2 \\
\hline
\end{tabular}


Table 6.2. (continued).

\begin{tabular}{|c|c|c|c|c|}
\hline Breeding Area & Status & Eggs? & Hatching & $\begin{array}{l}\text { Young } \\
\text { Fledged }\end{array}$ \\
\hline Lower Vasco & Occupied & Unknown & Unknown & $?$ \\
\hline Lydia Lane & Occupied & Unknown & Unknown & 0 \\
\hline Marino & Failed & Yes & No & 0 \\
\hline Mendenhall & Successful & Yes & 2 April & 2 \\
\hline Mexican House & Unknown & - & - & $?$ \\
\hline Middle Indian Creek & Successful & Yes & 20 April & 1 \\
\hline Mill Creek & Successful & Yes & 2 April & 1 \\
\hline Mines Road & Failed & Yes & 21 April & 0 \\
\hline Minniear & Unknown & - & - & $?$ \\
\hline Morgan Territory & Occupied & Unknown & Unknown & 0 \\
\hline Morrison Canyon & Unknown & - & - & $?$ \\
\hline Mt. Allison & Occupied & Unknown & Unknown & 0 \\
\hline N3 Bathtub & Successful & Yes & 9 April & 1 \\
\hline N3 Coulter & Successful & Yes & 26 April & 1 \\
\hline N3 HQ & Occupied & Unknown & Unknown & 0 \\
\hline Niles Canyon & Successful & Yes & 14 April & 1 \\
\hline North Crane Ridge & Successful & Yes & 7 April & 2 \\
\hline North Peak & Occupied & Unknown & Unknown & $?$ \\
\hline Oak Flat Corral & Failed & Yes & 12 April & 0 \\
\hline Oak Flat Golf & Successful & Yes & 3 April & 2 \\
\hline Ordway & Successful & Yes & 25 April & 1 \\
\hline Pala Seca & Unknown & - & - & $?$ \\
\hline Patterson & Successful & Yes & 17 April & 1 \\
\hline Patterson Pass & Unknown & - & - & $?$ \\
\hline Patterson Pond & Occupied & Unknown & Unknown & $?$ \\
\hline Pegleg Ridge & Unknown & - & - & $?$ \\
\hline Pine Canyon & Failed & Yes & Unknown & 0 \\
\hline Pipe Cross & Failed & Yes & No & 0 \\
\hline Pleasanton Ridge & Occupied & Unknown & Unknown & 0 \\
\hline Quimbey & Successful & Yes & 2 April & 1 \\
\hline Rocky Ridge & Successful & Yes & 13 April & 1 \\
\hline Rose Peak & Unknown & - & - & $?$ \\
\hline Round Valley & Successful & Yes & 8 April & 2 \\
\hline Seeno & Occupied & Unknown & Unknown & 0 \\
\hline
\end{tabular}


Table 6.2. (continued).

\begin{tabular}{lllll}
\hline \hline & & & & Young \\
Breeding Area & Status & Eggs? & Hatching & Fledged \\
\hline Shell Ridge & Failed & Yes & Unknown & 0 \\
Sibley & Successful & Yes & 14 April & 1 \\
Site-300 & Failed & Yes & No & 0 \\
South Livermore & Failed & Yes & Unknown & 0 \\
SRI & Failed & Yes & Unknown & 0 \\
Sulpher Spring & Unknown & - & - & $?$ \\
Sunol Towers & Occupied & Unknown & Unknown & $?$ \\
Tassajara & Failed & Yes & Unknown & 0 \\
Tesla & Occupied & Unknown & Unknown & $?$ \\
Tunnel Creek & Occupied & Unknown & Unknown & $?$ \\
Upper Indian Creek & Successful & Yes & 24 April & 1 \\
Upper JDG & Successful & Yes & 2 April & 2 \\
Vasco Road & Successful & Yes & 16 April & 2 \\
Wally & Successful & Yes & 12 April & 2 \\
Walpert Ridge & Occupied & Unknown & Unknown & $?$ \\
Welch Creek & Occupied & Unknown & Unknown & 0 \\
Williams' Gulch & Successful & Yes & 7 April & 1 \\
\hline Totals: & Known Breeding Areas & 85 & 39 \\
& Breeding Areas Known to be Occupied & 74 & \\
\hline \hline
\end{tabular}

${ }^{1}$ Reproductive terminology follows Postupalsky (1974).

${ }^{2}$ Hatching dates usually extrapolated from age of fledglings. 
to the breeding season and seven were found either before or during incubation in 1996 (see Steenhof and Kochert 1982 for rules applying to reproductive estimates). The 57 pairs produced 37 young to fledging age, for an average of 0.65 young per territorial pair (S.E. $=0.10$ ). As a matter of interest, the average reproductive rate of 10 golden eagle populations studied worldwide was 0.78 fledglings per territorial pair (see Table 6.2 in Hunt et al. 1995).

\subsection{Discussion of Reproductive Estimate}

To what extent our estimate of 0.65 fledglings per pair represents the yearly average for the population is unknown. The estimate is markedly lower than that for 1994, but there is good reason to believe the latter was inflated (see Section 4.6). The lower value in 1996 may derive partly from less favorable conditions in that year, specifically, a higher incidence of prolonged rainfall that may have affected prey availability, egg laying, and egg survival. We continue to investigate these possibilities because of the importance of the reproductive estimate to our population model. As Steenhof (1987) correctly maintains, population estimates based on one or two years of data must be regarded as highly tentative.

\subsection{PLANS FOR CONTINUED RESEARCH}

The confidence intervals associated with our survival estimates are currently broad because, (1) we are still in the process of completing our samples of radio-tagged eagles and (2) we have monitored the survival of those recently tagged for a relatively short time. Our plans are to finish the tagging by mid-summer 1996, with emphasis on increasing the number of breeders in our sample, a challenging and difficult task, given their extreme state of wariness. We will continue the weekly aerial roll-call surveys through at least 1997, and for 2-3 years longer, if possible.

We anticipate a far more detailed analysis of our data as they accumulate to more statistically acceptable levels. In particular, we will examine the possible relationship of capture location to the distribution of WRA-related fatalities in the tagged sample and whether this represents a bias. We will attempt to more clearly define the breeding population affected by WRA mortality. We will work on perfecting our method for calculating population equilibrium and the floater-to-breeder ratio so that the variance associated with the $F: B$ estimate can be estimated.

Were a higher level of support to materialize for this research, we would perform a nest survey in 1997 to compare with our 1996 results that appear to be differing so strongly with those obtained in 1994. Additionally, we would perform an equestrian survey throughout the WRA every two or three months for the purpose of, (1) more accurately estimating the rate of transmitter destruction by turbine blades, (2) quantifying the overall kill, and (3) identifying the turbine configurations most likely to kill eagles and other raptors. 


\subsection{ACKNOWLEDGMENTS:}

We thank the following individuals and agencies for their help:

Tom Cade of the Peregrine Fund conceived of this project and provided advice and encouragement throughout. Ian Newton of the Institute of Terrestrial Ecology (UK) gave important conceptual guidance as did Alan Hastings of the University of California at Davis. We thank Peter Law who wrote the mathematical equations for computing the floater-to-breeder ratio at equilibrium. We honor the memory of Butch Olendorff of the Bureau of Land Management who helped us get started.

We thank Bob Thresher, Holly Davis, Karen Sinclair, and William Algiene of the National Renewable Energy Laboratory; Dick Curry, Joan Stewart, Karen Lougheed, Denise Weingart, Ron Barsic, and the field maintenance and operations staff of KENETECH Windpower; Joe DiDonato, Steve Bobzien, Ken Burger, Roger Epperson, Ray Budzinski, and Dan Reasor of the East Bay Regional Park District; Cynthia (Struzik) Haynes of the U.S. Fish \& Wildlife Service Enforcement Branch; Tim Koopman, Frank Marino, Roger Boucher, and Joe Naras of the San Francisco Water District; Terry Cox of the Contra Costa Water District; Steve Abbors and Joe Miyamoto of the East Bay Municipal Utility District; Jim Woolett, Jim Lane, and Milt Grissom of Lawrence Livermore Laboratory; Larry Ferri and Jess Cooper of Mount Diablo State Park; Rebecca Black of Ed Levin Park; Tom Gaines and Jerry Mattson of SRI International; Fred Arlt of the Valecitos Nuclear Facility; the folks at Tri-Valley Helicopters; the Livermore Airport flight controllers; Jim Estep of Jones \& Stokes Associates, Inc.; Mark Fuller and Karen Steenhof of the Raptor Research Technical Center; Ron Jurek and Debbie Osborn of the California Department of Fish and Game; Gary Falxa and Peter Lickwar of the U.S. Fish and Wildlife Service; Jim Grier of North Dakota State University; Mike Nicholson of the Livermore Area Recreation and Parks Department; Paul Rankin of Concord Navy Base; Ron Arnold of the Hetch Hetchy Project; Dan Cather of the Walnut Creek Open Spaces District; Kent Carnie of the World Center for Birds of Prey. We thank Gary Beeman, Bob Richmond, and Colleen Lenihan for valuable information on local eagle nest locations, Matt Brown for volunteer help, Richard Amarelo for help with data proofing, Bill Clark for help in the field and for aging eagles, and the Peeters (Pam and Julian) for their help and support. Kim Titus, Grey Pendelton, and Chris Bunck advised us regarding sampling and analytical procedures. Alan Franklin gave a useful tip on the best date, for analytical purposes, to advance eagles from one population segment to another. Vance Tucker modeled the dynamics of transmitter destruction by turbine blades. Kenetech Windpower, Inc. paid for our tracking flights during January - March 1995. We thank Lynn Creekmore, Lou Sileo, and Carol Meteyer of the National Wildlife Health Center, Madison, Wisconsin, for postmortum examination of eagle fatalities.

Special thanks to the many land owners who helped us with information about eagles and/or let us visit their property:

Joe Aljoe and Art Cherry of the N3 Cattle Co., Mike Arata, Paul Banke of the Patterson Ranch, Wally and Roz Breuner, Greg and Shelley Bringelson, Steve Brooks, Mr. and Mrs. Wayne 
Calhoun, Elaine Caires, Steven and Jim Coates, Pat and Mark Connolly, Loree Cornwell, Reese and Ilene Cowden, Don and Mimi Devani, Harry Engstrom, Stan Escover, Darlene Excel, Coleman Foley and son, John Ginochio, Mr. and Mrs. John Gomez, Joe Jesse, Jay Hodges and the Hodges family trust, Ione Holm, John and Ann Lindl, Jill and Dennis Mallory, Mike and Paul Marciel, Mark and Melody Mariani, Chuck and Donna Neuenschwander, Vibert and Annette Purviance, Patty, Clara and Donna of Ruby Hill, Cathy Robocker of Diablo Grande, Dayton and Pearl Silva, the folks at Vaquero Farms, Hugh Walker and Lois Walker, and Cindy and Richard White. 


\subsection{LITERATURE CITED:}

Arcese, P., J.N.M. Smith, W.M. Hochachka, C.M. Rogers, and D. Ludwig. 1991. Stability, regulation, and the determination of abundance in an insular song sparrow population. Ecology $73: 805-822$.

Bowman, T.D., P.F. Schempf, and J.A. Bernatowicz. 1995. Bald eagle survival and population dynamics in Alaska after the Exxon Valdez oil spill. Journal of Wildlife Management 59:317324.

Brown, J.M. 1969. Territorial behavior and population regulation in birds: A review and reevaluation. Wilson Bulletin 81:293-329.

Bunck, C.M. 1987. Analysis of survival data from telemetry projects. Journal of Raptor Research 21:132-134.

Bunck, C.M., C. Chen, and K. H. Pollock. 1995. Robustness of survival estimates from radiotelemetry studies with uncertain relocation of individuals. Journal of Wildlife Management 59:790-794.

Gargett, V. 1975. The spacing of black eagles in the Matopos, Rhodesia. Ostrich 46:1-44.

Gargett, V. 1977. A 13-year population study of the black eagles in the Matopos, Rhodesia, 1964-1976. Ostrich 48:17-27.

Haller, H. 1982. Raumorganisation und dynamik einer populationsokologie des steinahlers in den Alpen. Der Ornithologische Beobacter 79:168-211.

Hansen, A.J. 1987. Regulation of bald eagle reproductive rates in Southeast Alaska. Ecology 68:1387-1392.

Heisey, D.M. and T.K. Fuller. 1985. Evaluation of survival and cause-specific mortality rates using telemetry data. Journal of Wildlife Management 49:668-674.

Hunt, W.G. 1987. Radio telemetry in the study of raptor habitat selection. Journal of Raptor Research 21:144-146.

Hunt, W.G. 1988. The natural regulation of peregrine populations. Pages 667-676 in T.J. Cade, J.H. Enderson, C.G. Thelander, and C.M. White, editors. Peregrine falcon populations: Their management and recovery. The Peregrine Fund, Inc., Boise, Idaho.

Hunt, W.G., D.E. Driscoll, E.W. Bianchi and R.E. Jackman. 1992. Ecology of bald eagles in Arizona. Report to U.S. Bur. of Reclamation by BioSystems Analysis, Inc., Santa Cruz, California. Contract No. 6-CS-30-04470. 
Hunt, W.G., R.E. Jackman, T.L. Brown, J. G. Gilardi, D.E. Driscoll and L. Culp. 1995. A pilot golden eagle population study in the Altamont Pass Wind Resource Area, California. Report to National Renewable Energy Laboratory, Subcontract No. XCG-4-14200 to the Predatory Bird Research Group, University of California, Santa Cruz.

Kenward, R.E. and S.S. Walls. 1994. The systematic study of radio-tagged raptors: I. Survival, home-range, and habitat-use. Pages 303-315 in B.U. Meyburg and R.D. Chancellor, editors. Raptor Conservation Today. World Working Group for Birds of Prey, Pica Press, London.

Krebs, C.J. 1989. Ecological Methodologies. Harper Collins, New York. 654 pp.

Murray, B.G., Jr. 1979. Population Dynamics: Alternative models. Academic Press. New York.

Murray, B.G., Jr. 1982. On the meaning of density-dependence. Oecologia 53:370-373.

Newton, I. 1991. Population limitation in birds of prey: A comparative approach. Pages 3-21 in C.M. Perrins, J.D. Lebreton, and G.J.M. Hirons, editors. Bird population studies: Relevance to conservation and management. Oxford University Press, Oxford, England.

Newton, I. 1992. Experiments on the limitation of bird numbers by territorial behavior. Biological Review 67:129-173.

Orloff, S. and A. Flannery. 1992. Wind turbine effects on avian activity, habitat use and mortality in Altamont Pass and Solano County Wind Resource Areas. Report to the Planning Departments of Alameda, Contra Costa and Solano Counties and the California Energy Commission, Grant No. 990-89-003 to BioSystems Analysis, Inc., Tiburon, California.

Pollock, K.H., S.R. Winterstein, C.M. Bunck and P.D. Curtis. 1989. Survival analysis in telemetry studies: the staggered entry design. Journal of Wildlife Management 53(1):7-15.

Pulliam, H.R. 1988. Sources, sinks, and population regulation. American Naturalist 132:652661.

Ratcliffe, D.A. 1962. Breeding density in the peregrine falcon Falco peregrinus and raven Corvus corax. Ibis 104:13-39.

Sarrazin, F., C. Bagnolini, J.L. Pinna, E. Danchin, and J. Clobert. 1995. High survival estimates of griffon vultures (Gyps fulvus fulvus) in a reintroduced population. Auk 111:853-862.

Steenhof, K. 1987. Assessing raptor reproductive success and productivity. Pages 157-170 in B.A. Giron-Pendleton, B.A. Millsap, K.W. Cline and D.M. Bird [eds.], Raptor Management Techniques Manual. Natl. Wildl. Fed., Washington, D.C. 
Steenhof, K. and M.N. Kochert. 1982. An evaluation of methods used to estimate raptor breeding success. Journal of Wildlife Management 46:885-893.

Tjernberg, M. 1985. Spacing of golden eagle Aquila chrysaetos in relation to nest site and food availability. Ibis 127:250-255.

Trent, T.T. and O.J. Rongstad. 1974. Home range and survival of cottontail rabbits in southwestern Wisconsin. Journal of Wildlife Management 38:459-472.

Tucker, V.A. 1996. A mathematical model of bird collisions with wind turbine rotors. Journal of Solar Energy Engineering. In Review. 


\section{APPENDIX A: WHY WE RADIO-TAGGED BOTH SEXES}

Since the time of our 1995 report, there has developed an interesting controversy about whether we should radio-tag both sexes or only females, the latter being the conventional method in population modeling. Proponents of the females-only option suggested that we release, without radios, all males we happen to capture. Their argument centered largely on the idea that males are less important to reproduction than females and that there are enough males to service the females. Some expressed the opinion that the possibility of cuckolding makes the link between fecundity and survivorship tighter for females than for males.

Before addressing these ideas, we should say that, from a practical standpoint, tagging males as well as females requires relatively little additional effort and expense and detracts in no way from the capture and tagging of females. Both sexes are more or less equally attracted to our bait, and it is difficult to distinguish them at a distance as they differ only in size. It would be impossible for us to intentionally catch females, and, in the long run, we would tend to capture at least as many males and would encounter more or less equal numbers of each sex as fledglings. The cost of the male's transmitter is small relative to the cost of fielding a trapping team whose sole purpose might be to catch females. Finally, the extra cost of roll-call surveys for males is not proportional to the number tagged because surveys for females must cover the same ground.

In any case, the notion that male golden eagles are less vital to reproduction than females is erroneous. Male golden eagles provision their mates through most of the breeding season and are virtually the sole providers of food for the family during the first two-thirds of the chick cycle. Successfully fledging a brood of young to independence requires full-time participation of one male and one female. Therefore, it is incorrect to assume that a shortage of males would be of less consequence to the population than a shortage of females.

Likewise, the notion is false that cuckoldry would make the male less important in a demographic analysis. While the male's investment of time and energy associated with insemination during the brief period of ovulation may be small, his investment in foraging and territorial defense is very large. Genetic parentage is not an element in demography. What is required of both eagle sexes is their presence in the territory throughout the breeding season, and in order to be present they must be alive. That is the substance of demography.

Another often-mentioned justification for considering only females appears to be the expectation that they will tend to disperse farther than males and therefore (1) exist in lower proportions in the area of their natal origin, and (2) experience higher mortality as a consequence of their dispersal into outlying territory. While there is no suggestion of any such tendency among the 179 eagles we have radio-tagged to date, the vast majority of which have remained in the study area, we must point out that the predicted female bias in dispersal is irrelevant to the kind of analysis we should be proposing. If, indeed, females tagged as juveniles show a higher tendency than males to eventually settle outside the study area, then that would be grounds to concentrate 
our attention on locally-derived males, since these would be present in greater proportions in the study area and would therefore be more vulnerable to turbine-related mortality.

As we have said, the restriction of population modeling to females is within the bounds of longestablished convention. The original Leslie Matrix described 50 years ago was a females-only model. Wildlife demographers, drawing upon earlier studies of insect populations and life table concepts developed by the life insurance industry, focused largely on game species because research funds were available for determining the population effects of hunting. In deer, ducks, grouse, and almost all other game species, males are able to withstand higher mortality rates and exist in far lower proportions than females without compromising the speed at which a depressed population can return to the level set by the carrying capacity of the landscape. In other words, males of polygynous or promiscuous species with no male function in the rearing of offspring are far more "expendable" than females and thus, within reasonable limits, are not required in the modeling of population dynamics. Eliminating them from demographic computations gives a simpler picture of population response to variation in levels of mortality and fecundity. However, for reasons stated above, raptors do not fit at all within this framework, and to arbitrarily drop males from consideration is to run a high risk of underestimating the effect of their survivorship on population health and stability.

Regarding this issue, Dr. Ian Newton, the foremost authority on the population ecology of raptors, after reading our 1995 report and considering the advice we had received regarding the females-only sampling, made the following reply in his May 1995 letter to Dr. Tom Cade:

"In many animals, including many mammals, this [sampling only females] would be entirely appropriate. But in birds of prey, as you are well aware, it is the males that for most of the breeding cycle do all the hunting (a period lasting several months in eagles), while the females remain at the nest tending eggs or young. Over the year as a whole, then, males are likely to be more exposed to turbine mortality than females. Hence, restricting the study to females will probably underestimate the turbine-related mortality. In addition, in those raptor species for which information is available, females are surplus to males in adult populations. Thus, any raptor population is likely to be more vulnerable to increased male than female mortality. Although the sex ratio of golden eagle populations is at this stage unknown, there is no reason to suppose that it would differ from other species in this respect.

In my view, it would be conceptually best to radio-tag samples of both sexes, as was done in the first year, but if ... [you must sample]...only one sex, it should be males not females. Restricting the tagging to only one sex, whether male or female, would of course greatly increase the workload involved."

The latter point is especially relevant to this research. We believe, as does Dr. Newton, that because our budget is limited and because our data do not yet suggest a sex difference in survival, we are justified in pooling the sexes for survival estimation (see Bowman et al. 1995, Kenward and Walls 1994, Sarrazin et al. 1995). Releasing one sex untagged would effectively double the amount of time, effort, and money necessary to tag a comparable pooled sample. 
The argument against pooling the sexes supposes that, because they differ in size and reproductive role, a gross difference in survival is to be expected. In the absence of information regarding this difference, the lumping of the sexes would impart an element of uncertainty regarding the survival of the chosen sex, in this case, females.

Let us explore this concern. Clearly, if we were to choose one eagle sex for survival estimation, it should be the one with the lowest true survival rate because that one would be first to exhaust its supply of floaters and impact the breeding segment. Let us assume that our golden eagle population conforms to Dr. Newton's expectation that males are the limiting sex. Now say, for example, that the true annual survival rate of subadult males is 0.70 and that of females is 0.80 . If equal numbers of both are tagged and the samples are pooled, our survival estimate will tend toward 0.75 , which misses the desired value by 0.05 . If, instead, we arbitrarily choose to sample only females, our estimate would tend to miss the mark by 0.10 , doubling the error. Thus we learn that, for the purpose of modeling the population effects of reduced survival in raptors, it is better to lump the sexes than inadvertently choose the one in surplus.

There is no reason to resist exploring a possible sex difference in survival, particularly since the additional cost of tagging and tracking both sexes is relatively small. If there is no true difference in the survival of males and females, then survival data on a mixed sample of the sexes would give the same result as a sample of one sex alone with the added, powerful benefit that the sample would be twice as large. If, on the other hand, as a study of both sexes progresses, the tracking data suggest that the sexes do not survive equally, we will be glad to have tagged them both. At that point, it would be wise to continue monitoring the tags for a long enough period to obtain the needed confidence intervals for the more vulnerable sex. The tag batteries are supposed to last four to five years. 


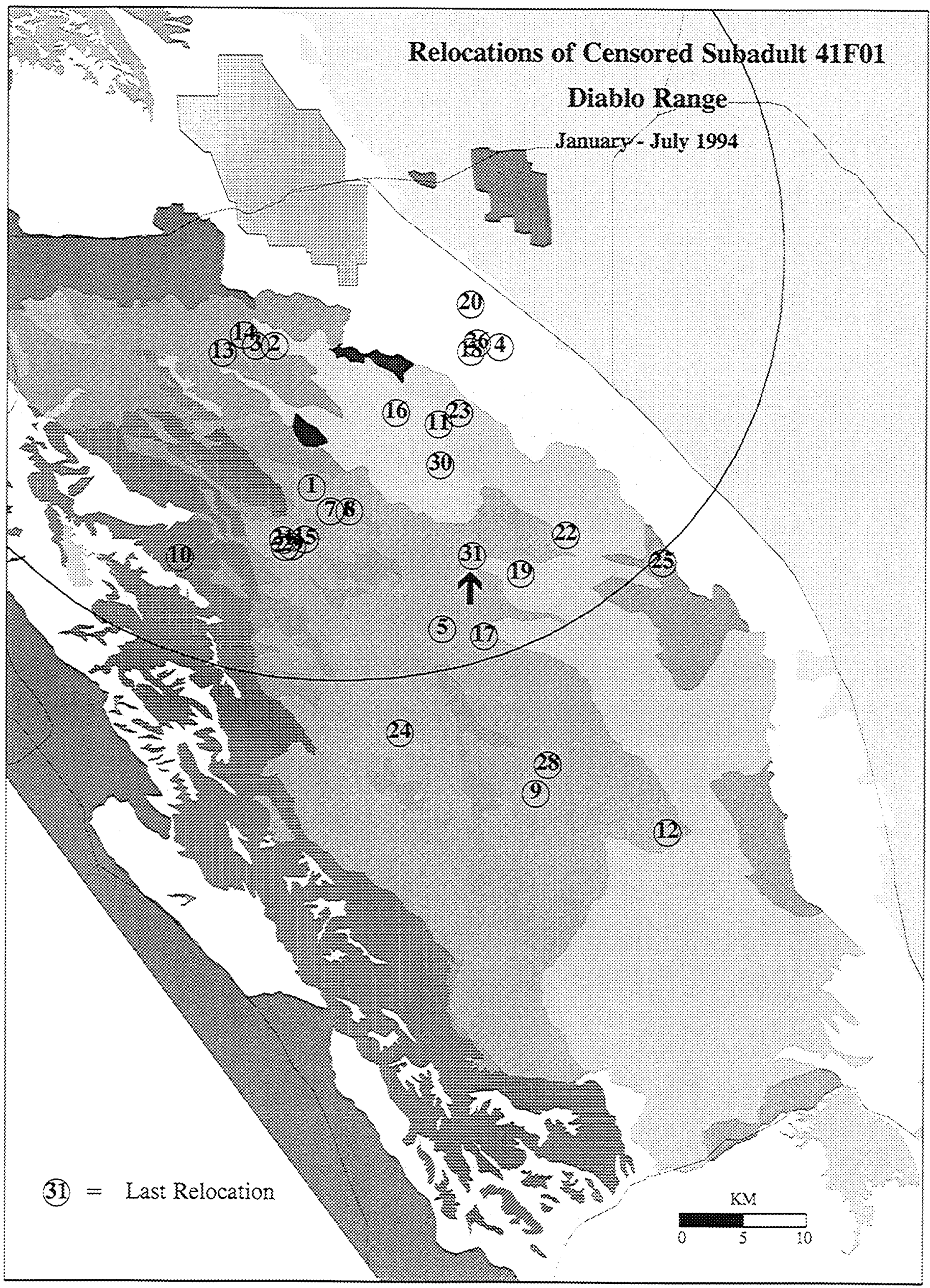




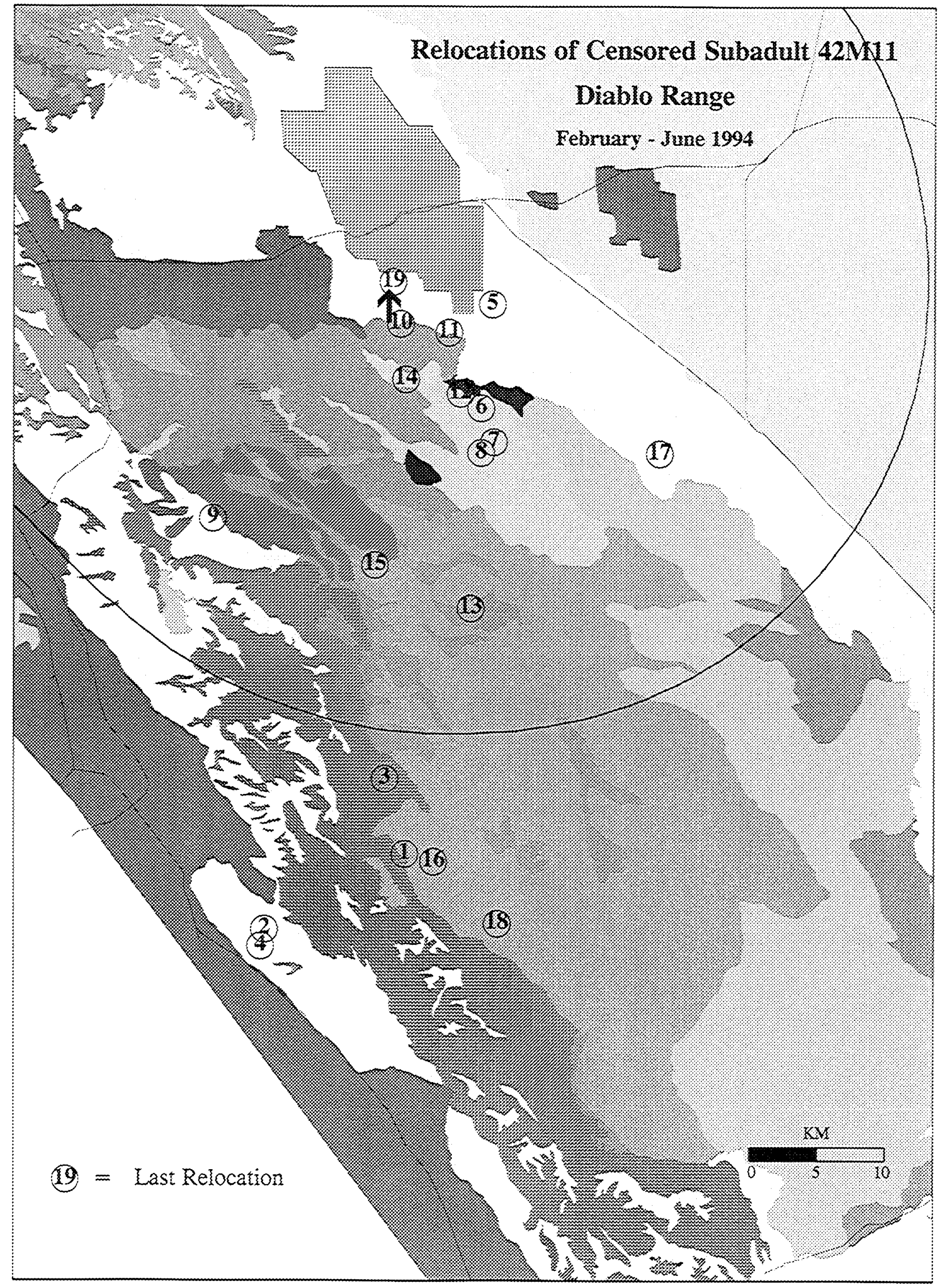




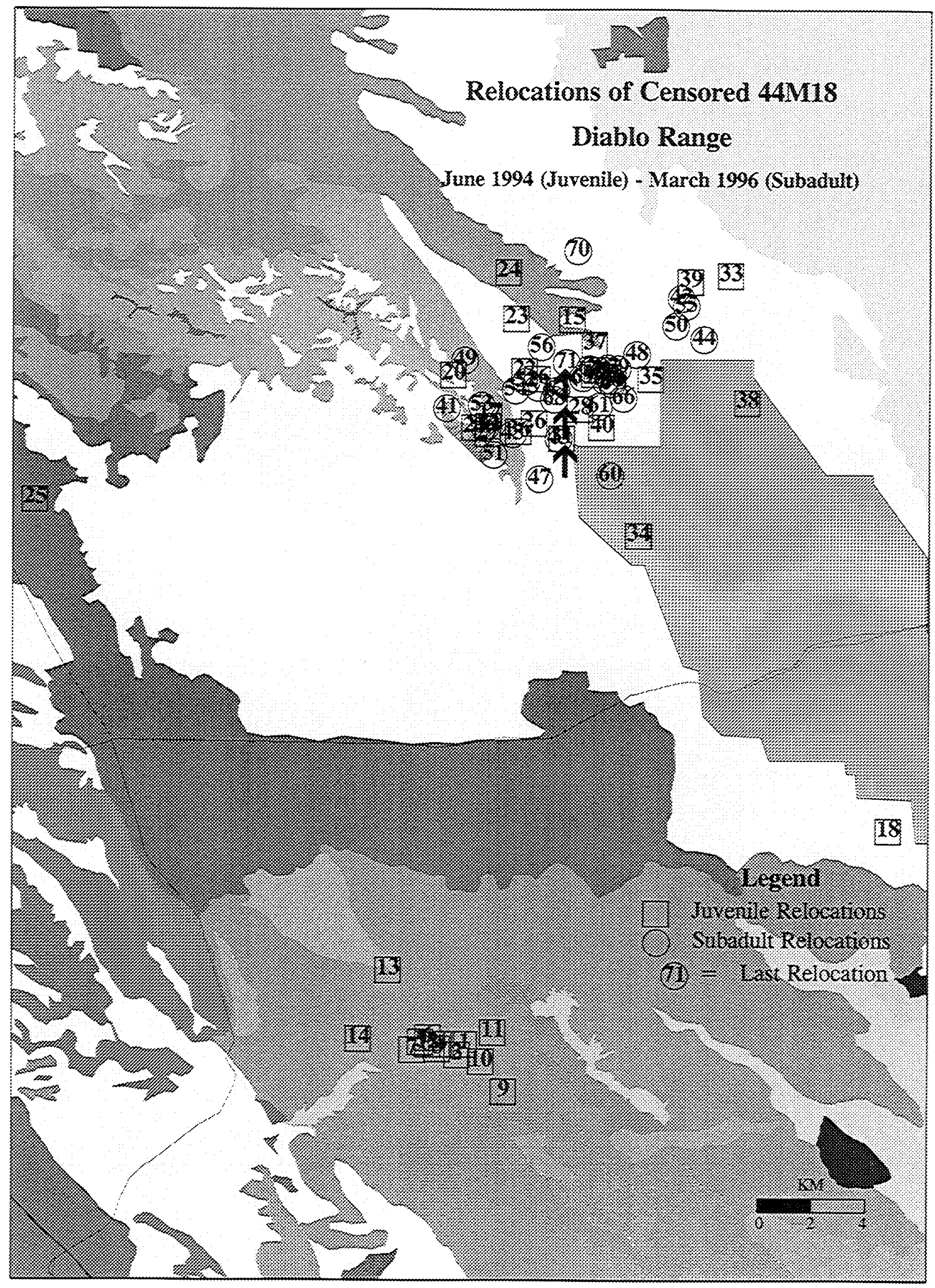




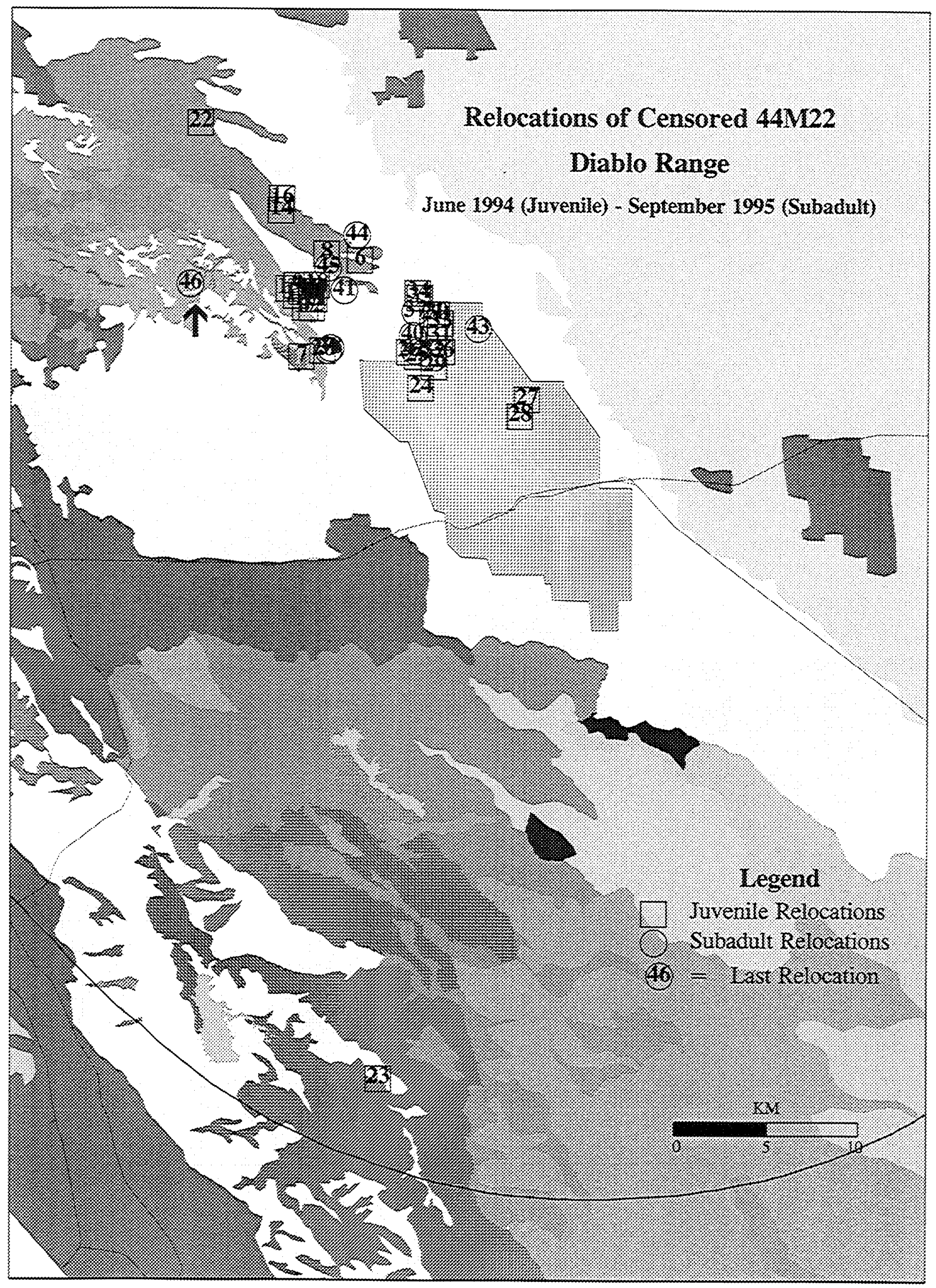




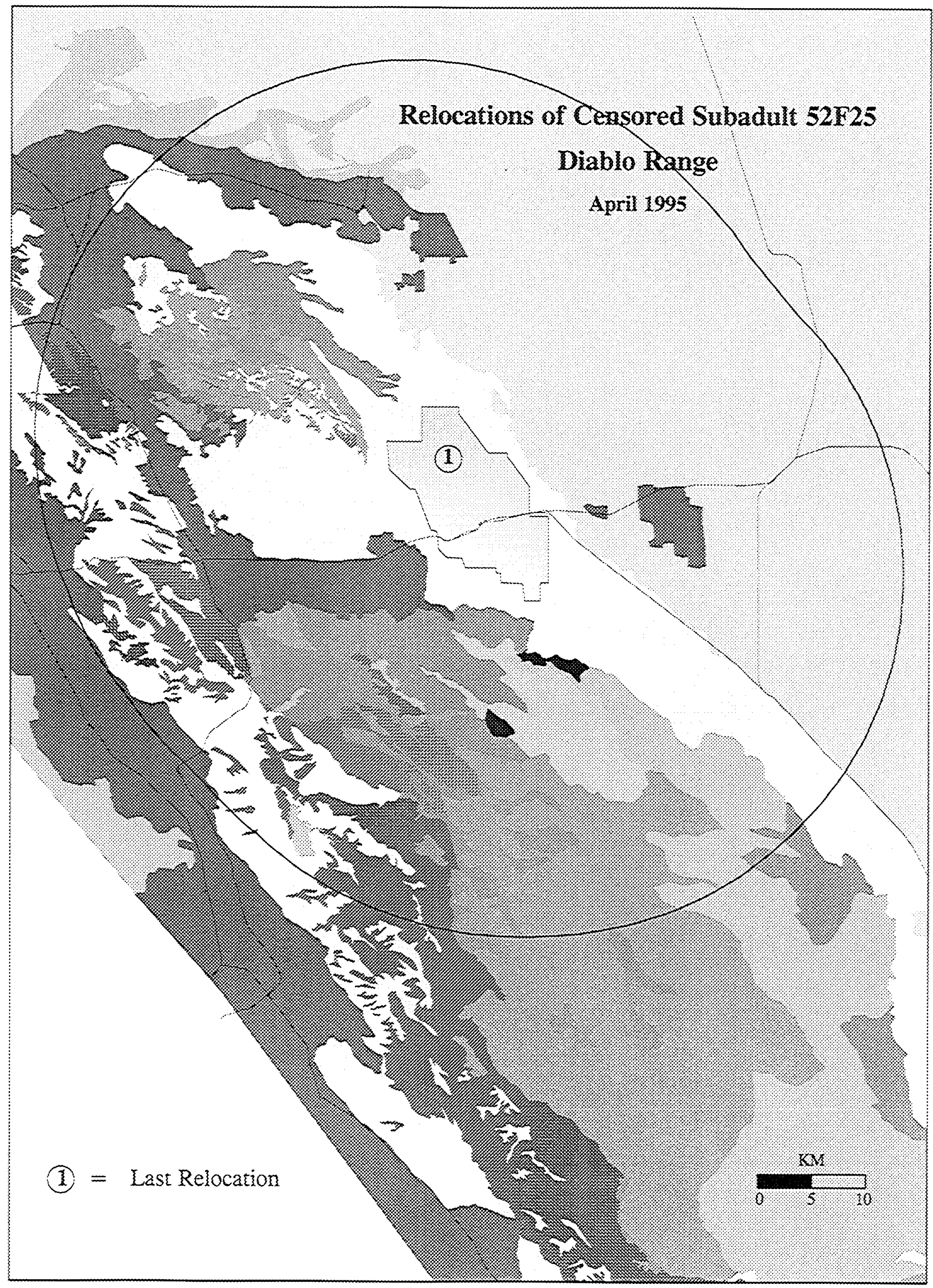




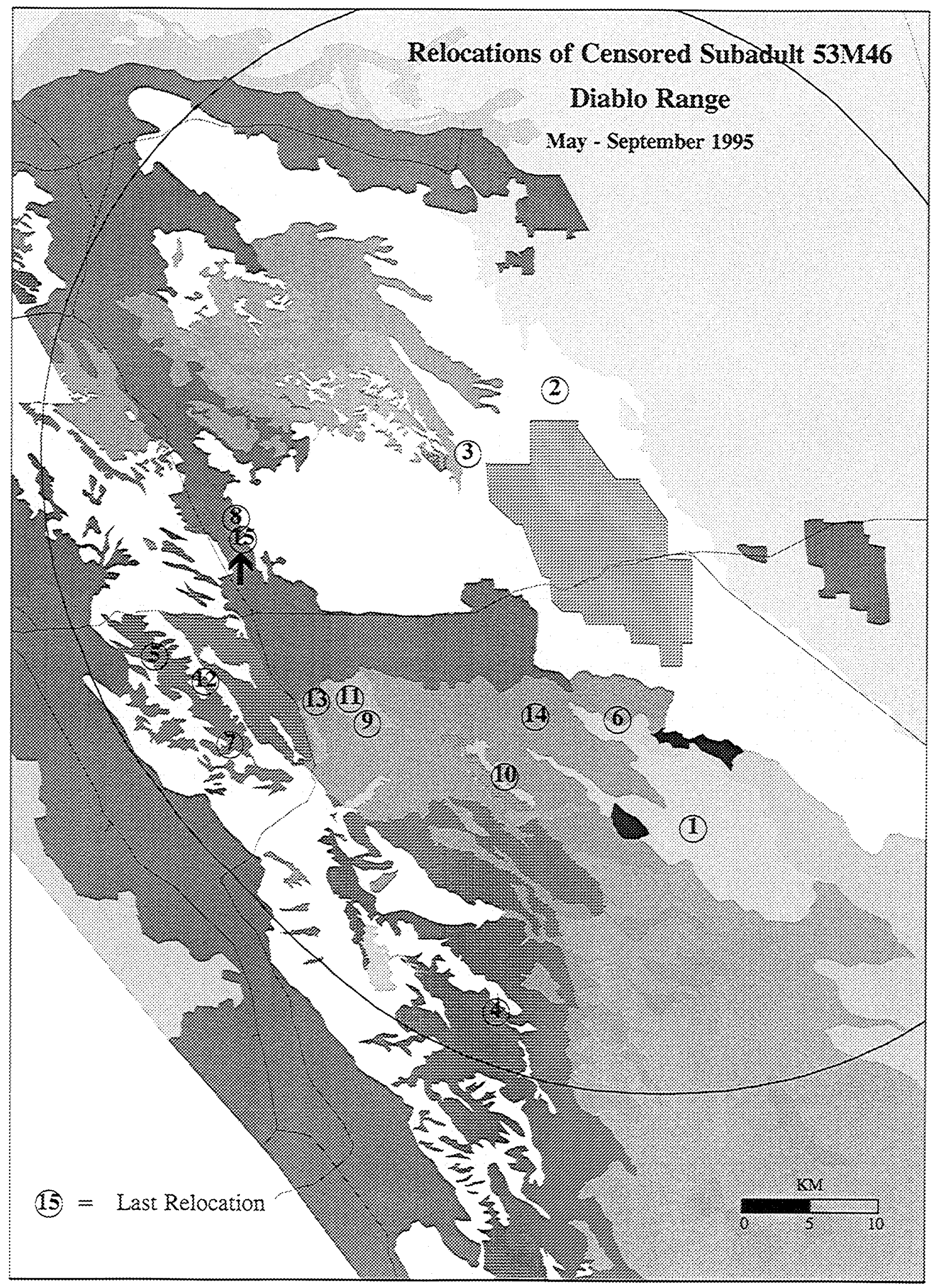




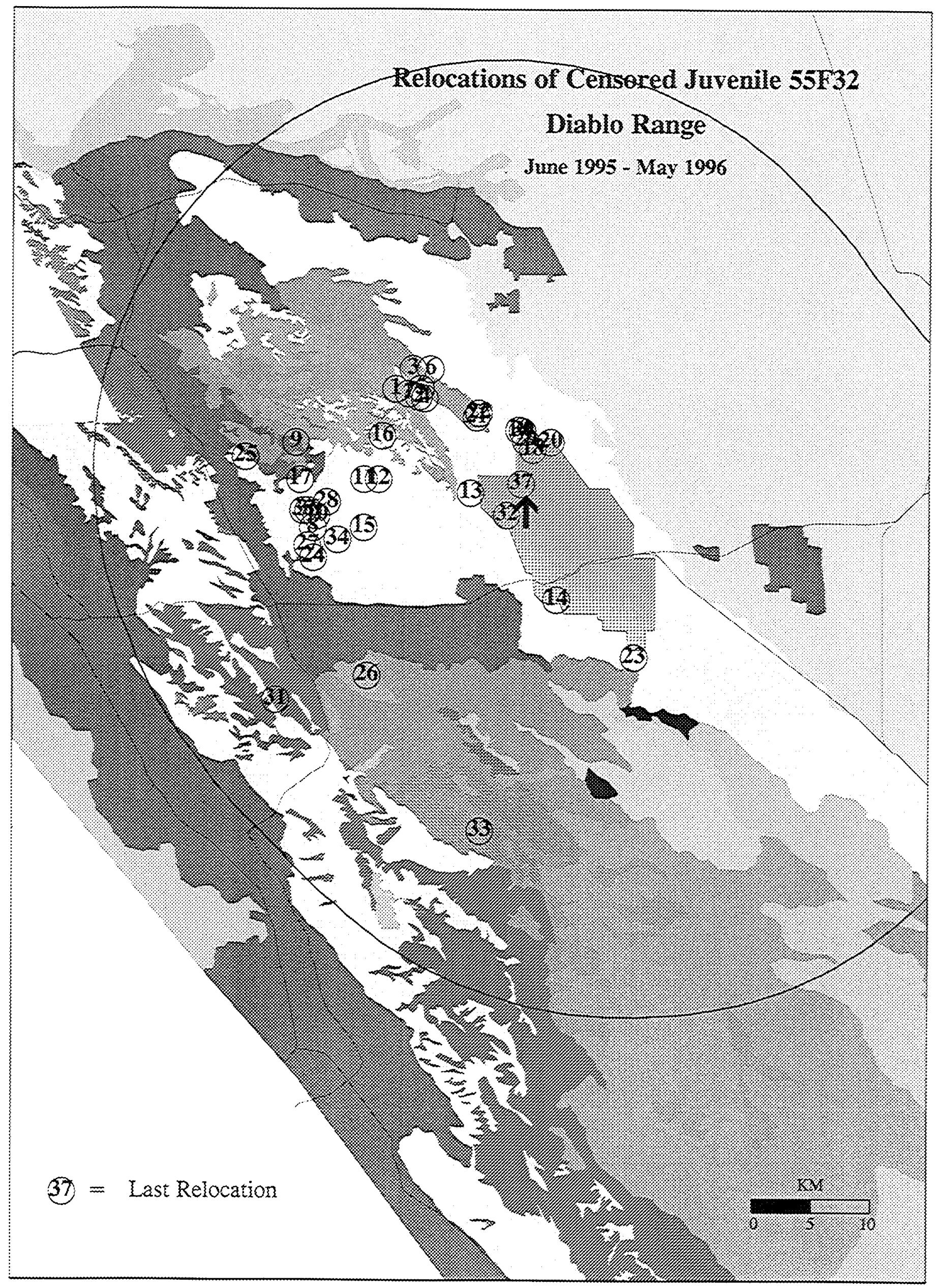




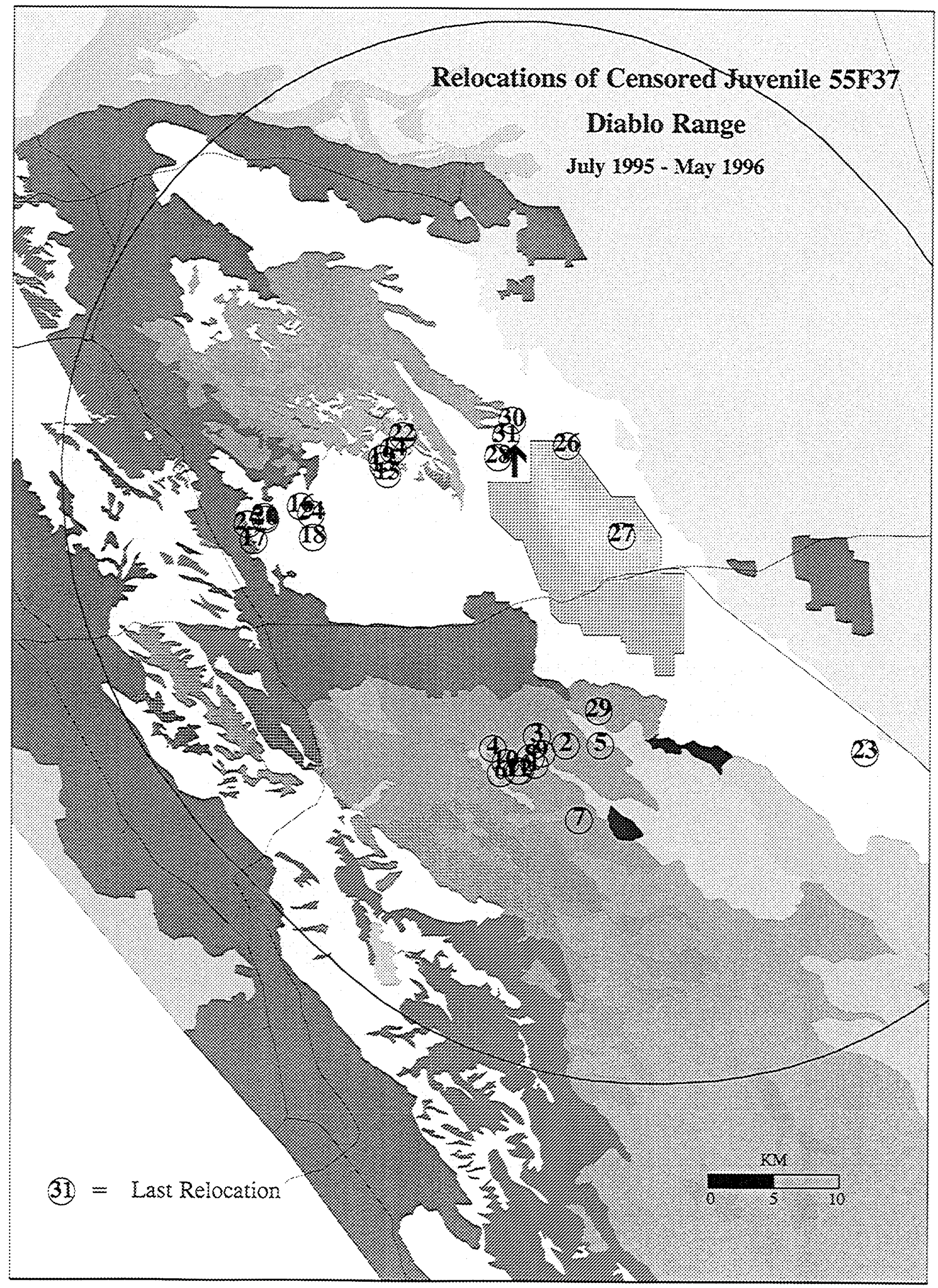




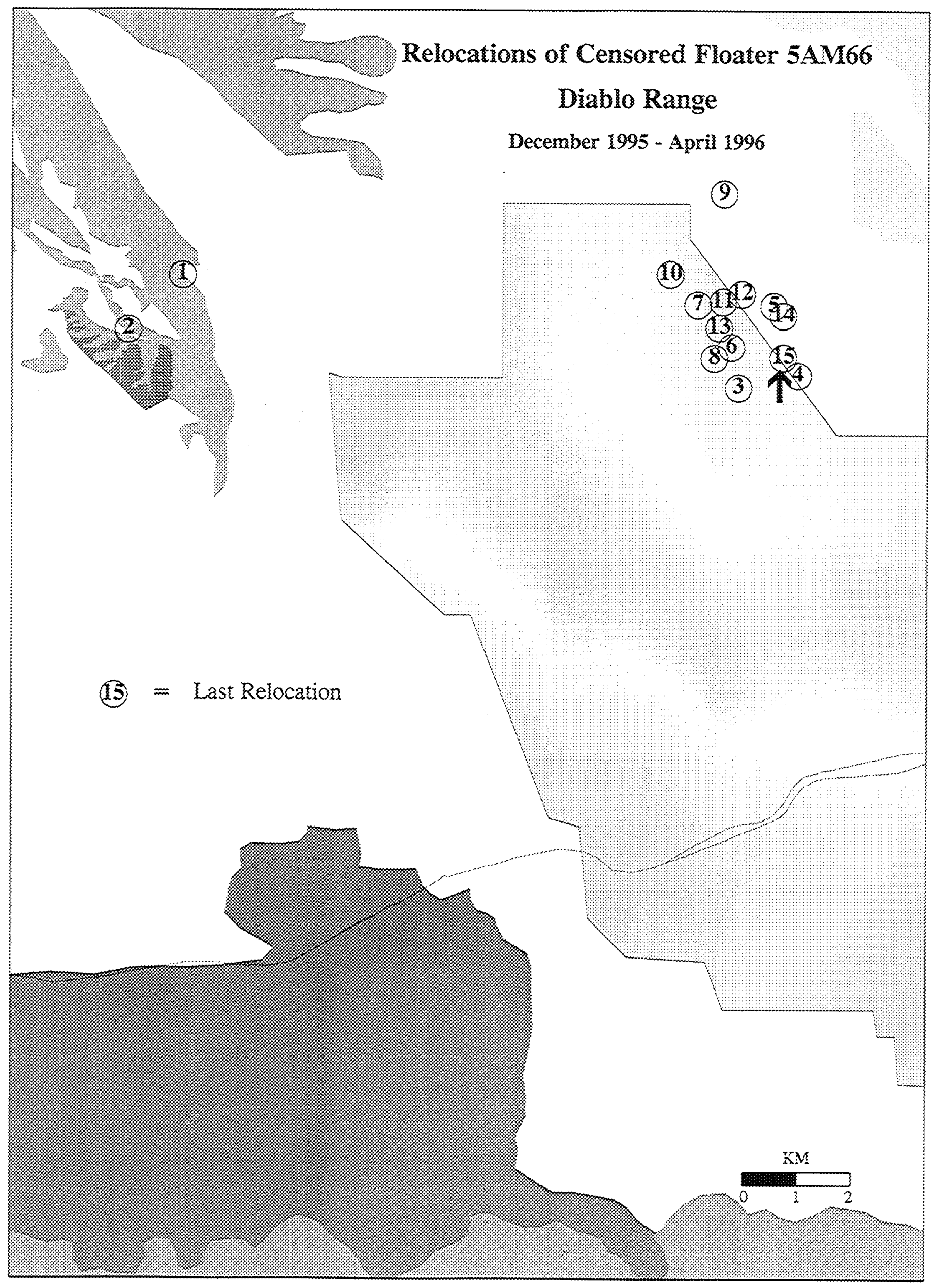




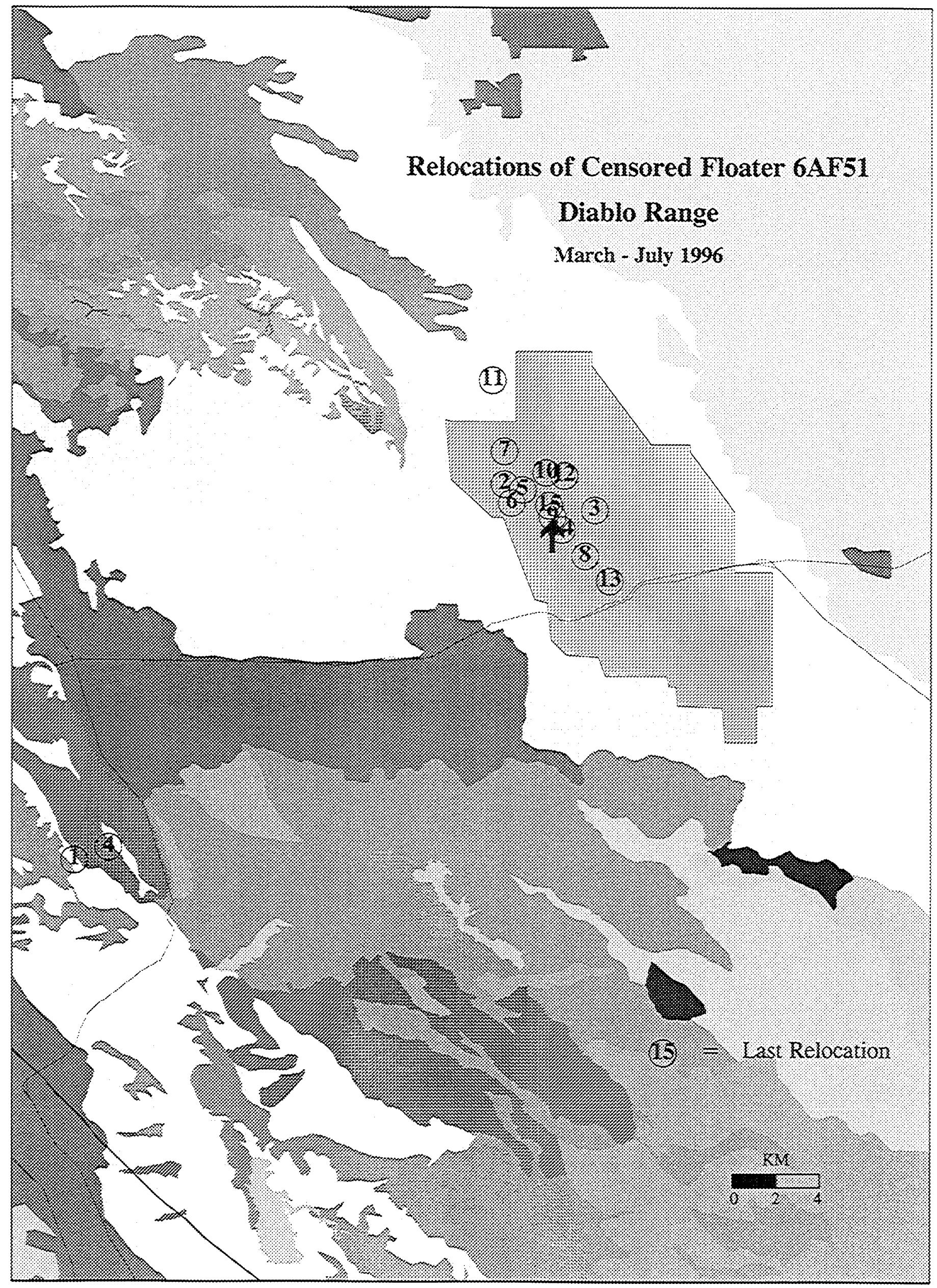


APPENDIX C: RELOCATIONS OF 99 RADIO-TAGGED GOLDEN EAGLE CASUAL TIES IN THE DIABLO RANGE STUDY AREA 


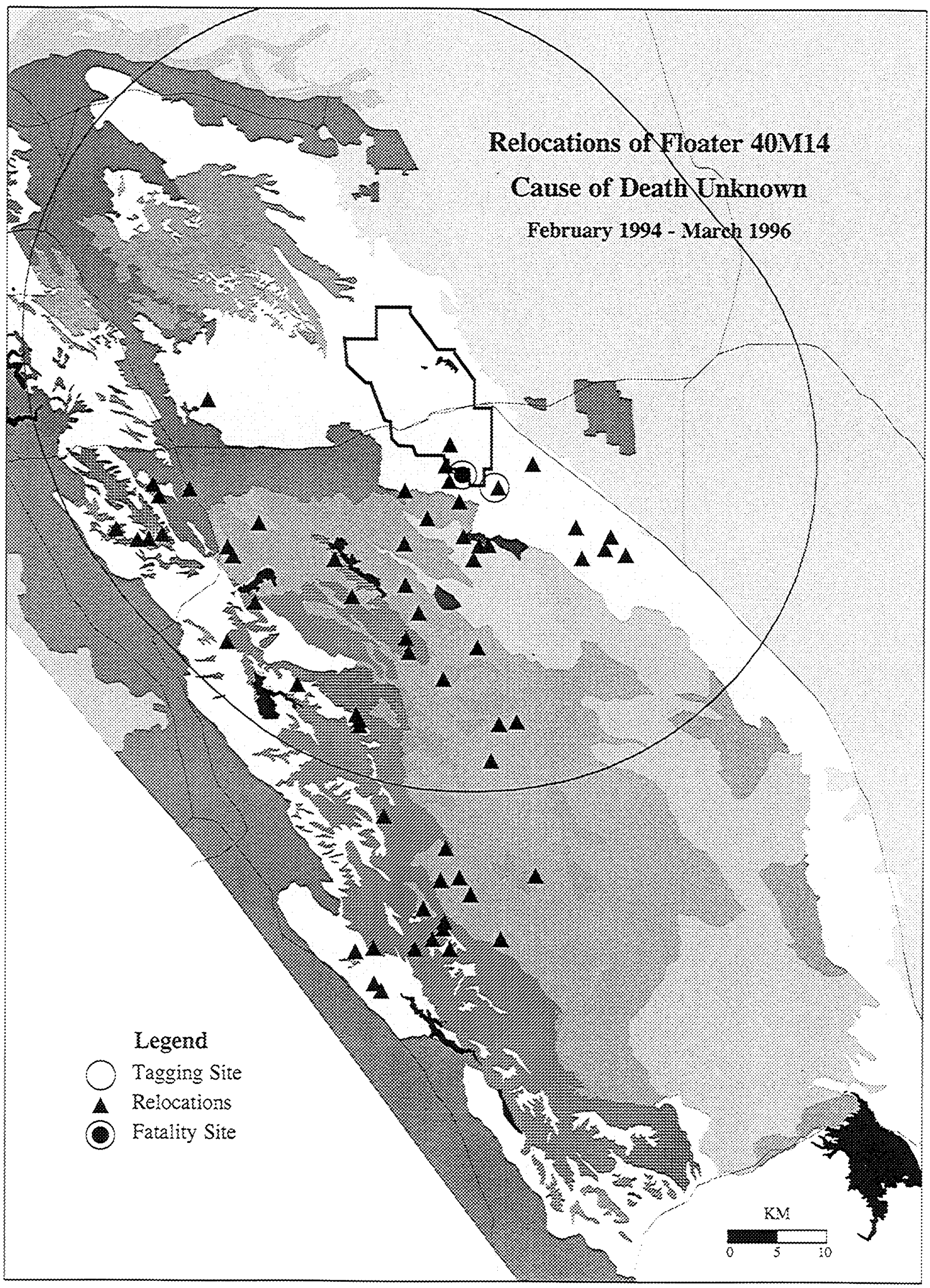




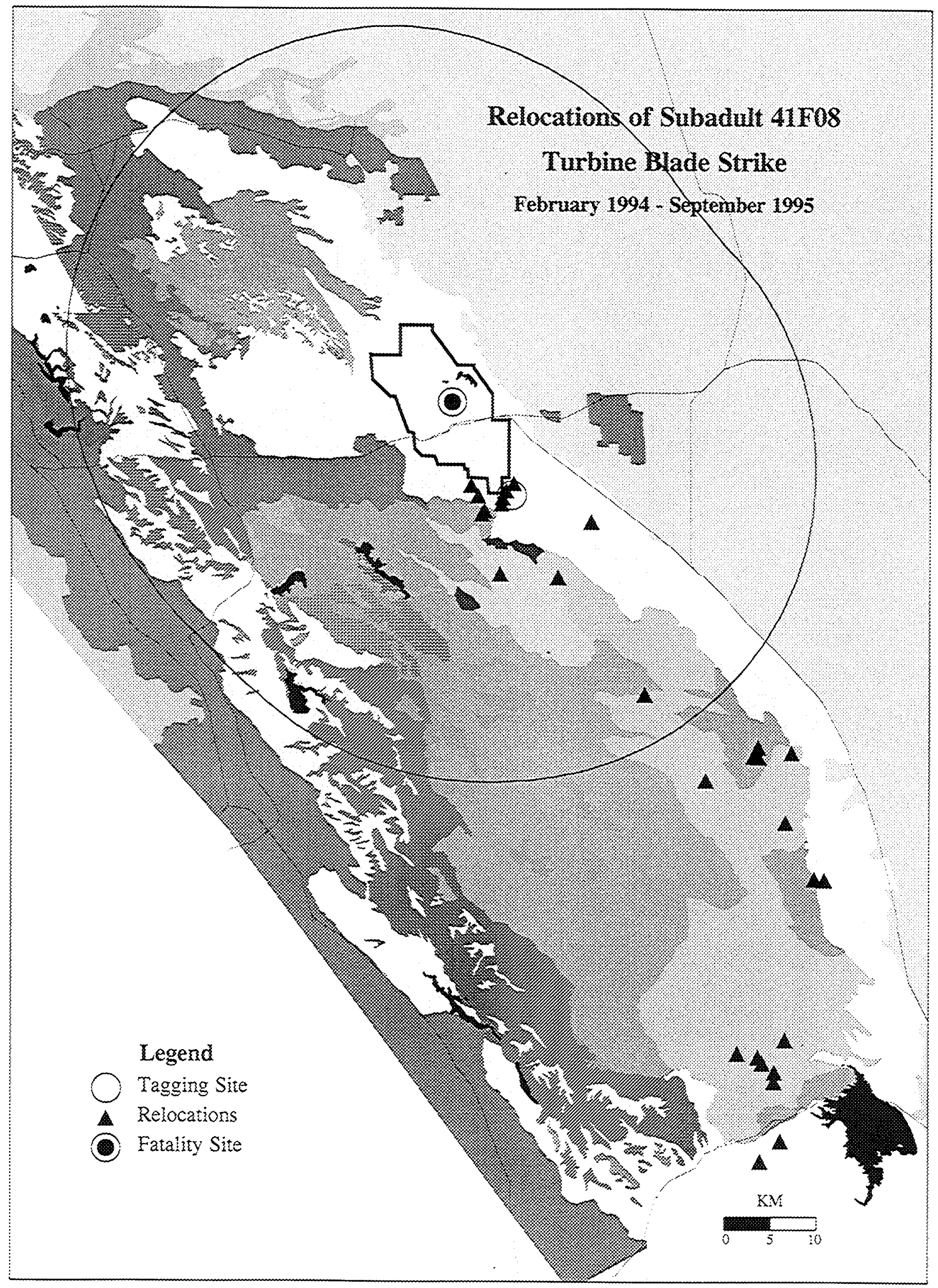




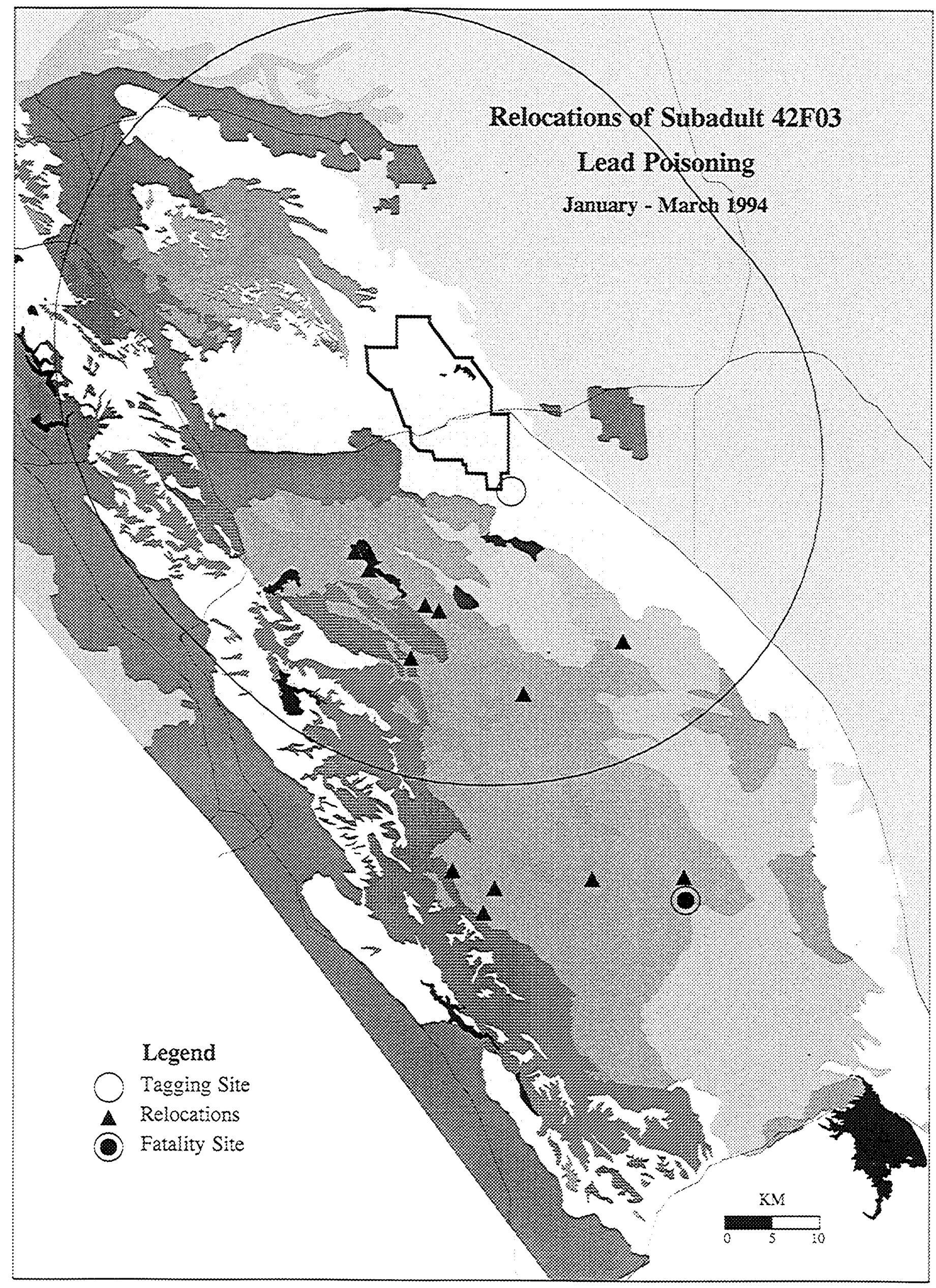




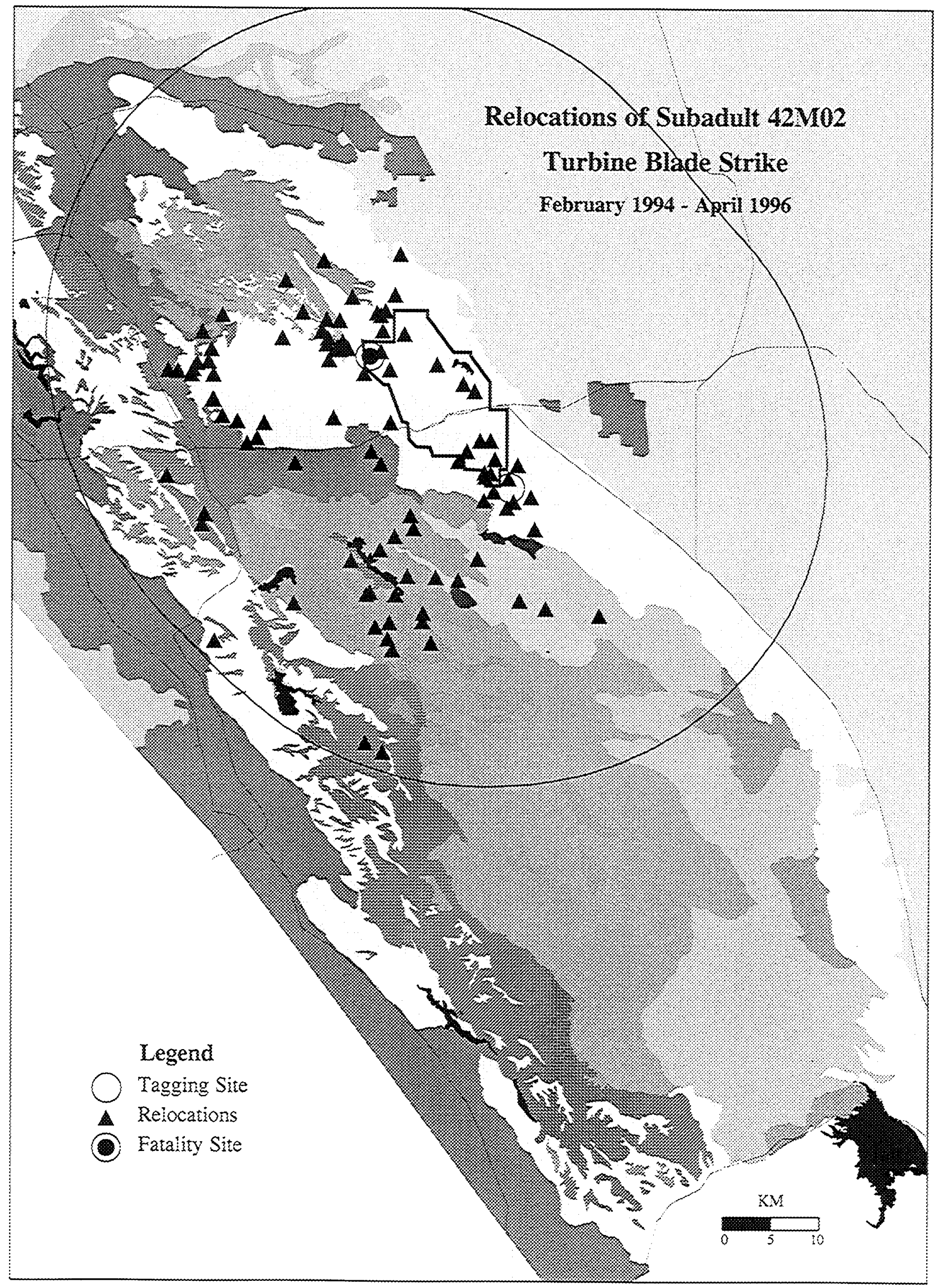




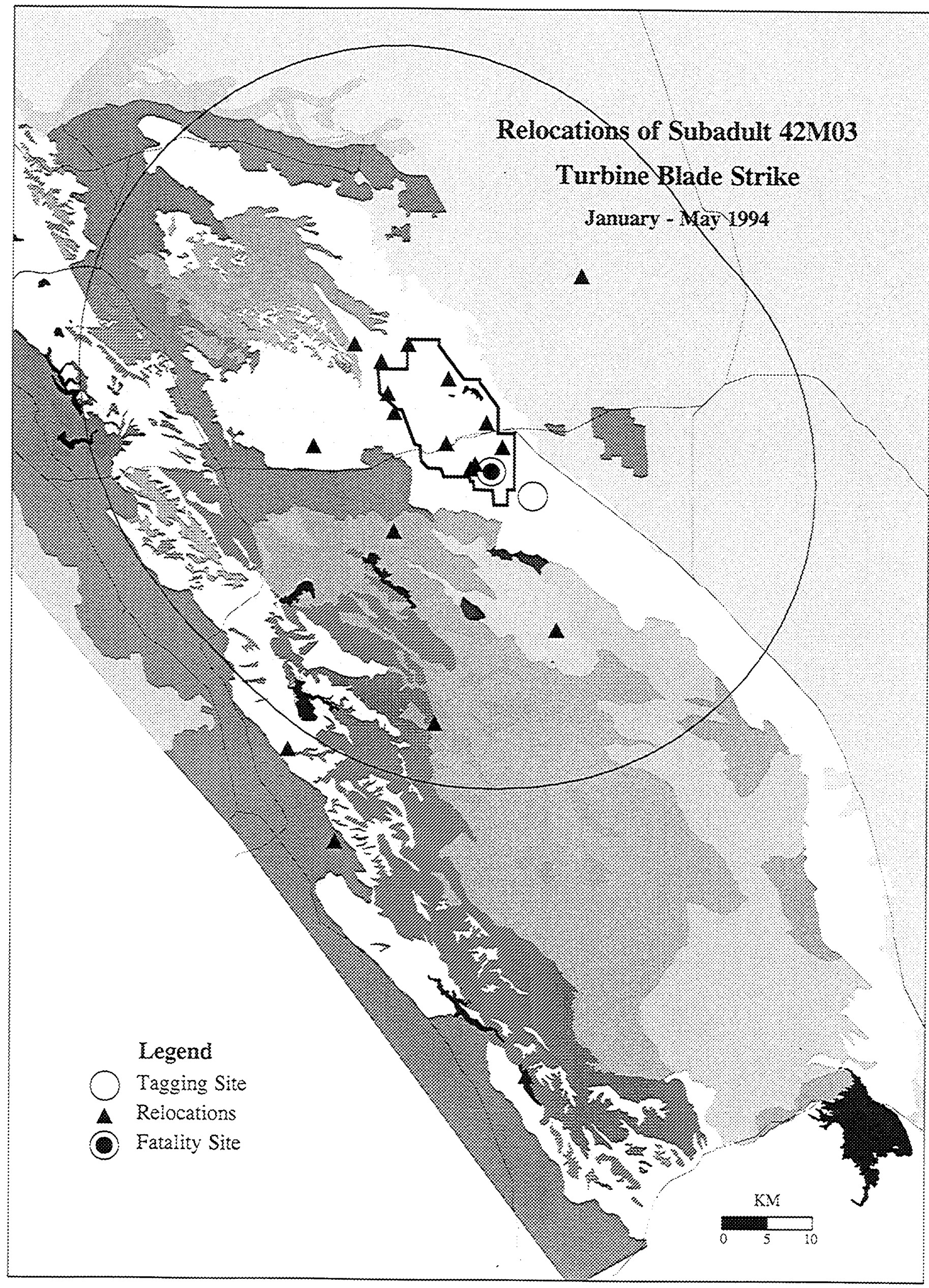




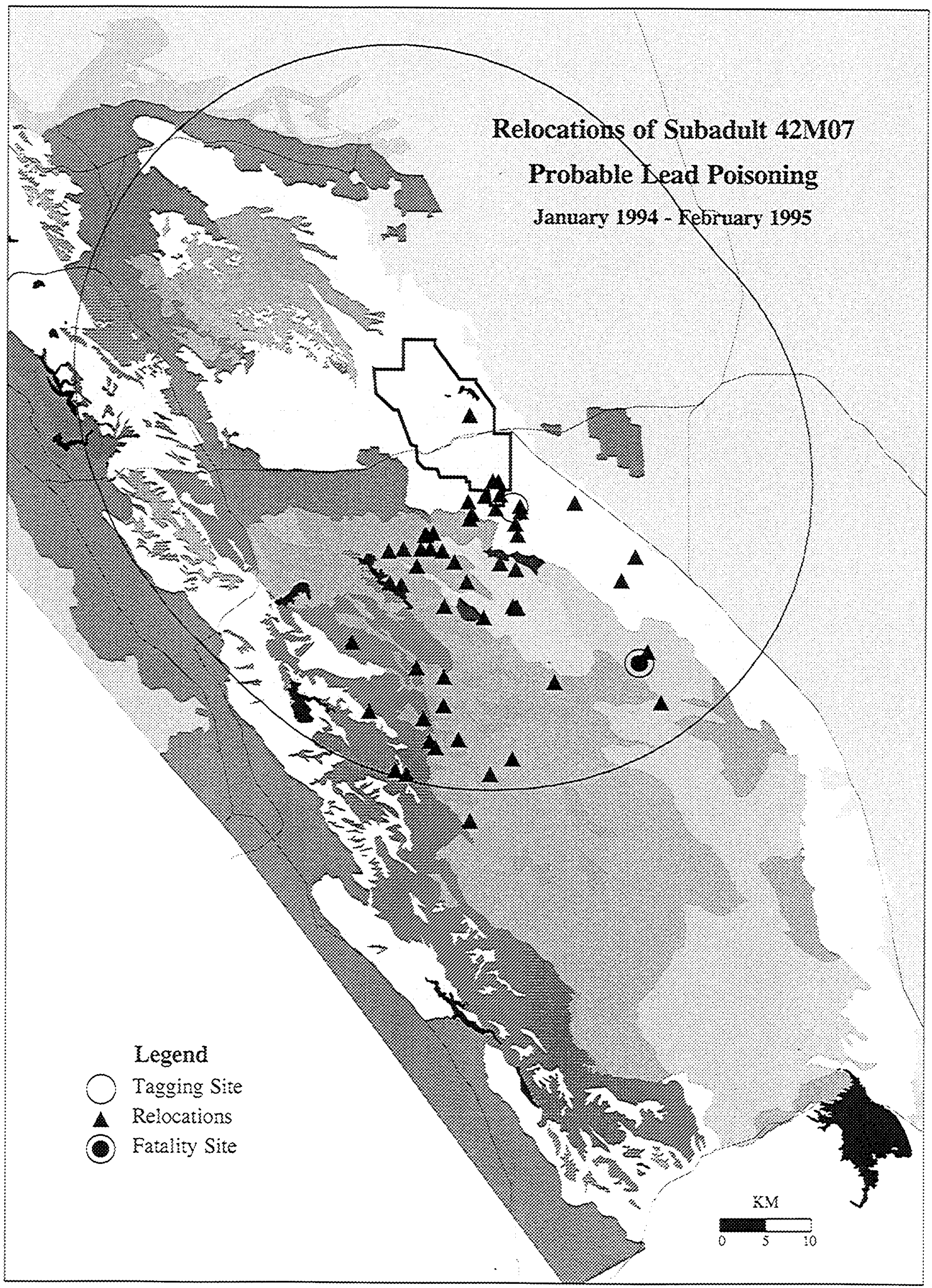




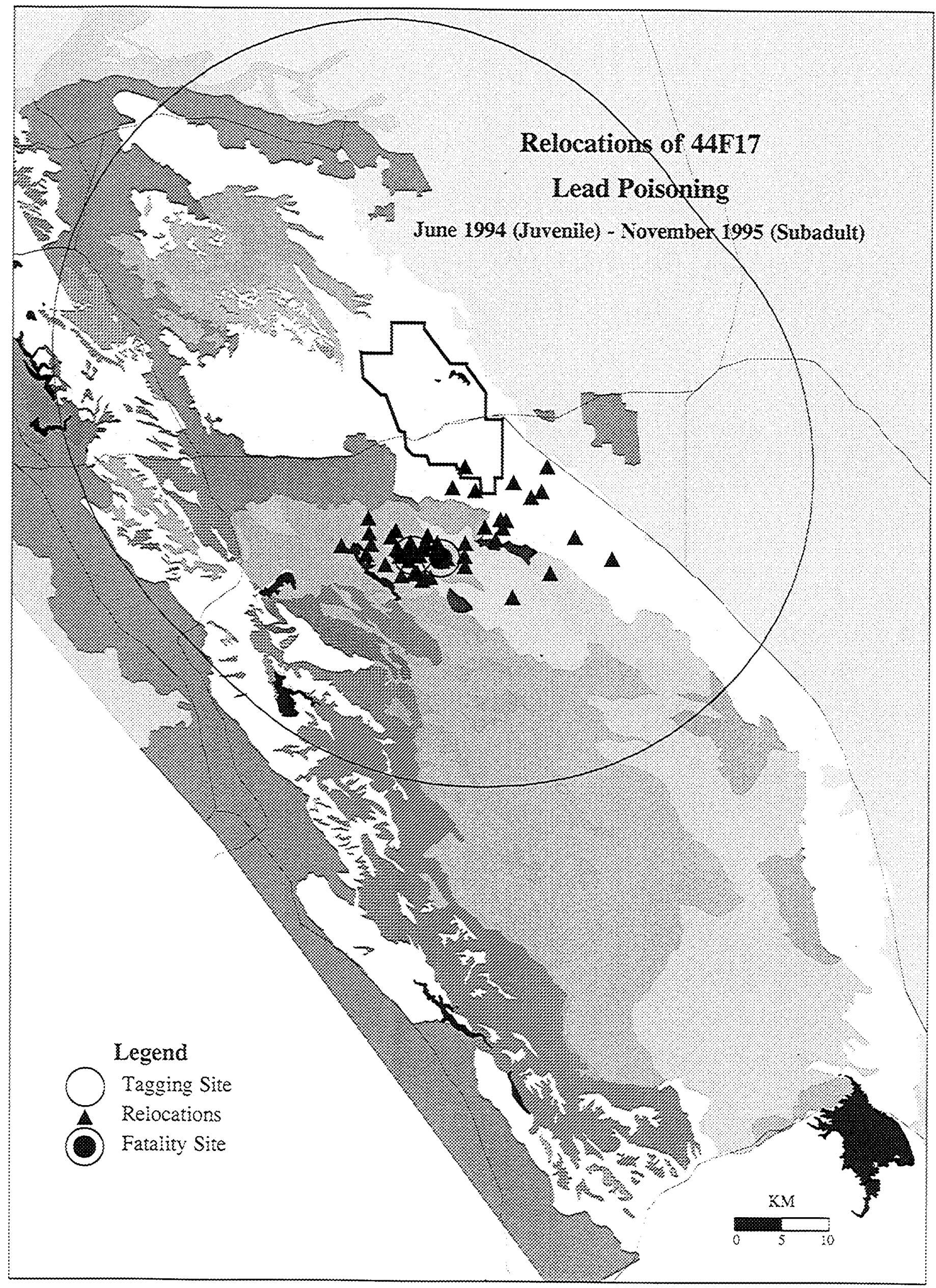




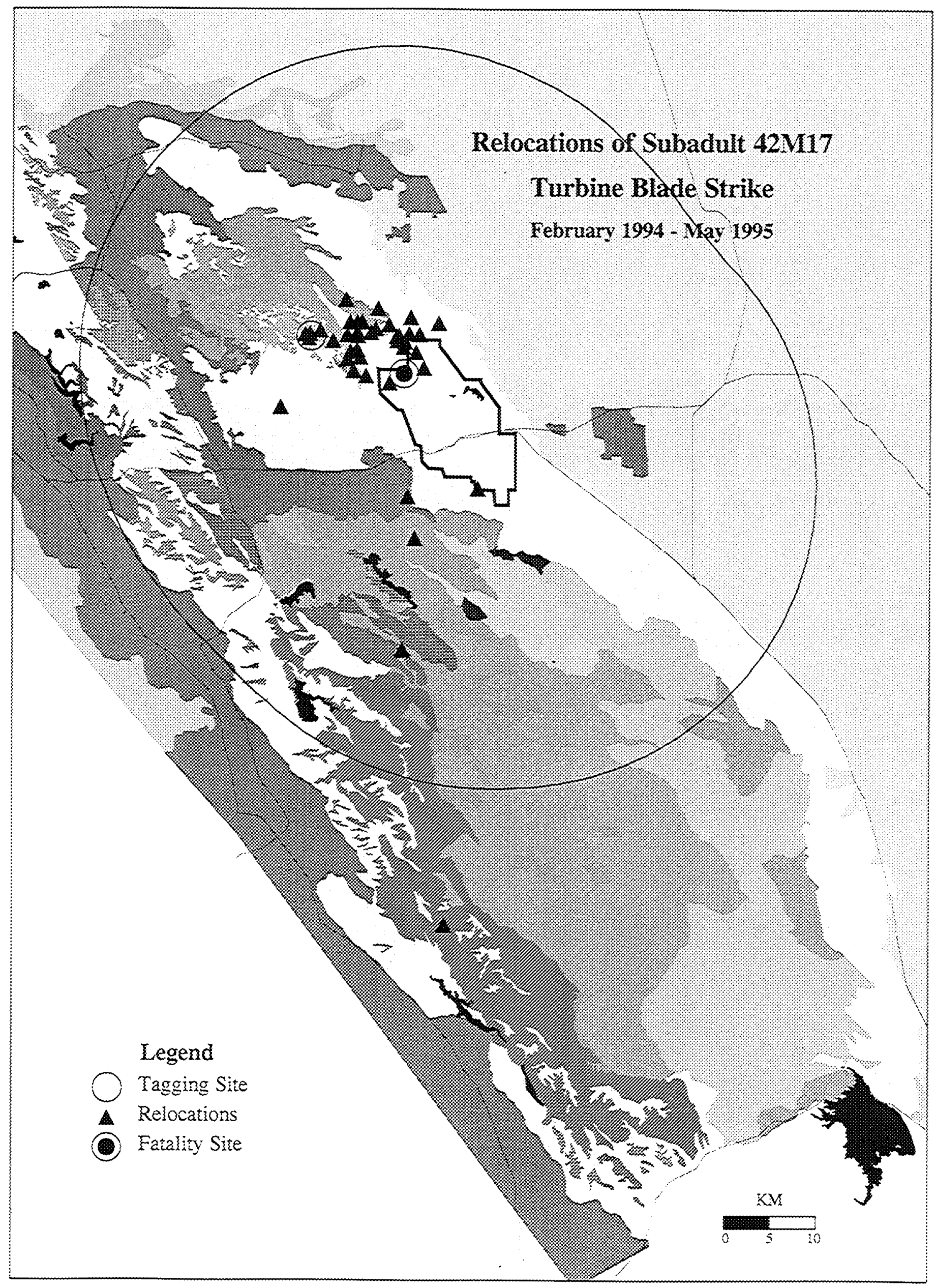




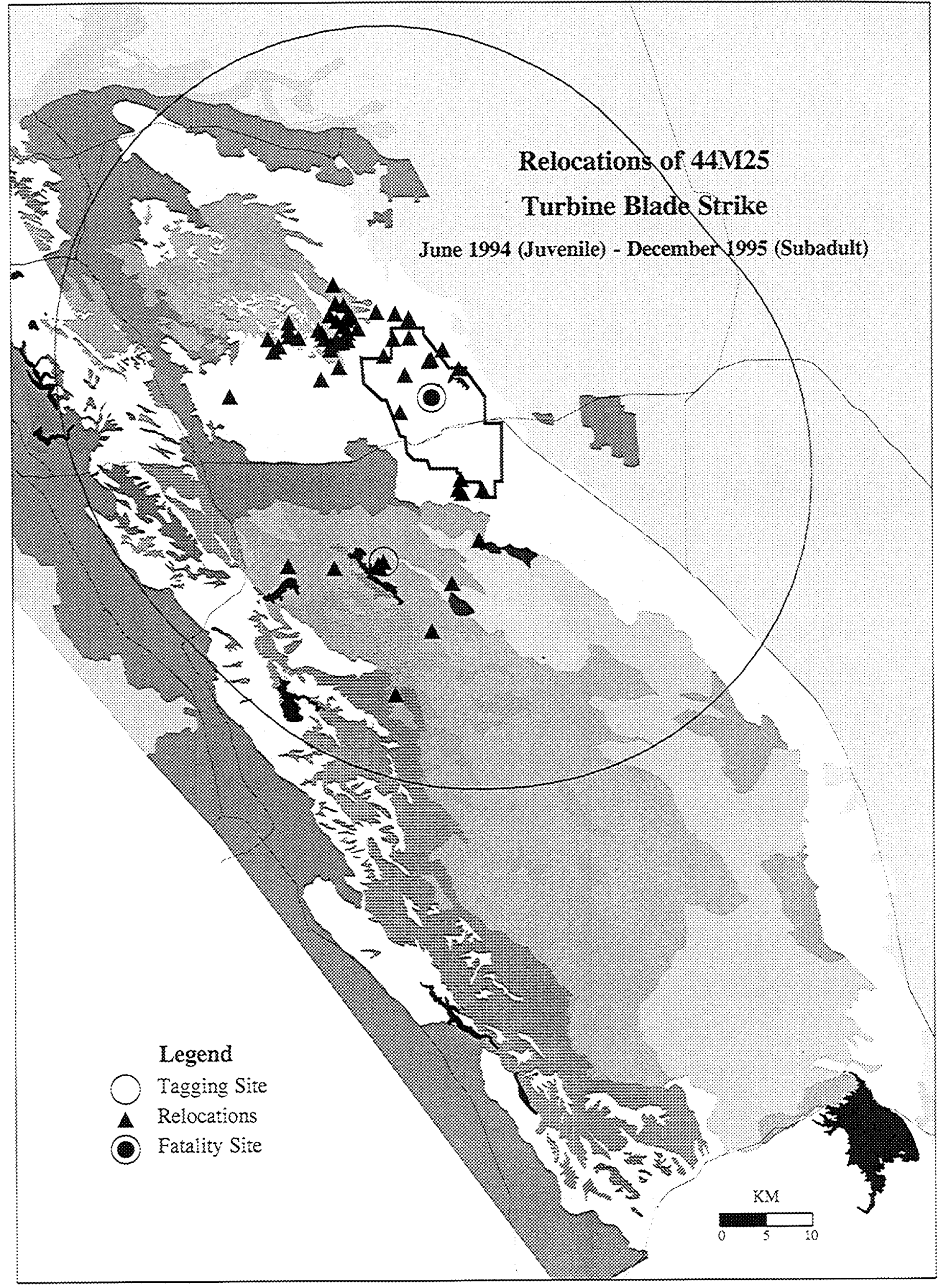




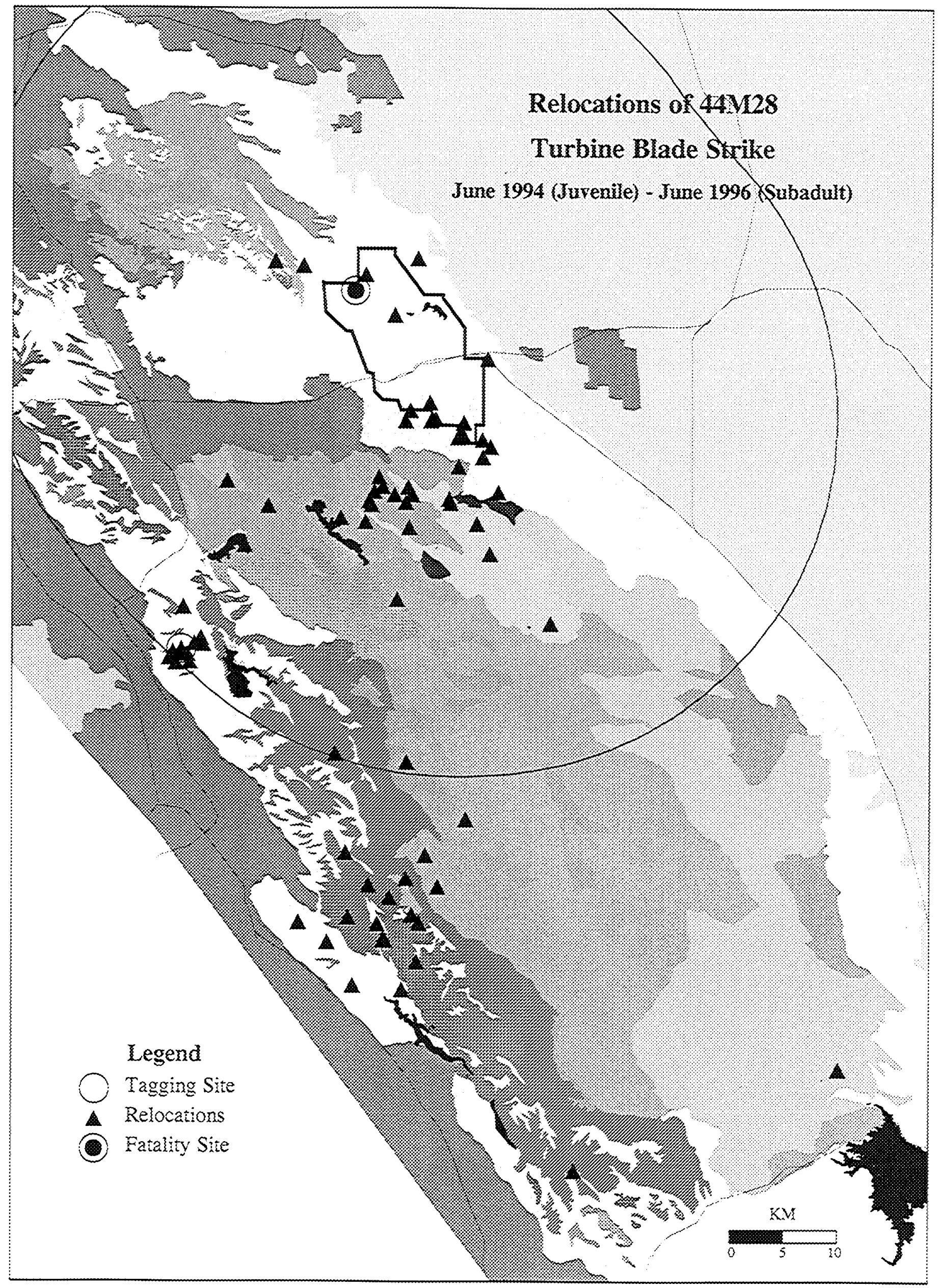




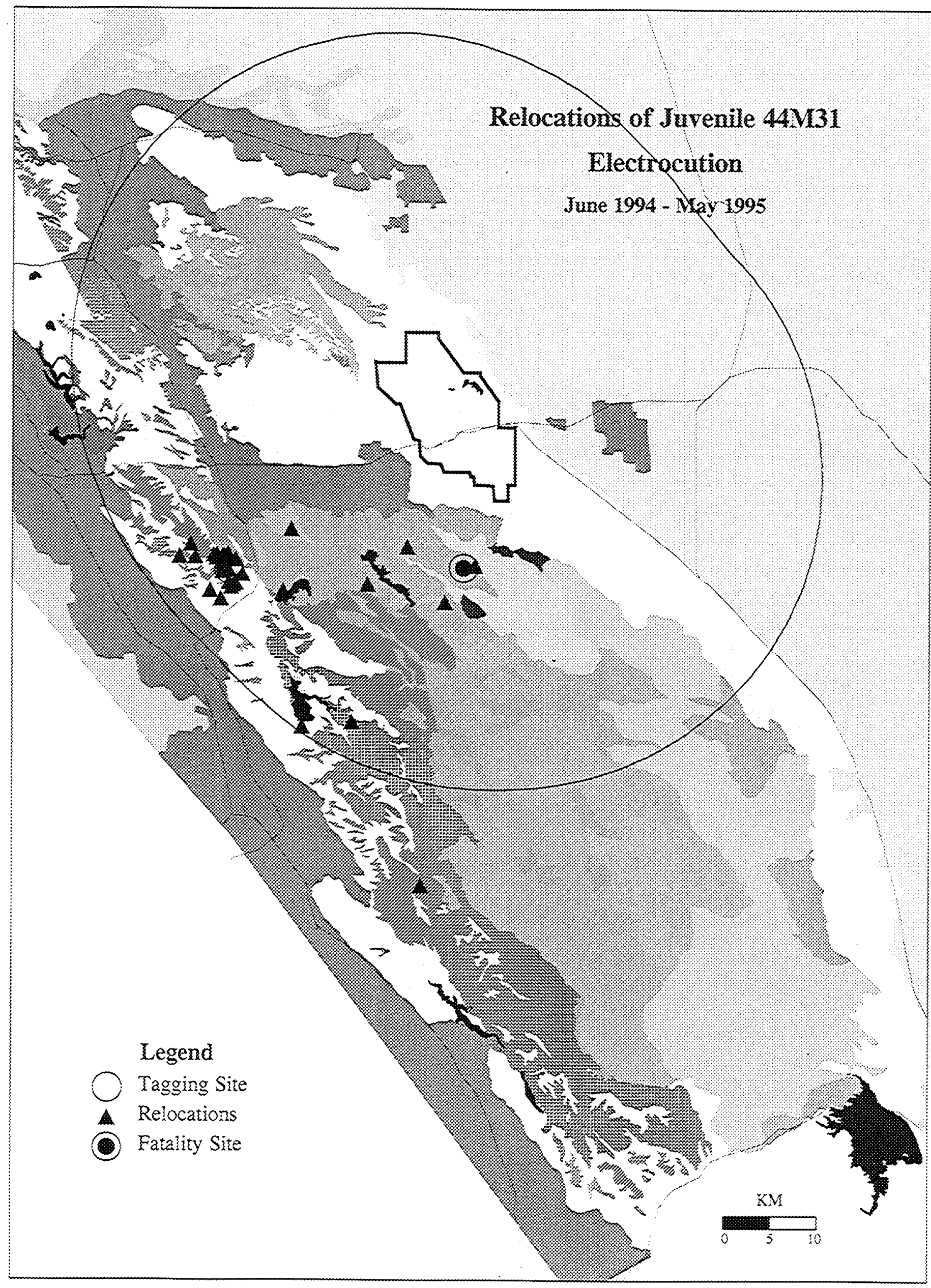




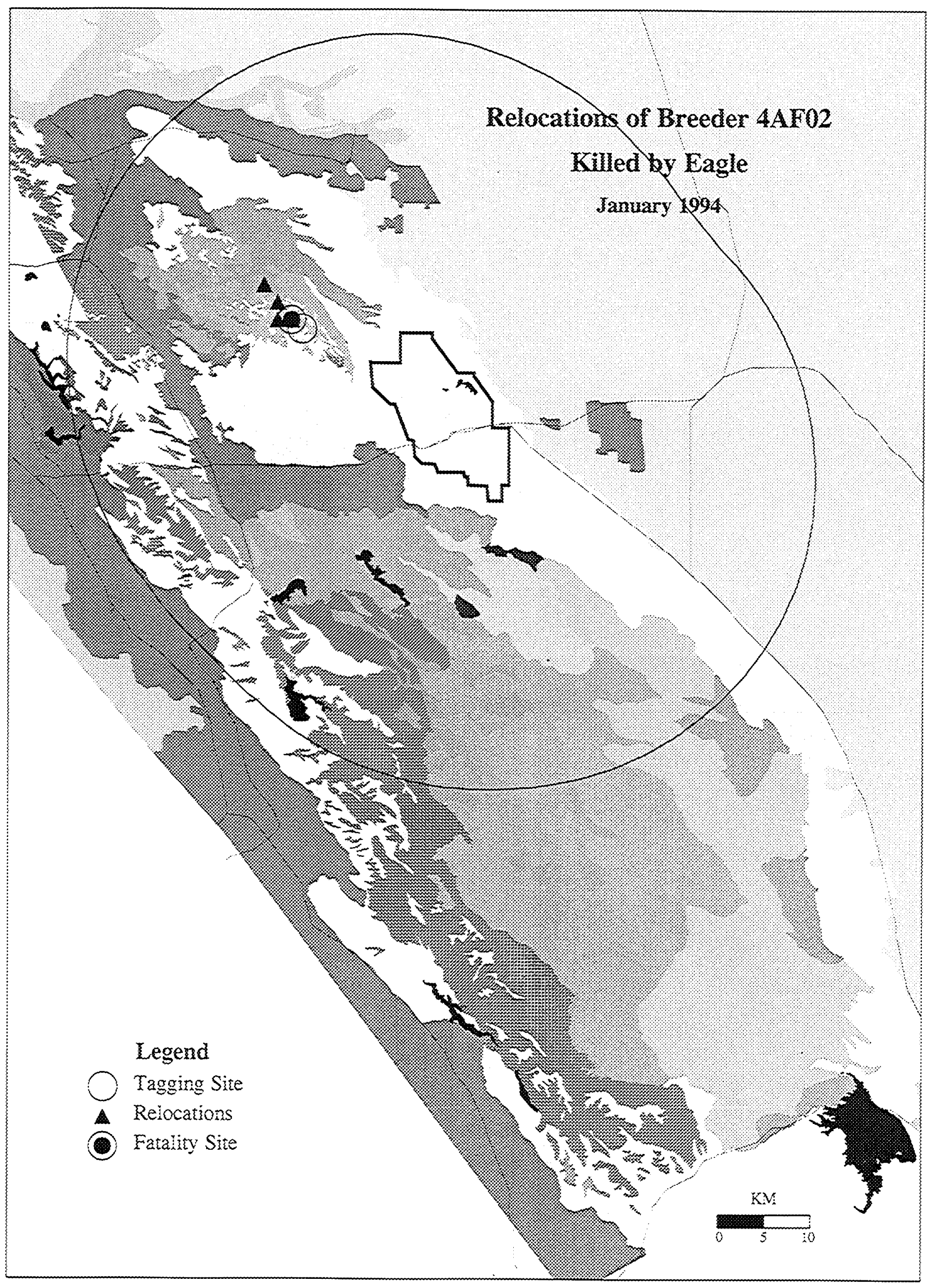




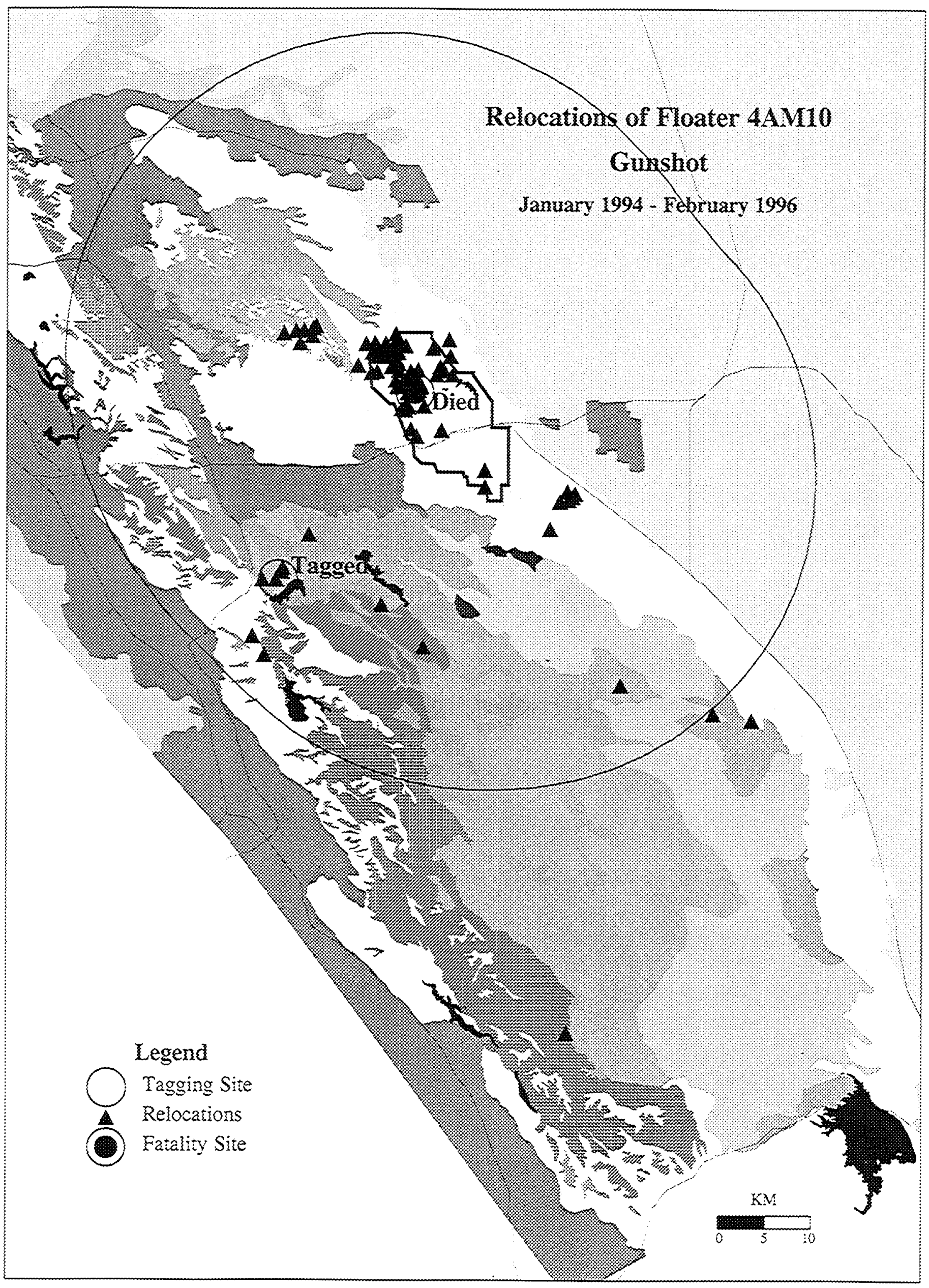




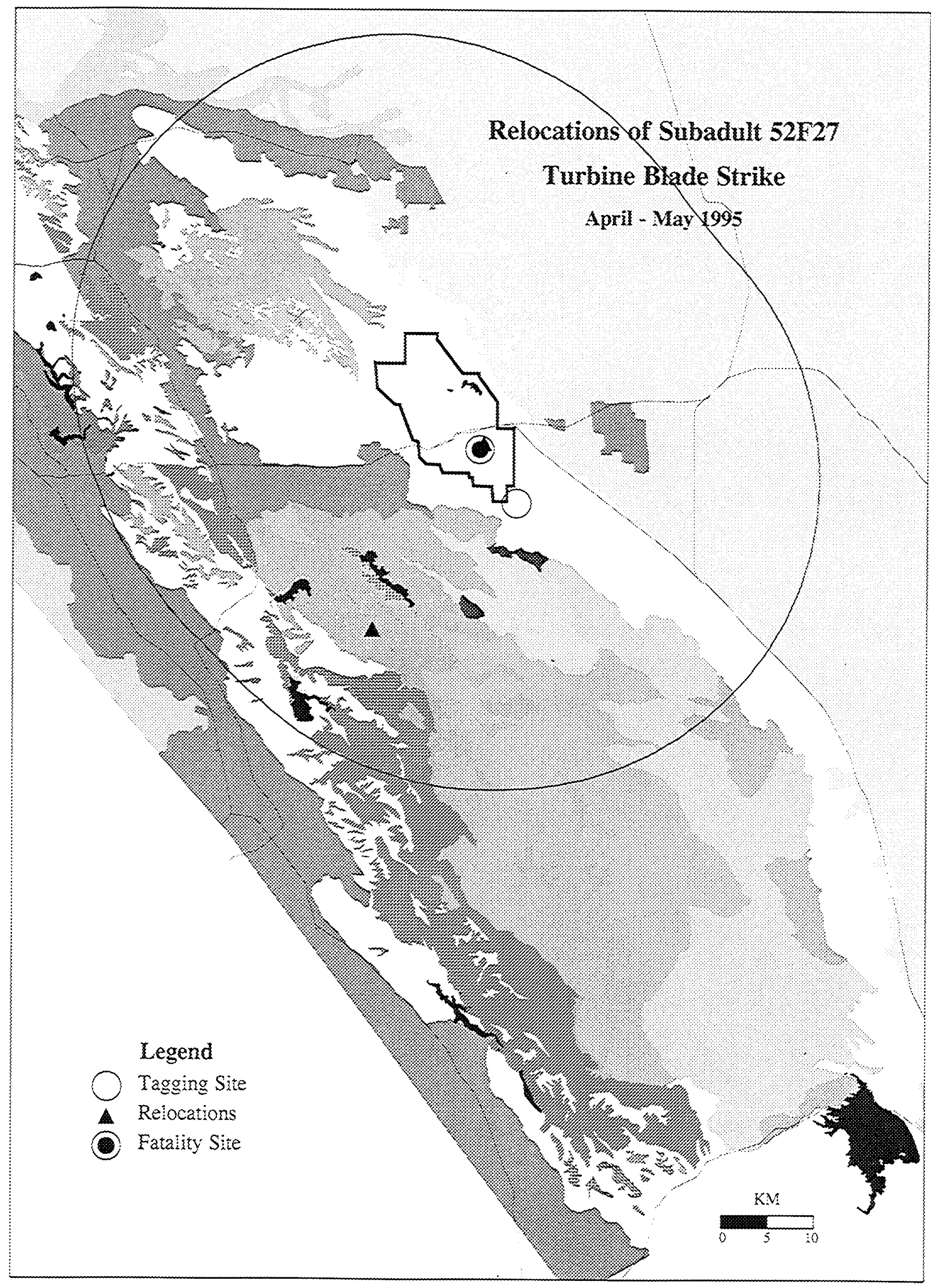




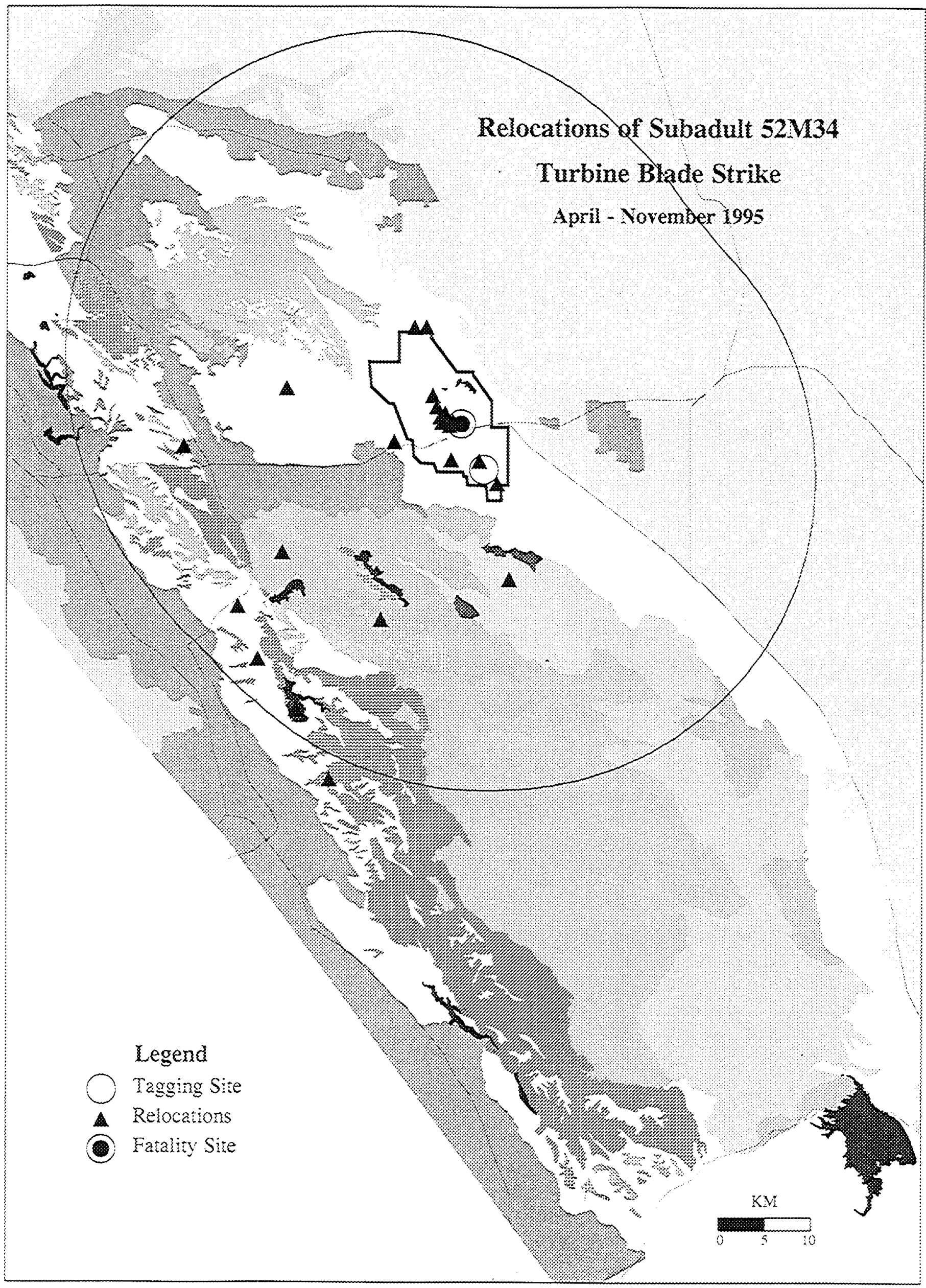




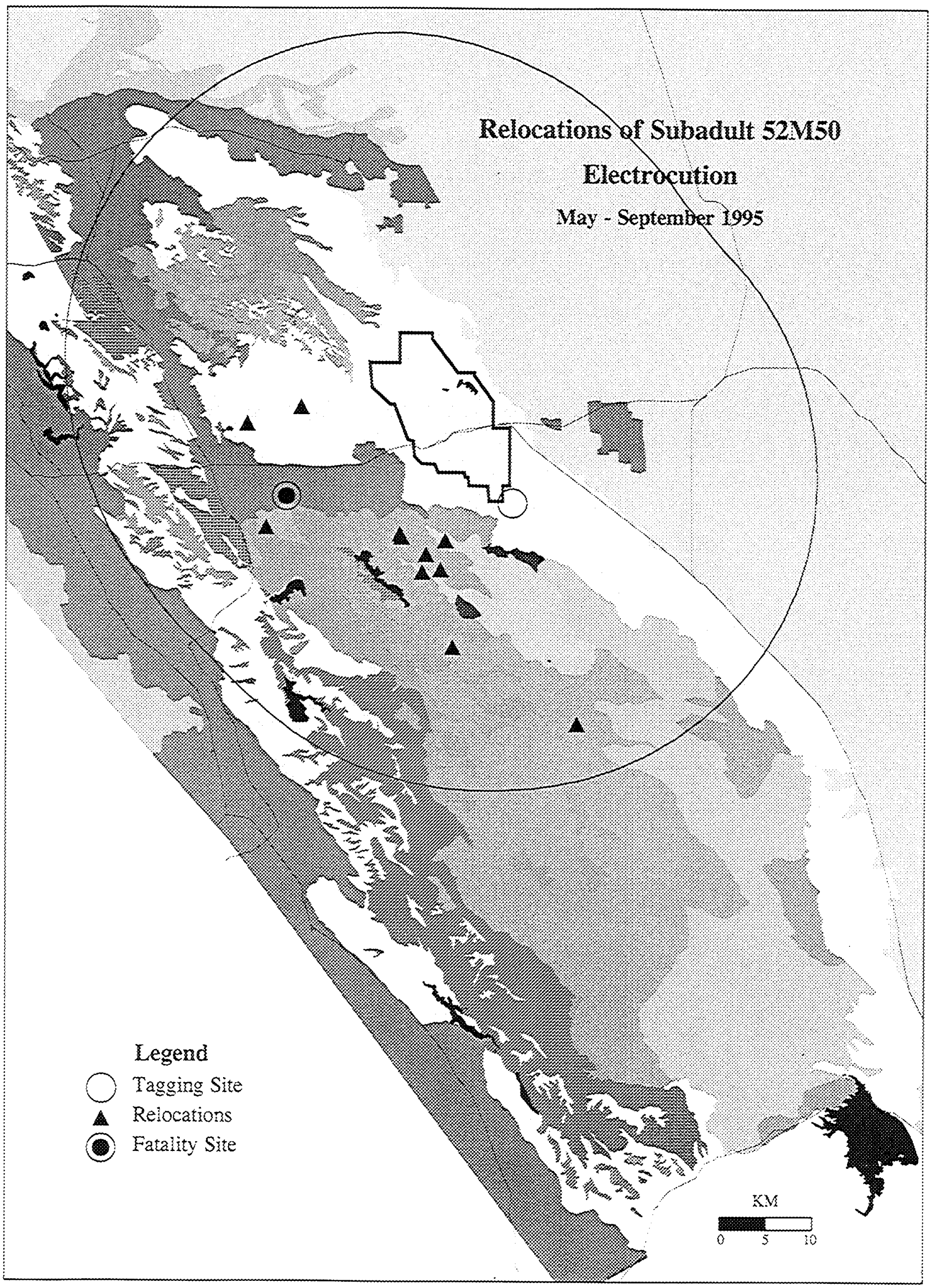




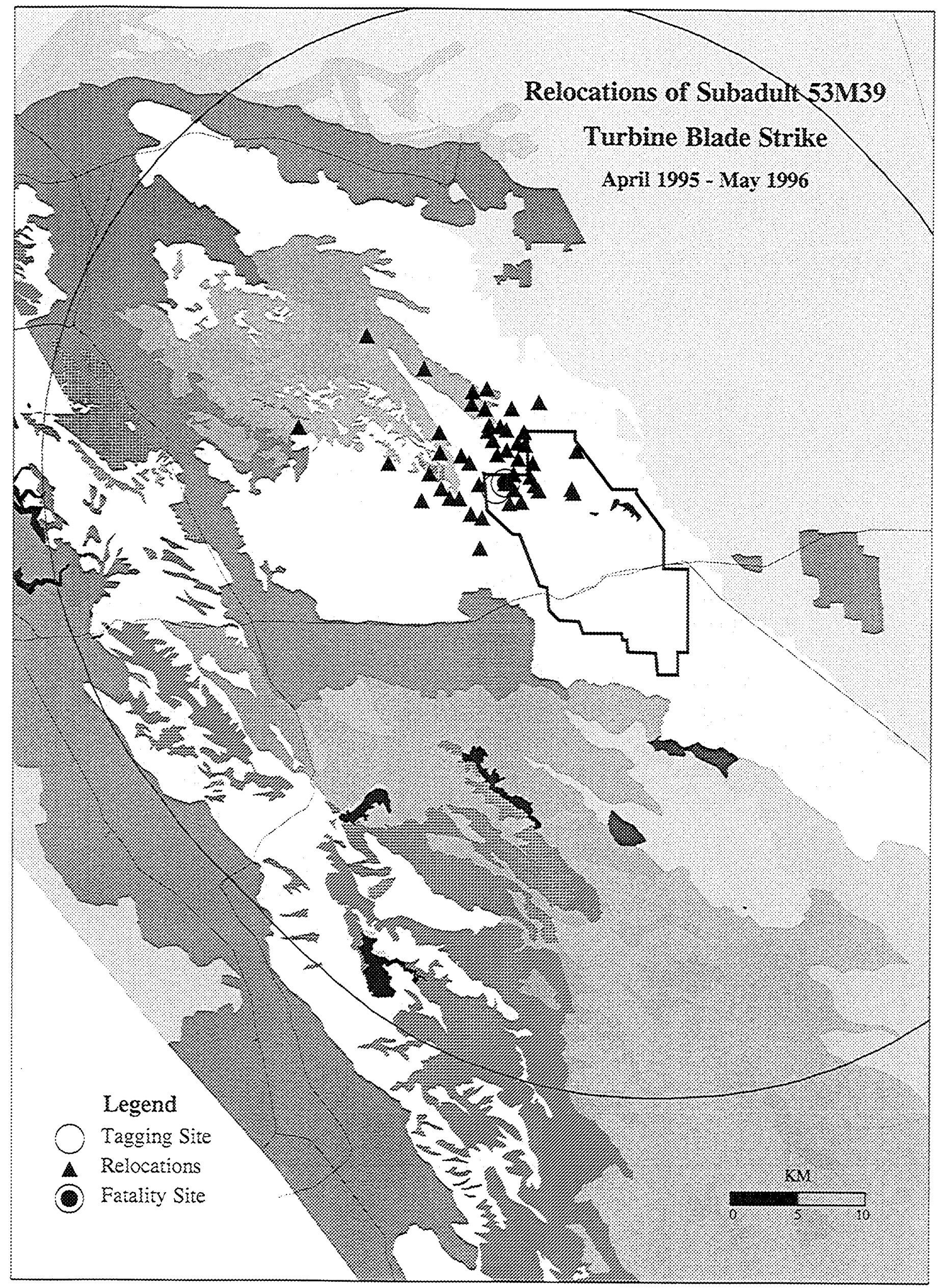




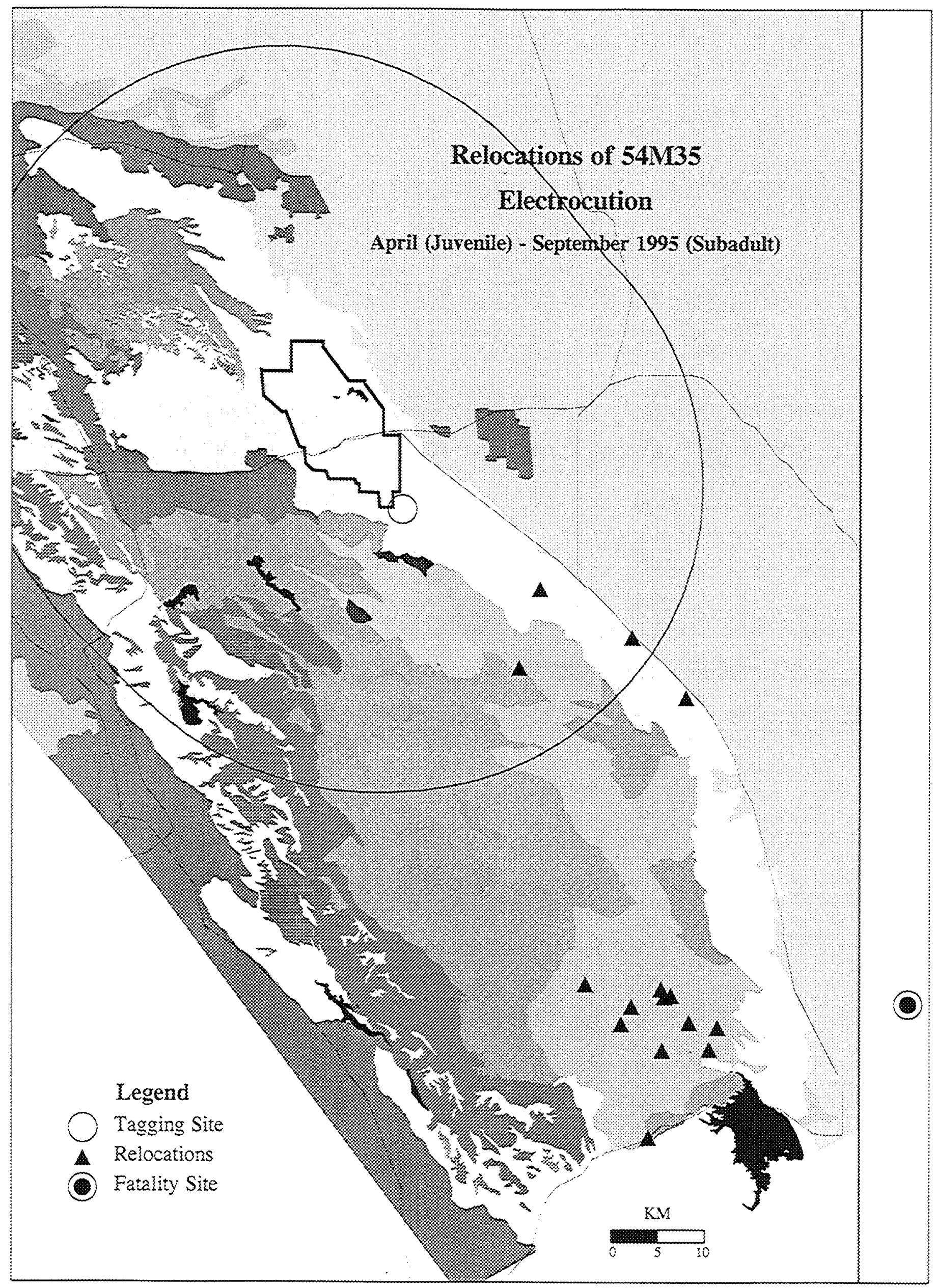




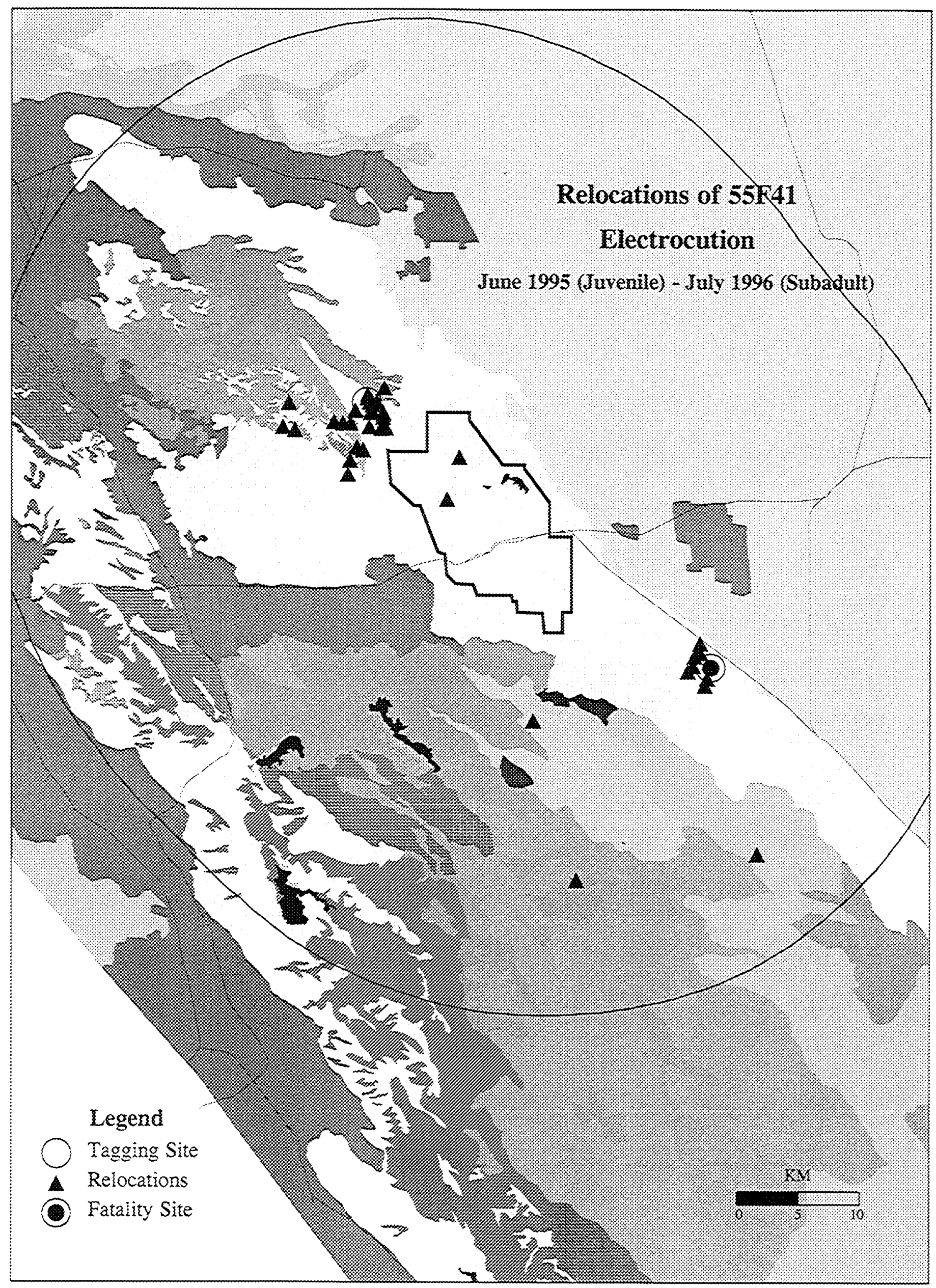




\section{REPORT DOCUMENTATION PAGE}

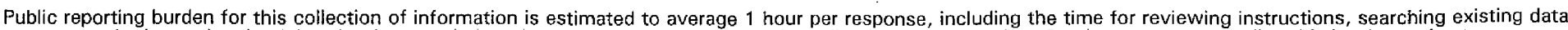

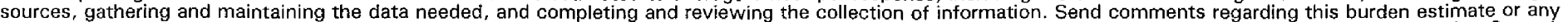

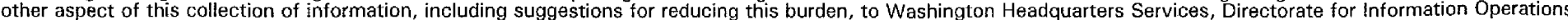

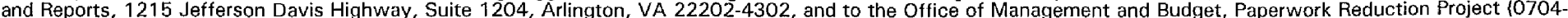
0188), Washington, DC 20503.

\begin{tabular}{|l|l|l|}
\hline 1. & $\begin{array}{l}\text { 2. REPORT DATE } \\
\text { MaY } 1997\end{array}$ & $\begin{array}{l}\text { 3. REPORT TYPE AND DATES COVERED } \\
\text { Subcontractor Report }\end{array}$ \\
\hline
\end{tabular}

4. TITLE AND SUBTITLE

A Population Study of Golden Eagles in the Altamont Pass Wind Resource Area Second-Year Progress Report

5. FUNDING NUMBERS

C: XAT-6-16459-01

TA: WE714110

6. AUTHOR(S)

Predatory Bird Research Group

Long Marine Laboratory

University of California

Santa Cruz, California

7. PERFORMING ORGANIZATION NAME(S) AND ADDRESS(ES\}

Predatory Bird Research Goup

Long Marine Laboratory

University of California

Santa Cruz, California 95064

9. SPONSORING/MONITORING AGENCY NAME(S) AND ADDRESS(ES) AGENCY REPORT NUMBER

National Renewable Energy Laboratory

1617 Cole Blvd.

Golden, CO 80401-3393

8. PERFORMING ORGANIZATION REPORT NUMBER

11. SUPPLEMENTARY NOTES

NREL Technical Monitor: Karin Sinclair

12a. DISTRIBUTION/AVAILABILITY STATEMENT

National Technical information Service

U.S. Department of Commerce

SR-440-23087

DE97050799

5285 Port Royal Road

Springfield, VA 22161

12b. DISTRIBUTION CODE

UC-1210

13. ABSTRACT (Maximum 200 words)

This report details the results of field studies conducted from November 1994 through August 1996 in the Altamont Pass. This report updates and supplements the first year's report, A Pilot Golden Eagle Population Study in the Altamont Pass Wind Resource Area California (NREL/TP-441-7821). The primary focus of the research is to quantify the effect of turbine-related mortality on the golden eagle population. To do this, the research must result in the quantification of both survival and reproduction.

To estimate the survival rates of both territorial and non-territorial golden eagles, 179 individual birds were tagged with radiotelemetry transmitters. Weekly surveys by airplane were conducted to locate the tagged eagles in relation to the WRA and monitor their survival.

To estimate the reproductive rate, 74 territorial pairs of golden eagles were observed in the study area and their reproductive outcomes were determined.

The final report on this research project will incorporate the estimates of survival and reproduction to predict the effect of WRA mortality on population age structure.

14. SUBJECT TERMS

15. NUMBER OF PAGES

Key words: wind energy-environmental impacts, avian interactions; Altamont Pass; golden eagles

17. SECURITY CLASSIFICATION OF REPORT Unclassified
18. SECURITY CLASSIFICATION OF THIS PAGE Unclassified
19. SECURITY CLASSIFICATION OF ABSTRACT Unclassified
16. PRICE CODE

20. LIMITATION OF ABSTRACT

UL

Standard Form 298 (Rev. 2-89) Prescribed by ANSI Std. 239-18 